\title{
Drug Delivery to the Bone Microenvironment Mediated by Exosomes: An Axiom or Enigma
}

\author{
Sasmita Samal ${ }^{1,2}$ \\ Pratigyan Dash ${ }^{1,2}$ \\ Mamoni Dash (D)
}

'Institute of Life Sciences, Nalco Square, Bhubaneswar, Odisha, 751023, India;

${ }^{2}$ School of Biotechnology, Kalinga Institute of Industrial Technology (KIIT)

University, Bhubaneswar, Odisha,

751024, India
Correspondence: Mamoni Dash Institute of Life Sciences, Bhubaneswar, Odisha, India

Email Mamoni.dash@ils.res.in

\begin{abstract}
The increasing incidence of bone-related disorders is causing a burden on the clinical scenario. Even though bone is one of the tissues that possess tremendous regenerative potential, certain bone anomalies need therapeutic intervention through appropriate delivery of a drug. Among several nanosystems and biologics that offer the potential to contribute towards bone healing, the exosomes from the class of extracellular vesicles are outstanding. Exosomes are extracellular nanovesicles that, apart from the various advantages, are standing out of the crowd for their ability to conduct cellular communication. The internal cargo of the exosomes is leading to its potential use in therapeutics. Exosomes are being unraveled in terms of the mechanism as well as application in targeting various diseases and tissues. Through this review, we have tried to understand and review all that is already established and the gap areas that still exist in utilizing them as drug delivery vehicles targeting the bone. The review highlights the potential of the exosomes towards their contribution to the drug delivery scenario in the bone microenvironment. A comparison of the pros and cons of exosomes with other prevalent drug delivery systems is also done. A section on the patents that have been generated so far from this field is included.
\end{abstract}

Keywords: drug delivery, bone diseases, exosomes, nanosystems, RANK-RANKL pathway, exosome-liposome hybrid

\section{Introduction}

Bone is a complex rigid organ of the human body which provides the basic skeletal framework, stores calcium, and produces blood cells. ${ }^{1,2}$ The adult bone comprises $50-70 \%$ mineral as hydroxyapatite $\left[\mathrm{Ca}_{10}\left(\mathrm{PO}_{4}\right)_{6}(\mathrm{OH})_{2}\right]$, about $20-40 \%$ organic matrix, consisting mostly of type I collagen., ${ }^{3,4}$ A well-balanced homeostasis requires active communication between osteoblasts and osteoclasts mediated by various cytokines and growth factors. ${ }^{5-8}$ However, this delicate balance tends to get lost with time due to aging, ${ }^{9}$ hormonal imbalance, ${ }^{10,11}$ impaired signaling pathways, ${ }^{12,13}$ external factors, etc. leading to excess osteoclastic bone resorption as compared to bone formation. Drugs that inhibit the osteoclastic activity or induce bone formation are important for treating osteoporosis, ${ }^{14,15}$ bone metastases, ${ }^{16}$ osteosarcoma, ${ }^{17}$ arthritis, ${ }^{18}$ and Paget's disease. ${ }^{19}$

The currently available drug treatments are based on the principle of either suppressing osteoclast formation (e.g; estrogens, SERMs) or suppressing osteoclast activity (e.g; Bisphosphonates). ${ }^{20}$ However, besides the anabolic effects of most of the drugs on bone, they have certain limitations which include affecting the normal bone cells as well as other tissues including uterus, ${ }^{21}$ breasts. $^{22-24}$ Also, the 
intravenous $^{25}$ or oral administration ${ }^{26}$ of high doses of drugs for a prolonged period can cause secondary adverse effects. $^{27}$ Thus, it is clear that bone-drug delivery application is yet to meet perfections in terms of targeting and eliminating the side effects. Therefore, it is important to understand the disease-specific pathways for more accurate tailored targeting mechanism and a controlled release at the target site. The research area of controlled drug delivery to bone has experienced tremendous progress owing to the emergence of nanotechnology. ${ }^{28,29}$ The novel features of these nanosystems have enabled sitespecific drug delivery, ${ }^{30}$ high loading efficiency, ${ }^{31}$ controlled release, ${ }^{32}$ prolonged blood circulation time, ${ }^{33}$ etc. Moreover, with the emergence of BPs, tetracycline, and acidic oligopeptides (AO), having the highest affinity for bone hydroxyapatite, ${ }^{34-36}$ the bone-specific targeting has boosted up. Several polymer-drug conjugates ${ }^{37}$ and multifunctional hybrid nanoparticles (HNPs) for enhanced drug activity has received great impetus in recent years. ${ }^{38-40}$ In spite of several progresses, some challenges and obstacles are involved in the translation of these nanomaterials from laboratory to clinical therapy. High cost to benefit ratio, rapid clearance of bare nanoparticles by mononuclear phagocyte system (MPS), bioaccumulation, and cytotoxicity are some of the major limitations. ${ }^{41-43}$

In this context, exosomes, the nano-sized (30-120 nm) lipid bilayer vesicles secreted by almost all eukaryotic cells ${ }^{44,45}$ have come up as an important tool for diagnostic and therapeutic purposes. ${ }^{46-48}$ Right from the discovery of exosomes in 1987, by Johnstone et al from sheep reticulocytes, ${ }^{49}$ these were thought to be the cell garbage cans, which remove wastes or byproducts from cells. ${ }^{50}$ Thanks to the advancement of electron microscopic technology, the vital role of exosomes as the cellular messenger has been revealed. ${ }^{51-53}$ Compared with the synthetic nano-delivery systems, exosomes have gained much attention because of some of their vital characteristic features. As exosomes are released by budding off from the plasma membrane, they tend to contain surface adhesion proteins and carry various cargos like protein, lipids and nucleic acids, ${ }^{54,55}$ which also shows their strong cargo loading and cargo protection ability. They show tremendous inherent capacity to interact with recipient cells. ${ }^{56,57}$ They can be internalized by the host cell and transfer their payload, thereby modulating the host cell machinery, ${ }^{58,59}$ which proves their inherent cargo delivery properties. Exosomes qualify all the criteria to become an effective and safe delivery vehicle such as high biocompatibility, ${ }^{60}$ strong cargo loading ${ }^{61}$ and cargo releasing ability, ${ }^{62}$ ability to cross difficult biological barriers, ${ }^{63,64}$ easy surface modification and drug loading, ${ }^{65,66}$ etc. Recent studies have revealed the pivotal roles played by bone cell-derived exosomes in maintaining normal bone homeostasis by transferring biologically active molecules to target cells. $^{67-69}$ In a study, exosomal miR-214 released from osteoclasts significantly suppressed osteoblast activity and the inhibition of exosome secretion via Rab27a siRNA potentially prevented osteoblast dysfunction. ${ }^{70}$ In another study, osteoblast-derived exosomes mediated intracellular communication was seen to play important role in osteoclast differentiation. ${ }^{71}$ Furthermore, bone marrow mesenchymal stem cell (BM-MSC) derived exosomes have been seen to regulate osteoblastic activity and differentiation $^{72}$ to promote fracture healing ${ }^{73}$ and osteoporosis improvement ${ }^{74}$ via important paracrine signaling. BM-MSC-derived exosomal miR-150-3p could effectively promote osteoblast proliferation and differentiation in the ovariectomized (OVX) rat model of osteoporosis. ${ }^{75}$ These findings provide new insights and motivation to exploit the naturally occurring exosomes for finding novel treatments of existing bone diseases.

In this review, the major highlight is the utilization of exosomes as a potential drug delivery vehicle to treat bone diseases as compared to conventional nanosystems. A brief idea of the biogenesis and importance of exosomes in bone homeostasis regulation is provided. Then, the potential advantages and limitations of each of these nano-drug transporters are compared with naturally occurring exosomes. Furthermore, the existing patents on the therapeutic applications of exosomes as a drug carrier device targeted to the bone have been listed out. Lastly, the improved translational potential of exosomes by using innovative engineering techniques to enhance the targeting efficiency and prolonged stability in the blood has been discussed.

\section{The Clinical Need for Drug Delivery Systems to Bone}

Drugs and therapeutic strategies are currently available for common bone disorders occurring due to increased bone resorption like osteoporosis, bone metastasis, osteosarcoma, osteoarthritis, and Paget's disease. ${ }^{76}$ These broadly include bone-targeted anti-resorptive drugs like bisphosphonates (BPs), ${ }^{77,78}$ antibody treatment, ${ }^{79}$ combination anti-resorptive therapy, ${ }^{80,81}$ antibiotics like tetracyclines, ${ }^{82}$ chemotherapeutic agents $^{83,84}$ and hormonal therapy. ${ }^{85}$ The Food and Drug 
Administration (FDA) approved anti-resorptive drugs BPs, ${ }^{86}$ such as alendronate, risedronate, ibandronate and zoledronic acid, are used to treat osteoporosis, ${ }^{87,88}$ bone metastases ${ }^{89,90}$ and osteosarcoma ${ }^{91,92}$ by inhibiting bone demineralization ${ }^{93,94}$ and tumor growth. ${ }^{95,96}$ Denosumab, a RANKL-inhibitor, ${ }^{97,98}$ is a human monoclonal antibody-based treatment, ${ }^{99}$ which has been strongly discussed for its superior effects on skeletalrelated events (SREs), ${ }^{100,101}$ osteoporotic prevention in postmenopausal women ${ }^{102}$ over BPs and treatment of bone metastases. ${ }^{103}$ Tetracyclines having a high affinity for bone hydroxyapatite $(\mathrm{HA})^{104}$ inhibit matrix metalloproteinases $(\mathrm{MMPs})^{82,105}$ involved in bone metastasis. Standard chemotherapeutic drugs, such as doxorubicin, ${ }^{106,107}$ cisplatin, ${ }^{108}$ ifosfamide, ${ }^{109}$ cyclophosphamide, ${ }^{110}$ and high-dose methotrexate ${ }^{111}$ with leucovorin rescue, ${ }^{112}$ are being used singly or in combination with osteosarcoma chemotherapeutic regimen $^{107,113,114}$. Selective estrogen receptor modulators (SERMs) such as raloxifene, ${ }^{115}$ bazedoxifene ${ }^{116,117}$ and lasofoxifene $^{118}$ are FDA approved drugs used for the prevention and treatment of postmenopausal osteoporosis. ${ }^{119}$

Despite the significant innovation of pharmaceutical drugs for various diseases, these are not able to achieve the proposed goal in most of the cases due to the various disadvantages associated with the drugs. For example, nitrogencontaining bisphosphonates have a short plasma half-life, low drug absorption, slow-release effect of higher affinity BPs, some side effects like osteonecrosis of the jaw (ONJ), atrial fibrillation (AF), esophageal cancer, musculoskeletal pain etc ${ }^{120}$ are associated. Moreover, lingered anti-fracture benefits are observed after stopping the treatment therapy, for which drug holidays are recommended. ${ }^{121}$ Although zoledronate has come up as an advanced drug, the optimal dosing interval has to be established for different patient populations. ${ }^{122}$ In the case of antibody treatment with denosumab, hypocalcemia is observed in severe cases of renal dysfunction. Osteoclastic inhibitors (BPs and denosumab) have been shown to adversely affect advanced breast cancer. $^{123}$ In some cases, the treatment requires oral administration of high doses of the drug to achieve effective drug concentrations in the target tissue, which results in drug accumulation in normal tissues. ${ }^{25}$ Moreover, some of the drugs may have poor biocompatibility and rapid clearance by body metabolism. Also, the higher hydrophobicity of some drugs results in poor penetration ability to cells. ${ }^{23,124}$ Therefore, there is an alarming need for the development of novel carriers for efficient drug delivery.

Potential drug delivery systems can control the rate of drug release at the targeted site and provide excellent stealth upon coating and drug protection from cellular degradation. $^{28,29}$ Recent decades have witnessed huge studies being done on bone-targeted delivery using nanotechnology as a potential solution to the current limitations (Figure 1). Nanomaterials provide the advantage of enlarged drug-loading capacity with a large surface area: volume ratio due to the smaller size (30-200nm), which also allows them to traverse biological barriers for more efficient delivery. ${ }^{125}$ Furthermore, the combination of conjugates, nanoparticles, and drugs has shown increased targeting ability and efficacy. ${ }^{77}$ In a study, magnetic nanoparticles $(20 \mathrm{~nm})$ coated with calcium phosphates $(\mathrm{CaP})$ were used to treat osteoporosis and bacterial infection. The study also demonstrated that the optimum dose of magnetic nanoparticles has the potential to promote osteoblast density and inhibit bacterial growth. ${ }^{126}$ For successful bone-targeted drug delivery, site-specificity, or active targeting by engineering the nanosystem surface with specific targeting moieties is essential. Wang D et al, synthesized polymeric bone-targeting conjugates based on PEG and poly[N-(2-hydroxypropyl)methacrylamide] (pHPMA) conjugated to well-known bone-targeting compounds, alendronate, and aspartic acid peptide as bonetargeting moieties. When tested for bone-targeting potential in vitro and mice $(\mathrm{Balb} / \mathrm{c})$, they found that these conjugates could specifically accumulate in the bone tissue and hydroxyapatite (HA) proving to be promising candidates for bonetargeted delivery of therapeutic agents. ${ }^{127}$ In a recent study, Sun et al came up with a novel bone-targeted nano-platform using mesoporous silica nanoparticles loaded with gold nanorods (Au@MSNs) which were then conjugated with zoledronic acid (ZOL) forming a novel nanosystem (Au@MSNs-ZOL). They demonstrated targeted bone delivery in vivo as well as an inhibited formation of osteoclast-like cells and enhanced osteoblast differentiation in vitro. ${ }^{128}$ With a limited number of such materials, Peng $Z$ et al synthesized carbon dots (1.5 to $5.0 \mathrm{~nm})$ (C-dots: CD1) from carbon nanopowder with non-toxic and unique affinity and specificity towards calcified bones in live zebrafish larvae. These novel nanodots can potentially be used as bioimaging agents for the early detection of bone diseases as well as drug carriers for targeted drug delivery. ${ }^{129}$ Although the improved nanotechnology methods are often successful for specifically treating osteogenic disorders, these also come up with environmental and health concerns due to toxic by-products and lack of biocompatibility as well as biodegradation issues. Medina-Cruz D et al have given an overview of green nanotechnology-based approaches to treat osteogenic disorders. These latest advancements have emerged as potential tools 


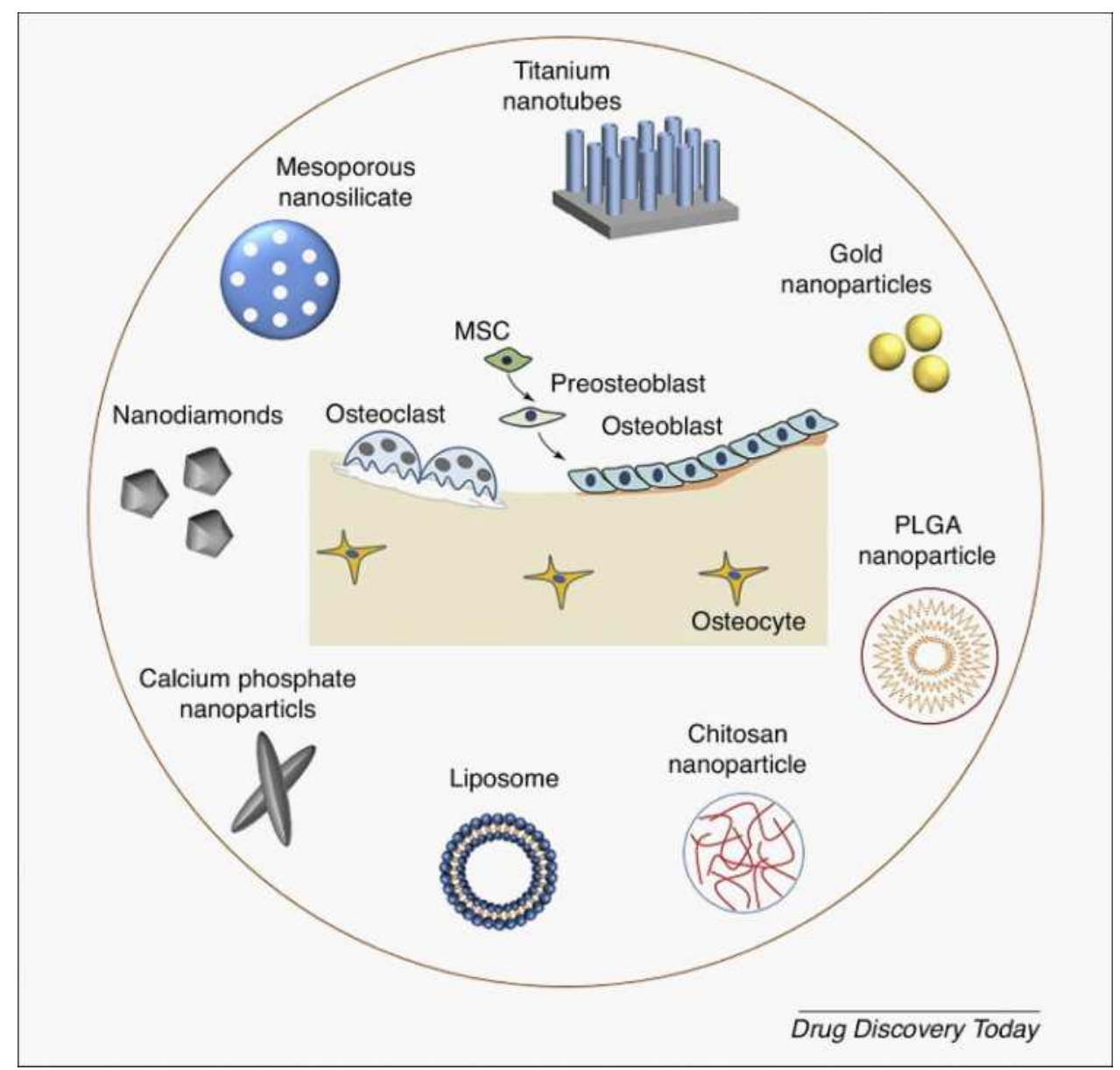

Figure I Examples of common nanomaterials used for targeted bone delivery. Titanium nanotubes, gold nanoparticles, calcium phosphate nanoparticles, and mesoporous silica nanoparticles (MSNs) constitute the inorganic nanomaterials. The organic nanomaterials include chitosan nanoparticles, poly(L-lactide-co-glycolide) PLGA nanoparticles, and liposomes. MSC: mesenchymal stem cell. Adapted with permission from Drug Discovery Today, Vol /edition number 22(9), Cheng H, Chawla A, Yang Y, et al, Development of nanomaterials for bone-targeted drug delivery, Pages No. 1336-1350, Copyright (2017), with permission from Elsevier. ${ }^{125}$

for efficient drug delivery to the bone without showing any side-effects and toxicity, unlike the traditionally synthesized nanomaterials. An informative discussion has been done on the use of various green nanotechnologies, such as polysaccharide-based, protein-based, calcium-based, and silicabased in bone regeneration and controlled delivery. ${ }^{130}$
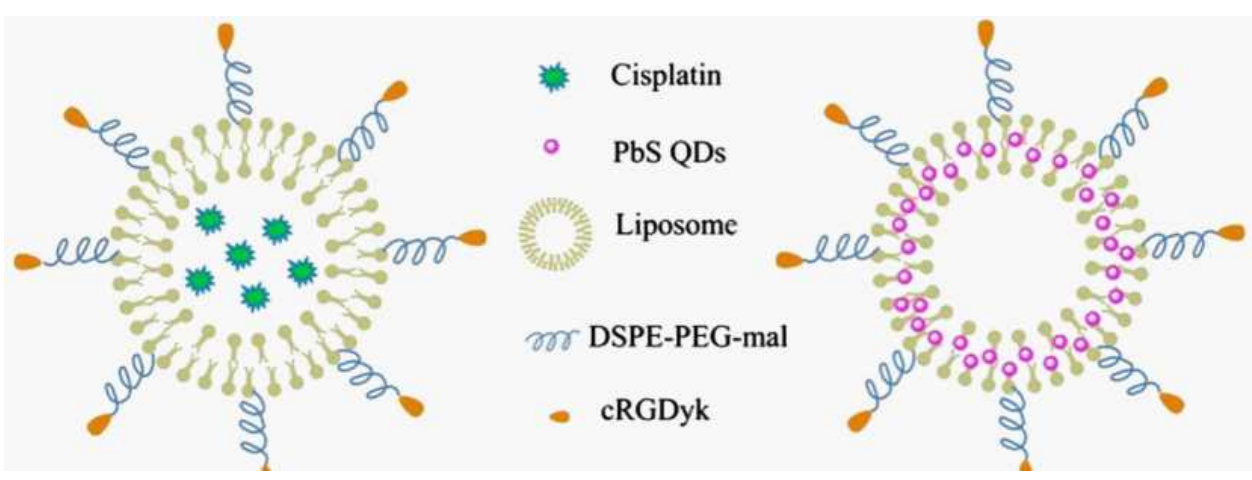

Figure 2 Schematic diagrams for the structure of RGD-CIS-liposomes and RGD-PbS-liposomes. Adapted with permission from Journal of Controlled Release, Vol /edition number 196, Wang F, Chen L, Zhang R, Chen Z, Zhu L, RGD peptide conjugated liposomal drug delivery system for enhance therapeutic efficacy in treating bone metastasis from prostate cancer, Pages No. 222-233, Copyright (2014), with permission from Elsevier. ${ }^{131}$ 
Wang F et al synthesized a liposomal drug delivery system conjugated with cyclic arginine-glycine-aspartic acidtyrosine-lysine peptide (cRGDyk) as the ligand for $\alpha_{\mathrm{v}} \beta_{3}$ integrin. They loaded it with hydrophilic cisplatin (CIS) and hydrophobic $\mathrm{PbS}$ quantum dots (PbS QD) to form RGDCIS-liposomes and RGD-PbS-liposomes, respectively (Figure 2) to target bone metastasis from prostate cancer. The resultant product, RGD-CIS-liposomes, showed improved therapeutic efficacy with selective accumulation at the tumor site, enhanced EPR effects, and synergistic antitumor activities in mice. ${ }^{131}$

A novel approach was attempted by Chaudhari et al to target bone metastasis. They prepared zoledronate conjugated PLGA nanoparticles (ZOL-PLGA) for specific bone targeting with higher affinity and utilized the synergistic effects of ZOL along with Docetaxel (DTX). Their results showed a remarkable increase in cellular uptake, facilitated delivery of DTX inhibiting cancer cell proliferation and increased apoptosis, prolonged blood circulation time, and higher tumor retention ability. ${ }^{37}$ A comparative analysis was done by Marra M between ZOL-containing self-assembly PEGylated NPs and ZOL-encapsulated stealth liposomes towards anti-cancer effect which suggested the development of ZOL-based NPs for the treatment of human cancer. ${ }^{132}$ Carmona et al developed a novel multifunctional nanodevice for bone cancer treatment. They functionalized the surface of mesoporous silica nanoparticles (MSNs) with carboxylic acid groups (MSN-COOH) and conjugated with a targeting ligand, lectin concanavalin A (ConA) (Figure 3). This novel multifunctional nanosystem showed a higher degree of internalization into human osteosarcoma cells (HOS) as compared to healthy pre-osteoblast cells (MC3T3-E1). Moreover, a lower dose of DOX loading $(2.5 \mu \mathrm{g} / \mathrm{mL})$ could kill almost all the HOS cells. ${ }^{133}$

From all the above examples it can be evidently inferred that as compared to the therapeutic drugs used alone, their loading into potential nano-delivery vehicles has better therapeutic efficacy in terms of enhanced drug stability, protection from lysosomal degradation, and prolonged blood circulation time. Also, it is translucent that enhanced targeting ability can be achieved by surface conjugation with molecules having a higher affinity to bone HA.

\section{Existing Drug Delivery Systems for Bone Therapeutics}

Drug delivery vehicles are diverse and have received enormous popularity due to the versatile applications they possess. Engineered and natural nanomaterials have the properties to deliver drugs or fluorescent molecules for therapeutic advantage. Different systems have different criteria for delivering a molecule of interest. Fabrication of nanoparticles to augment therapeutic dosage plays a key role in translational science. In this section, we have presented the most commonly used nanoparticles as well as the naturally occurring nanovesicles for drug carriers in bone therapeutics.

\section{Nanoparticles}

Polymeric nanoparticles

Polymeric nanoparticles prepared either from natural or synthetic polymers, have a wide array of biomedical

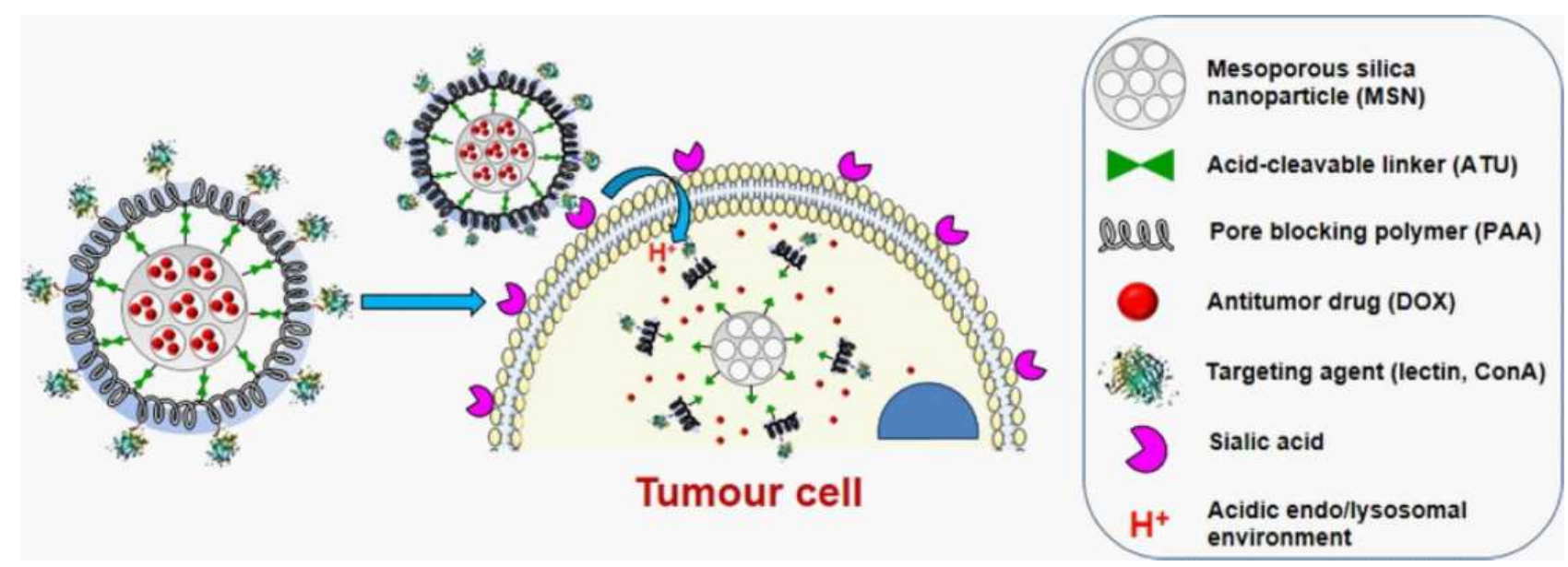

Figure 3 Schematic representation of modified multifunctional MSNs loaded with anti-tumor drug DOX for targeted bone cancer treatment. Adapted with permission from Acta Biomaterialia, Vol 65, Martínez-Carmona M, Lozano D, Colilla, M, Vallet-Regí M, Lectin-conjugated pH-responsive mesoporous silica nanoparticles for targeted bone cancer treatment, Pages No. 393-404, Copyright (2018), with permission from Elsevier. ${ }^{133}$ 
applications due to the fact that they are biodegradable and biocompatible. ${ }^{134}$ Most of the synthesized polymeric nanoparticles such as PLA (polylactic acid) and PLGA (polylactic glycolic acid) have even been approved for human consumption by the US FDA. Various polymers such as polycyanoacrylate and poly(lactide-co-glycolide) PLA or poly(lactic acid) have been used in targeted drug delivery, gene silencing, and siRNA delivery. ${ }^{135}$ Besides synthetic ones, natural polymers such as chitosan, dextran, albumin, and gelatin have also been used for encapsulating drugs and therapeutics. In addition to the effective cargo loading criteria, the smaller size (increased surface area-tovolume ratio) facilitates facile conjugation for attaching several ligand and functional groups to specifically target the desired site. ${ }^{136-138}$ Inert polymers such as polyethylene glycol are now being used as stealth coats to avoid the RES (Reticulo-endothelial system) and successfully evade the immune system to make the targeted drug delivery even more fruitful. ${ }^{139}$ Wang and co-workers studied effective combinational chemotherapy via encapsulation of both the drugs inside PEGylated PLGA nanoparticles directed to MG63 and Saos-2 osteosarcoma cell lines. PEG surface modification to PLGA NPs was successful in evading macrophage and thus the RES. The coencapsulated drugs in PLGA NPs exhibited dose and timedependent cytotoxicity and exerted higher cytotoxicity, apoptosis, and cell cycle arrest with evasion of RES as compared to free drug formulations. ${ }^{140}$

However, these polymeric coatings are also now being questioned as they are starting to become immunogenic. According to Garay et al, repeated infusion of PEGylated therapeutics can elicit a hypersensitive reaction and evoke anti-PEG antibodies against the nanomaterial. ${ }^{141}$ Apart from all these advantages, polymeric nanoparticles suffer from batch to batch variability and are prone to faster degradation.

\section{Polymeric Micelles}

Micelles comprise a polar hydrophilic head and a lipophilic tail that aggregate into an amphiphilic structure in solution. These compact structures are formed between a strong covalent bond that holds the molecules together and the intermolecular forces. Due to the peculiar size and morphology of these nanovesicles, they have gained much attention in targeted drug delivery system approaches. Amphiphilic block copolymers selfassemble into stable structures in aqueous media that can contain hydrophobic drugs. ${ }^{142}$ They are not mechanically cleared from the spleen and also possess minimal cytotoxicity with potent stability inside the body system. ${ }^{143}$ They can be made stimuli or thermosensitive based on the release of the drug at the required site. Alendronate (ALN), as a bone homing agent decorated with polymeric micelles encapsulated with docetaxel, has been developed for treating breast cancer bone metastases with better pharmacokinetics and sustained release. ${ }^{144}$

However, the major setbacks that micelles possess are the high cost for the preparation of micelles at a large scale and difficulty in loading hydrophilic drugs. ${ }^{145}$

\section{Dendrimers}

Dendrimers are nano-sized hyperbranched macromolecules with radial symmetry, containing an outer and an inner shell. They are defined by a highly intricate structure containing protruding functional groups resembling branches of a tree, thus the name dendrimer. ${ }^{146}$ Dendrimers can be attached to the periphery or can be engaged in their interior space. ${ }^{147}$ In most cases, dendrimers are employed because the functional groups are free for conjugation to various targeting moieties, such as monoclonal antibodies or folate that facilitate entry into the tumor or say destined cell. Janus peptide-based dendrimer comprising of RGD dimer and 5-FU dimer have been synthesized with the ability to carry a chemotherapeutic agent for the treatment of bone tumor. ${ }^{148}$ Drugs attached to polymeric dendrimers are highly soluble with enhanced stability. ${ }^{149}$ The limitation is the controlled multistep synthesis parameter.

\section{Mesoporous Silica Nanoparticles (MSNs)}

Mesoporous silica nanoparticles (MSNs) are widely used in targeted delivery approaches due to their hydrophobic core that enables loading of drug and hydrophilic surface that prevents opsonization as such. ${ }^{150}$ The amorphous silica matrix contains numerous uniform pores ranging from 2 to $50 \mathrm{~nm}$, each being tuned to the size of the drug to be loaded. MSNs have a higher potential in loading multiple drugs at a time and release of the drugs to the desired site. The large surface area is amenable to attaching multiple functionalities. ${ }^{151}$ Ma and team fabricated hollow mesoporous silica nanoparticles to deliver doxorubicin (Dox) and siRNA against the Bcl-2 protein (a protein that regulates apoptosis) that was decorated with folic acid conjugated polyethyleneimine (PEI-FA). ${ }^{152}$ Recently, mesoporous silica NPs have been fabricated 
with alendronate for bone-specific targeting and loaded with ibuprofen as the model drug. Alendronate was electrostatically bonded to the carboxyl end of MSNs. A high affinity between alendronate and hydroxyapatite was observed. The nanosystem proved to be a successful bone targeting entity with good biocompatibility towards normal human fibroblast cells (BJ-hTERT c). ${ }^{153}$

The major disadvantage of porous silica nanoparticles is due to the interaction of silanol groups with the surface of the phospholipids of the RBC membranes that can gradually lead to hemolysis. ${ }^{154}$

\section{Magnetic Nanoparticles}

For biomedical applications, magnetic nanoparticles are generally employed in detection, separation, and magnetorelaxometry with some extended advantages, such as hyperthermia, drug-targeting, nuclear magnetic resonance, and imaging. ${ }^{155}$ In targeted drug delivery approaches, the use of magnetic nanoparticles has exceeded rapidly in recent times. External magnetic field guides the iron oxide nanoparticles to the desired target area. To render the magnetic particles more biocompatible organic polymers are usually functionalized over them. ${ }^{156}$ Several examples can be cited for magnetic nanoparticles employed in drug delivery. For instance, $\mathrm{Hu}$ et al fabricated tamoxifen encapsulated magnetite/poly(L-lactic acid) composite nanoparticles for the in vitro anticancer activity against MCF-7 breast cancer cells. The nanofabricated system had enhanced cytotoxicity compared to free tamoxifen. ${ }^{157}$ Also, efforts have been made for preparing biocompatible $\mathrm{Fe}_{3} \mathrm{O}_{4}$ nanoparticles for human bone osteosarcoma cell (MG63). The doxorubicin-loaded magnetic nanoparticle exhibited better colloidal stability and biocompatibility with sustained release profile at low $\mathrm{pH}$ conditions. The self-healing attribute under an external AC magnetic field made the nanocarrier suitable for magnetic hyperthermia. ${ }^{158}$

However, this area requires intense in vivo studies which will lead to improved biocompatibility and negate the side effects due to the injection of magnetic nanoparticles. $^{159}$

\section{Liposomes}

Liposomes are made up of lipids and cholesterol and mimic lipid membranes. They can encapsulate both hydrophobic and hydrophilic molecules. Among all other nanoformulations, liposomes are a popular choice when it comes to being a drug delivery vehicle. A wide number of therapeutics (peptides, RNA moieties, drugs) can be encapsulated inside the aqueous phase of liposomes to increase the therapeutic advantage. Usually, liposomes consist of non-immunogenic lipids and have slower degradation kinetics. ${ }^{160}$ However, liposomes can also be decorated with various targeting ligands for facilitating active targeting. $^{161}$ Liposomes modified with TAT peptide enhanced the permeation of the liposomes facilitating the transfollicular pathway. Treatment of mannose modified liposomes encapsulating p-coumaric acid (ML-CA) in synovial macrophages isolated from AIA rats could result in reduced differentiation of osteoclast by downregulating the master transcription factor, NFATc1 that subsequently resulted in lower production of cytokines like Interleukins and TNF- $\alpha .^{162,163}$

Although various such advantages can be listed, the major limiting step for liposomes in DDS is the physical and chemical instability. Leakage of drugs out of the bilayer has also been reported in some cases. ${ }^{164}$ Other than this, heterogeneity in size distribution is also a crucial drawback.

\section{Cell Membrane Coated Nanoparticles}

Another promising area, which is rapidly evolving and is a newer niche in biomaterial, is using cell membranecoated nanoparticles. It acts as a bridge between synthetic nanocarriers and natural membranes. ${ }^{165}$ Synthetic nanoparticles confer long-term stability and natural membranes cloaked onto them evade the immune system. The presence of membrane proteins has the ability to bind with specific cells. The membrane proteins are isolated from the desired cell (for targeting) and then coated with a synthetic nanomaterial (PLGA, chitosan, MSNs, liposomes, gold nanocages) by different approaches like sonication and extrusion. ${ }^{166}$ Until now, various cells have been taken into consideration due to the unique properties of each cell type. RBCs evade the immune system, decreased uptake by macrophages, ${ }^{167}$ WBCs and platelets home to injured and inflammation prone areas, ${ }^{168}$ cancer cells for homotypic targeting to the desired cancer cell abiding by the principle of hemophilic adhesion between cell adhesion molecules in the cancer cell membrane. ${ }^{169}$ Although there is no such advancement being made for bone-related disorders with cell membrane-coated NPs, still some efforts are on the way to reach progress in this field. RBC coated PLGA NPs have been rehydrated into macroporous alginate scaffolds and it was observed that there are reduced infiltrating neutrophils in the case of RBC-PLGA- 
alginate scaffold treated cells isolated from C57BL/6J mice. $^{170}$

Cell membrane coated nanoparticles hold a promising future in translational science for mimicking the natural cell entities with synthetic nanocarriers,; however, this field is still in its pilot stage and the cost for manufacturing processes is usually higher than the synthetic nanomaterials. ${ }^{165}$

Along with the wide range of advantages, these nanosystems come with several challenges and major issues like bioaccumulation, cytotoxicity, and high cost-to-benefit ratio which make their translational use a difficult task. In this respect, modern-day clinical research is slowly shifting its gear in search of a more natural delivery system to meet the standards along with the added advantage of desired surface modification.

\section{Exosomes as a Powerful Tool for Drug Delivery to Bone \\ Biogenesis and Host Cell Interaction}

Based on the size and pathway of biogenesis, extracellular vesicles are categorized into three classes; apoptotic bodies $(1-4 \mu \mathrm{m})$, microvesicles $(100-1000 \mathrm{~nm})$ and exosomes $(30-150 \mathrm{~nm})$. Apoptotic bodies are generally released from the dying cells by cell membrane blebbing and programmed cell death; microvesicles are shed directly by outward budding of the plasma membrane; ${ }^{44}$ and exosomes, the smallest of all, are actively released to the extracellular environment after the fusion of late endosomes or multivesicular bodies (MVBs) carrying intraluminal vesicles (ILVs) with the plasma membrane.

Since exosomes are of endocytic origin, their biogenesis starts with the formation of an endosome, which is a membrane-bound component inside a eukaryotic cell. While early endosomes mature into late endosomes, ILVs (intraluminal vesicles) are also generated by the invagination of the endosomal membrane. ${ }^{171}$ These late endosomes with ILVs inside are known as MVBs (multivesicular bodies). Afterward, MVBs may either fuse with lysosomes and become degraded by hydrolysis or may fuse with the plasma membrane to release its ILVs into extracellular space. ${ }^{172}$ These vesicles once come out of the cell are known as exosomes (Figure 4A).

The function of exosomes in target cells is determined by the specific cargo they contain. Exosomes contain a variety of molecules of which proteins, lipids, and nucleic acids are the major cargos that regulate their specificity (Figure 4B). ${ }^{173}$ A large number of exosomal cargos, identified in exosomes, are compiled into a database named ExoCarta ${ }^{174}$ which has been subsequently integrated into a broader database Vesiclepedia, ${ }^{175,176}$ and a more recent one named EVpedia. ${ }^{177}$ According to ExoCarta datasets among the top 20 most identified proteins in exosomes, transmembrane proteins, such as CD81, CD9, CD63, Tspn8, and so on, are abundant. ${ }^{178}$ These marker proteins are generally involved in cargo and exosome biogenesis. Heat shock proteins like Hsp 70, Hsp 90, Hsp 27, etc., and MVB biogenesis proteins are also involved in the exosome biogenesis process. ${ }^{179}$ Membrane receptor proteins like transferrin receptors are involved in iron transportation. Lipid contents of exosomes do not necessarily represent parent cells, rather they play an important role in maintaining the exosomal structure, cargo sorting, and their biological activity. ${ }^{173}$ Inhibition of these lipids in a controlled cell culture environment leads to reduced secretion of exosomes. Sphingolipids are involved in $\mathrm{Ca}^{2+}$ influx and exosomal membrane construction. ${ }^{56}$ Loading of RNA species into exosomes is a tightly regulated mechanism. Exosomes do not come out with all the mRNAs present in the parent cell. mRNAs present in exosomes are involved in the intracellular transfer of genetic information as these could be translated into proteins in the target cell or could also regulate post-transcriptional modification. ${ }^{180}$ miRNAs are present in the most abundant form of nucleic acid in exosomes. miRNA-19b-3p released from tubular epithelial cells have been seen to promote macrophage activation in case of kidney injury. ${ }^{181}$ Recent genomic research suggests that long non-coding RNAs and more stable circular RNAs are also present in exosomes, which regulate the host cellular machinery. ${ }^{182}$ Due to the enriched forms of RNAs in specific disease conditions, circulating exosomes are being used as disease biomarkers and diagnostic purposes.

Exosomes can send vital signals to the recipient cells by unloading their payload. The fusion of exosomes can transfer cell surface receptors, transcription factors, genetic materials, oncogenes, and infectious particles into host cells thereby performing biological functions. ${ }^{183}$ Broadly, there are three proposed mechanisms of interaction between exosomes and host cells: (a) specific receptor-ligand binding, (b) membrane fusion of exosomes with the plasma membrane of the host cell, (c) receptormediated endocytosis/phagocytosis (Figure 4C). Studies suggest that intracellular communication via exosomes is 


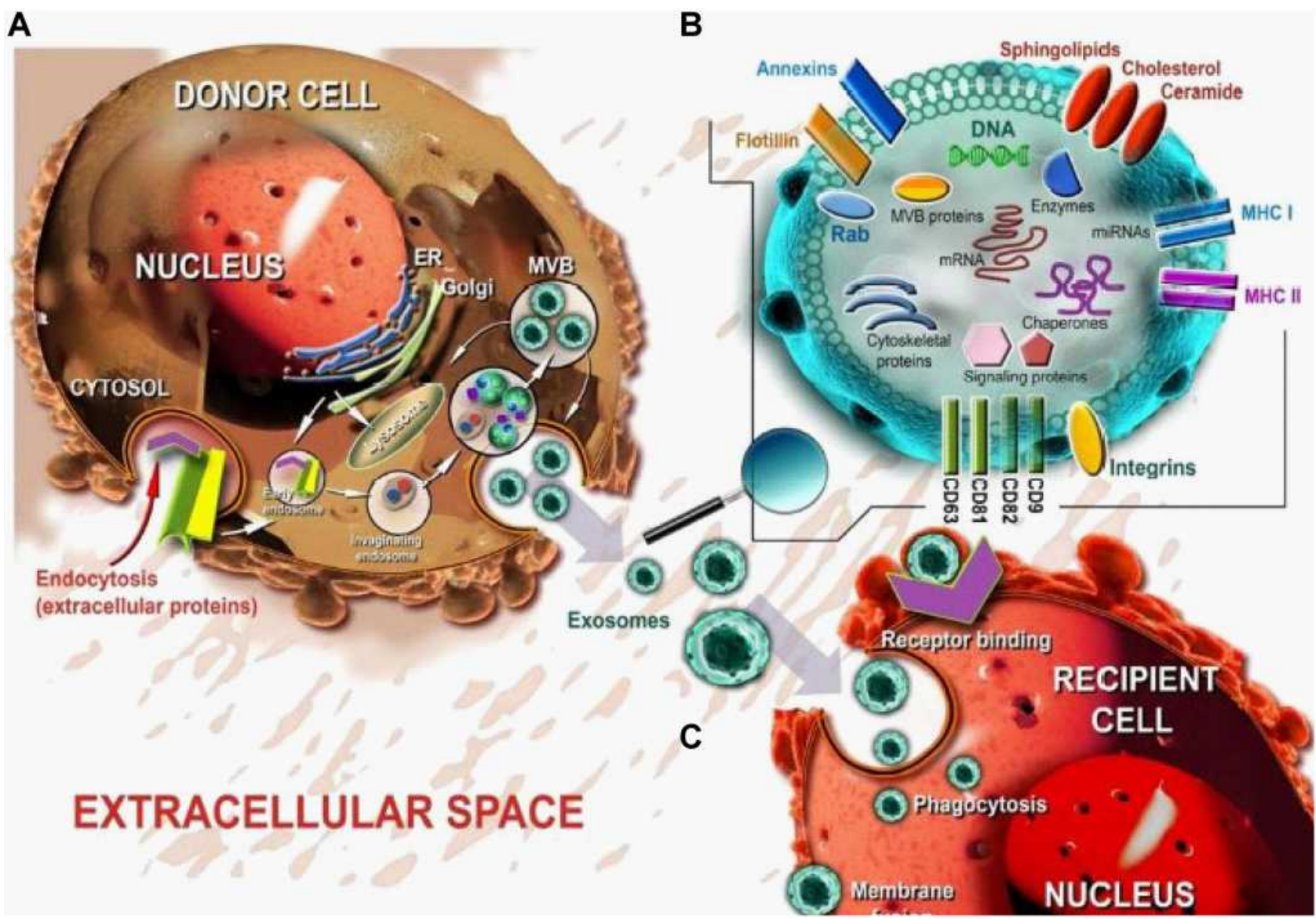

Figure 4 Representative image of exosome biogenesis and interaction with the recipient cell. (A) Early endosomes bud into MVBs (multivesicular bodies) as ILVs (intraluminal vesicles) from which exosomes are formed by merging with the plasma membrane. (B) Released exosomes carry a variety of components mainly proteins, lipids, and nucleic acids which can modulate the function once entered into the target cell. (C) Exosomes in the extracellular space can enter into the recipient cells by different mechanisms including (i) receptor binding, (ii) phagocytosis, and (iii) membrane fusion. Adapted with permission from Gulei D, Irimie Al, Cojocneanu-Petric R, Schultze JL, Berindan-Neagoe I. Exosomes-Small Players, Big Sound. Bioconjugate Chemistry. 20I8; 29(3):635-648. Copyright (C) 20I8 American Chemical Society. ${ }^{173}$

organ-specific and depends upon the recipient cells. However, this specific phenomenon is still not very clear and further studies should be done on understanding the exosomal interaction process.

\section{Exosomes in Maintaining Bone Homeostasis}

The process of bone regeneration is a complex but welldefined physiological and continuous remodeling process of bone formation. ${ }^{184}$ The entire adult life witnesses, bone as a tissue which possesses a tremendous inherent capacity for regeneration in response to either injury or during skeletal development. The cellular communication and crosstalk between osteoblasts and osteoclasts are responsible for the maintenance of bone homeostasis. $^{185}$ Exosomes are one such nanocommunicator that helps to maintain bone homeostasis through the exchange of vital cellular information. The last decade has evidenced a considerable amount of research results in the field of exosomes and specifically its role in the bone microenvironment. The regulated differentiation of osteoblasts and osteoclasts happens by the exchange of biologically active molecules (proteins, mRNAs, miRNAs) with target cells (Figure 5). ${ }^{67}$ Matrix vesicles, which are the family of extracellular vesicles have been shown to contain miR-125b, which targets the osteoblast precursors in the bone marrow microenvironment thereby increasing expression of antiosteoclastogenic factors, and bone mass in mice. ${ }^{186}$ MC3T3-E1 cell-derived exosomes promoted the differentiation of bone marrow stromal cells (ST2) to osteoblasts. These exosomes significantly influenced the miRNA profiles in the stromal cells, through the activation of the Wnt signaling pathway by inhibiting Axin1 expression and increasing $\beta$-catenin expression. ${ }^{187}$ Recently, in a mCherry transgenic zebrafish model, engulfment of osteoblast-derived EVs by osteoclasts 


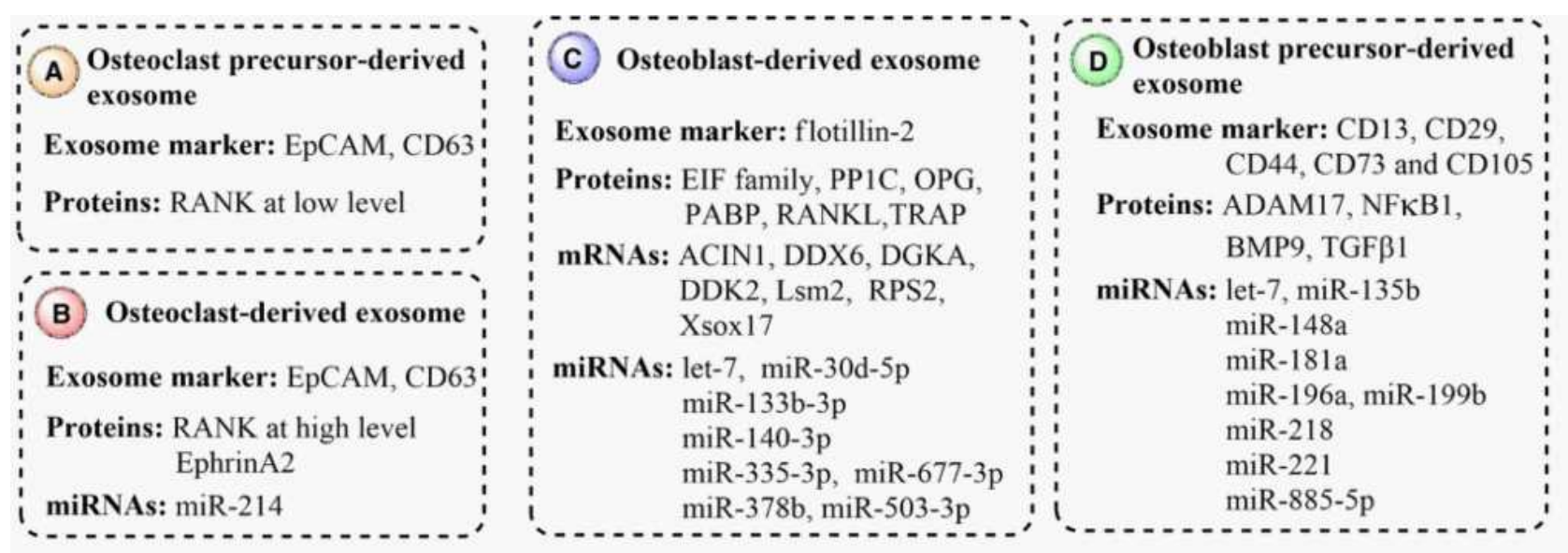

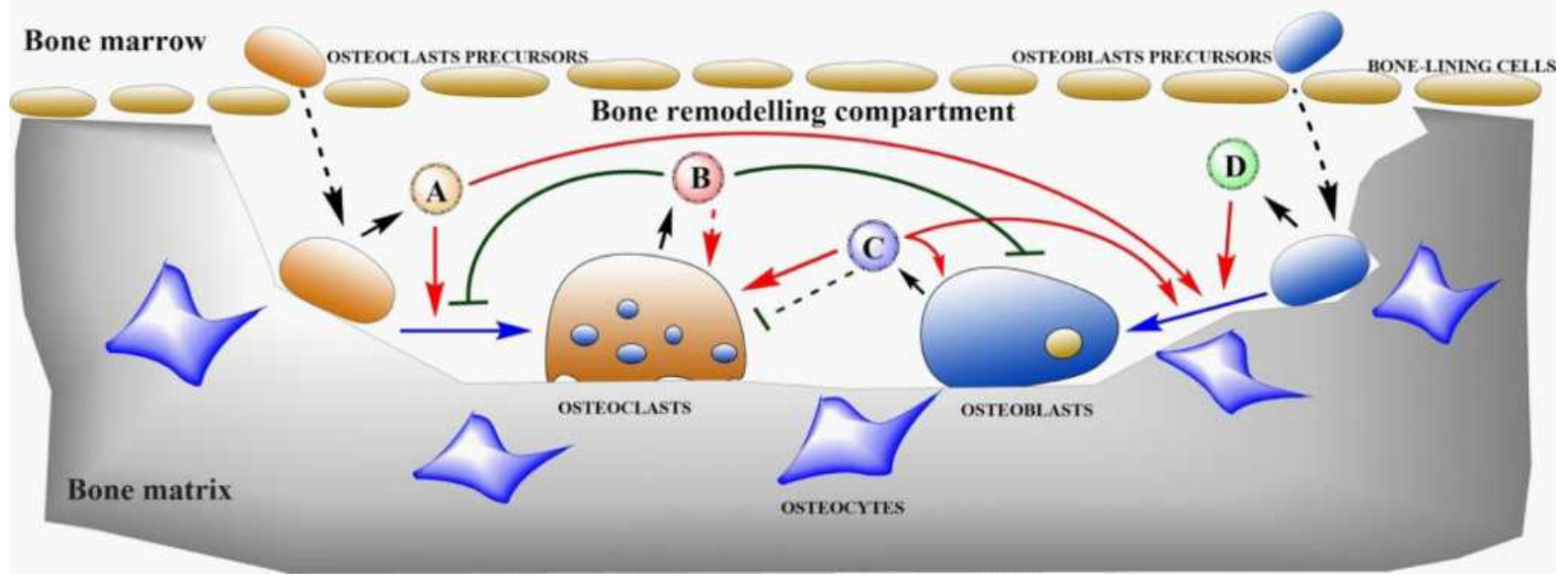

Figure 5 Illustration of regulation of bone homeostasis by the transfer of various biologically active molecules via bone-derived exosomes. Adapted with permission from Xie et al (2017). Copyright (C) 2016 The Authors. Journal of Cellular and Molecular Medicine published by John Wiley \& Sons Ltd and Foundation for Cell and Molecular Medicine. This article is an open access article under the terms of the Creative Commons Attribution License (http://creativecommons.org/licenses/by/4.0/), which permits use, distribution, and reproduction in any medium, provided the original work is properly cited. ${ }^{67}$

could be seen by live-imaging. This promoted osteoclast differentiation via RANKL signaling, suggesting the EV-mediated intercellular communication to promote osteoclastogenesis. $^{71}$ Osteoclast-derived exosomal miR214-3p inhibits osteoblastic bone formation, indicating that the inhibition of miR-214-3p in osteoclasts could be used for treating low bone formation skeletal disorders. ${ }^{15}$ These research findings give a strong and positive indication of the matrix formation and bone tissue regeneration via mineralizing osteoblast- and stem cell-derived exosomes.

Researchers have demonstrated that receptor activator of the nuclear factor $\kappa \mathrm{B}$ (RANK)/RANK ligand (RANKL) system, which plays an important role in osteoclast formation, greatly contributes to maintaining normal bone physiology. ${ }^{13,188}$ Osteoblasts express RANKL which, when interacts with RANK on the surface of monocyte precursor cells, promotes osteoclastogenesis by osteoclast maturation. ${ }^{189,190}$ It is now well known that exosomes play a very crucial role in bone cell-cell communication by stimulating the RANKL-RANK pathway. ${ }^{69}$ Exosomes from mature osteoclasts are enriched with RANK and it has been observed that their depletion inhibits osteoclast maturation and bone resorption. ${ }^{191}$ A very interesting feedback mechanism is observed in the regulation of bone homeostasis. RANKL-enriched exosomes secreted from osteoblasts are found to activate the osteoclastic function, whereas osteoclasts derived RANK-enriched exosomes competitively inhibit this process. Osteoclasts are also seen to inhibit osteoblastic differentiation by exosomal delivery of miR-214-3p (Figure 6). ${ }^{192,193}$

In a study conducted by Cappariello et al, exosomes isolated from Rankl ${ }^{-/}$osteoblasts showed the loss of function to regulate osteoclastic maturation, which proved the importance of Rankl in this process. Also, they demonstrated the internalization and shuttling of anti-resorptive 


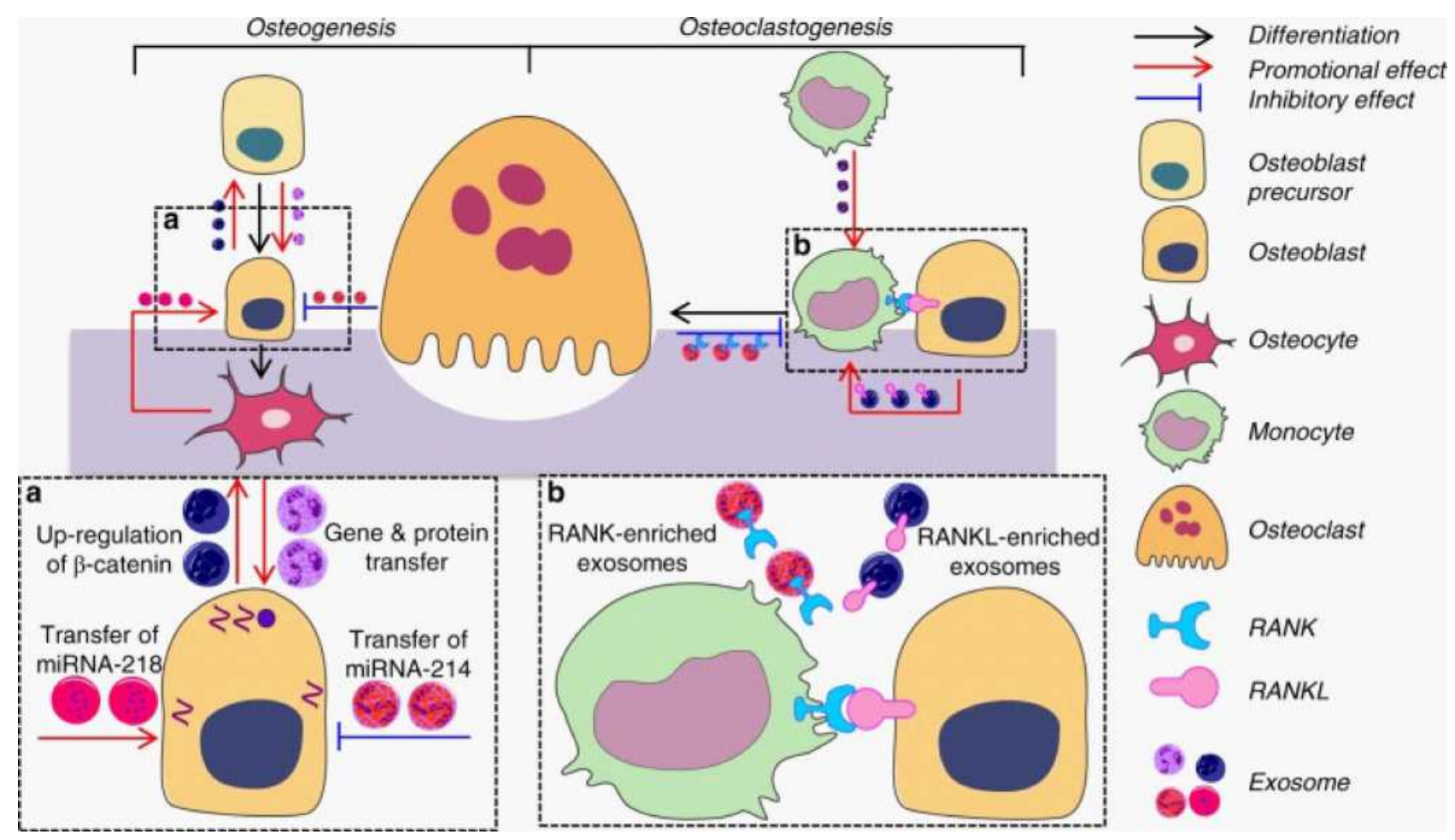

Figure 6 Schematic representation of RANK-RANKL mediated network of interaction between bone cells via the exosomal transfer of miRNA-2I4-3p. Adapted with permission from Gao et al Copyright (C) 2018, The Author(s). This is an open access article distributed under the terms of the Creative Commons CC BY license (http:// creativecommons.org/licenses/by/4.0/), which permits unrestricted use, distribution, and reproduction in any medium, provided the original work is properly cited. ${ }^{1 \overline{2}}$

drugs like zoledronate and dasatinib that inhibited osteoclastic activity in vitro and in vivo. ${ }^{194}$

\section{Exosome as a Potential Drug Delivery Vehicle to Bone Diseases}

An ideal drug delivery vehicle demands, targeted drug delivery of smaller doses to the target site in order to reduce toxicity and other unwanted side effects, biocompatibility, non-immunogenicity, and biodegradability. ${ }^{195}$ To fulfill these demands, a lot of attempts have been done over the past few decades to develop some innovative drug delivery systems, such as liposomes, ${ }^{196-198}$ micelles, ${ }^{199,200}$ polymeric and synthetic nanoparticles, ${ }^{201,202}$ extracellular vesicles, ${ }^{203-205}$ dendrimers, ${ }^{206,207}$ and so on. However, due to some of their limitations, the naturally occurring exosomes are gaining much attention in this aspect, thanks to their vital characteristic features. The advantages of using exosomes as drug delivery vehicles are as follows (Figure 7), ${ }^{208}$ a) direct communication with target cells due to exposed surface adhesion proteins, ${ }^{56,209}$ b) high cargo carrying capacity $^{210,211}$ c) cargo protection and enhanced targeting ability, ${ }^{212,213}$ d) passive targeting (EPR $)^{214}$ and prolonged blood circulation, ${ }^{215}$ e) easy surface modification ${ }^{216,217}$ and cargo loading, ${ }^{65,218}$ f) ability to cross difficult biological barriers, ${ }^{219,220}$ g) low immunogenicity and biodegradability. ${ }^{60,221}$

The native form of exosomes, released from cells, shows the intrinsic ability to transfer their internal cargo content to host cells. Song $\mathrm{H}$ et al found that the naturally occurring endothelial cell-secreted exosomes (EC-Exos) can deliver osteogenic regulating miRNA155 specifically to bone tissue, thereby inhibiting osteoclastogenesis in vitro and reducing bone resorption in an ovariectomized mouse model. Sequencing of exosomal miRNA revealed the abundance of miR-125 in endothelial cell-derived exosomes, which showed a higher bone targeting efficiency when tracked using Dil labeling, as compared to other bone cell-derived exosomes (Figure 8). They demonstrated that EC-Exos are promising nanomaterial with excellent bone targeting capacity which can be utilized in the therapeutics for bone resorption disorders. ${ }^{222}$

One of the key factors that are expected from a nanoscale delivery platform is the advantage of high payload and co-delivery of therapeutic agents. ${ }^{61}$ Mostly, the cargo molecules are loaded into exosomes in an ex vivo manner, after being purified from the cell of origin. ${ }^{223}$ 


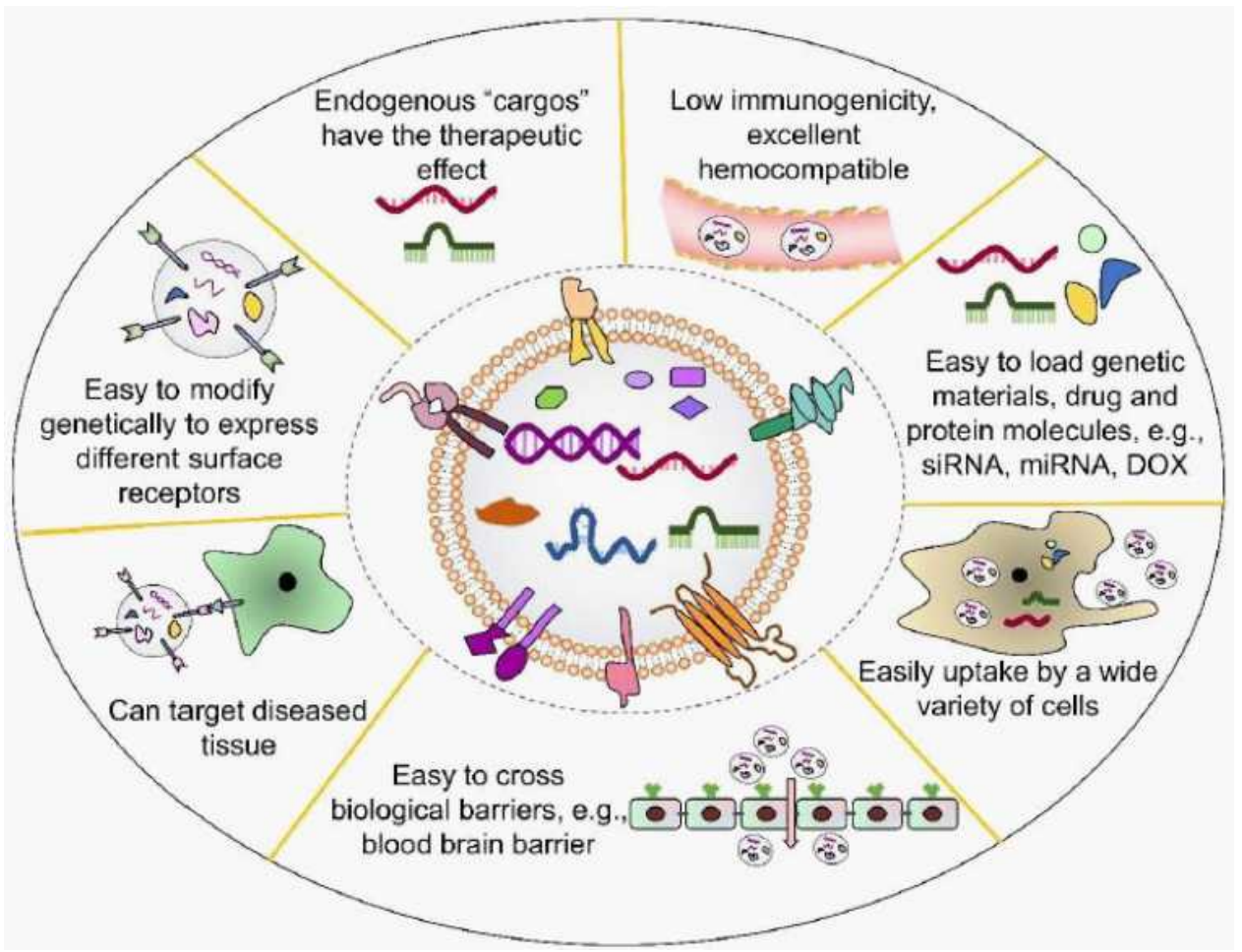

Figure 7 Various advantages associated with opting for exosomes as a drug delivery system. Reproduced from Peng, H; Ji, W; Zhao, R; Yang, J; Lu, Z; Li, Y; Zhang, X, Exosome: a significant nano-scale drug delivery carrier. Journal of Materials Chemistry B. 2020;8(34):759I-7608 with permission from Royal Society of Chemistry. ${ }^{208}$

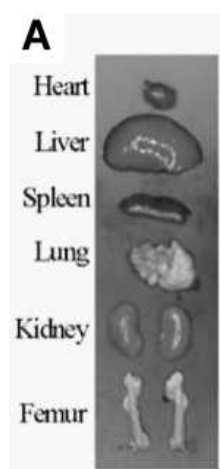

PBS

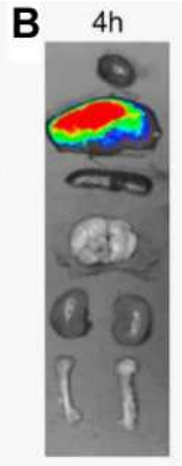

Dil

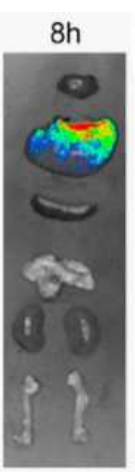

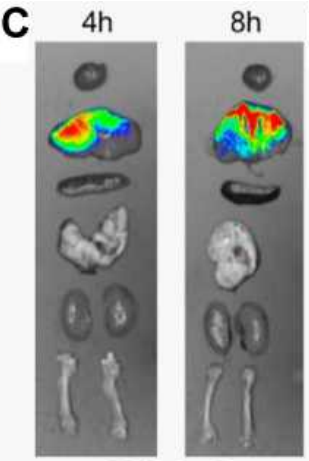

BMSCs-Exos

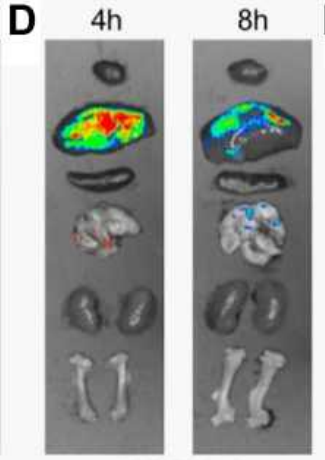

MC3T3-Exos

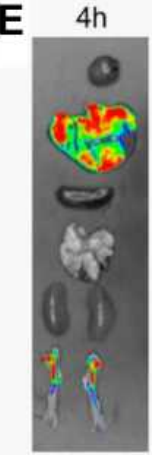

EC-Exos

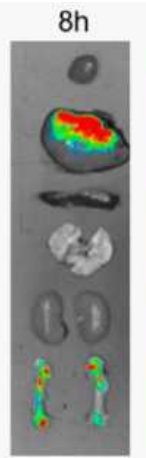

Low

Figure 8 Bone targeting efficiency of EC-Exos in vivo. Biophotonic images showing tissue distribution of Dil labeled exosomes in mice injected with A) PBS, B) DiL reagent, C) Dil-labeled BMSCs-Exos, D) Dil-labeled MC3T3-Exos, and E) Dil-labeled EC-Exos. Adapted with permission from Song H, Li X, Zhao Z et al. Reversal of Osteoporotic Activity by Endothelial Cell-Secreted Bone Targeting and Biocompatible Exosomes. Nano Letters. 2019;19(5):3040-3048. Copyright (C) 2019 American Chemical Society. ${ }^{22}$

The common approaches are simple incubation, freezethaw cycles, sonication, extrusion, and electroporation (Figure 9A). Out of these methods, Haney et al found the highest catalase loading efficiency as well as prolonged and sustained release in case of sonication (Figure 9B) ${ }^{213}$

In a study, Wei $\mathrm{H}$ and group developed a nano-drug formulation by loading chemotherapeutic drug doxorubicin (Dox) into exosomes (Exo-Dox) derived from mesenchymal stem cells, which showed enhanced cellular uptake and anti-tumor activity in osteosarcoma cell-line MG63 as compared to free doxorubicin (Figure 10A I, II). They also showed a much weaker uptake of Exo-Dox by myocardial $\mathrm{H} 9 \mathrm{C} 2$ cells and reduced cytotoxicity $\left(\mathrm{IC}_{50}\right.$ ), as compared to free Dox (Figure 10B I, II), thereby reducing the chances of cardiac toxicity, the major side effect induced by free Dox. ${ }^{224}$

Furthermore, the easy surface chemical modification makes exosomes most suitable for targeted drug delivery. 


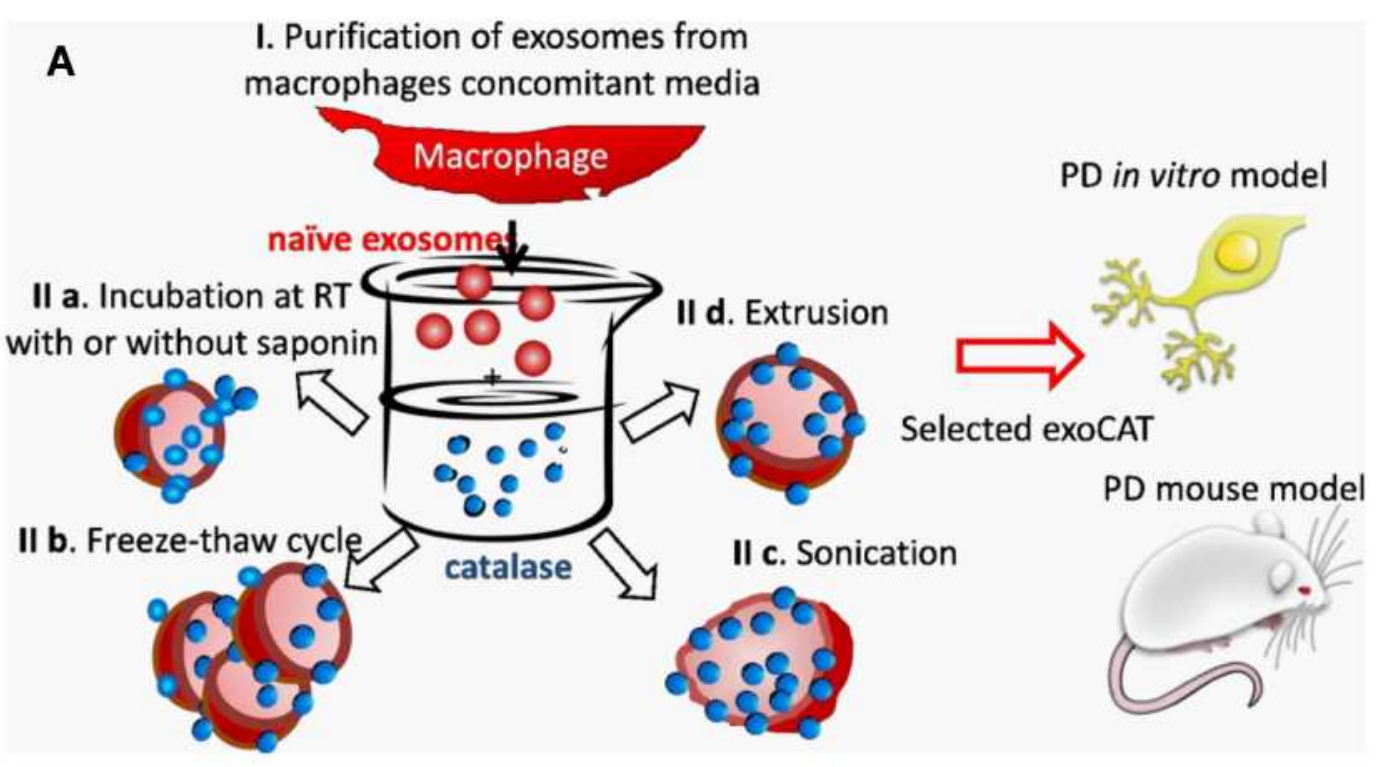

B

\section{$\begin{array}{llll}\text { I) Loading (western blot) } & \text { II) Loading (enzymatic activity) III) Release }\end{array}$}

\begin{tabular}{|lll|}
\hline 1 -catalase & 3 -incubation at RT & 5 -sonication \\
2 -empty exosomes & 4 -freeze/thaw & 6 -extrusion \\
\hline
\end{tabular}

(enzymatic activity)

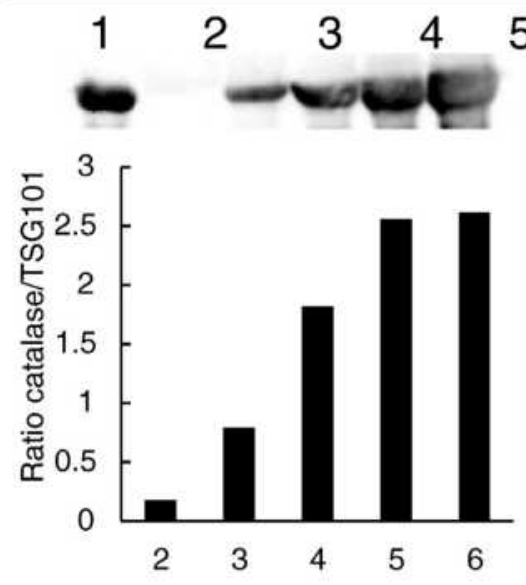

Formulation

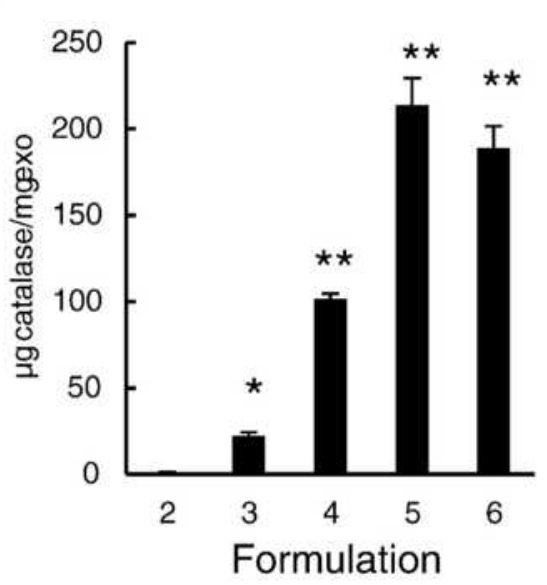

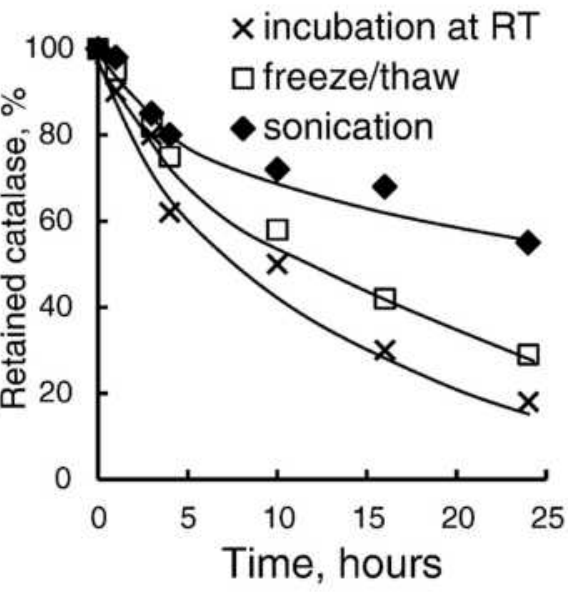

Figure 9 (A) Different approaches for drug incorporation into macrophage-derived exosomes in the presence of catalase. The novel exosomal-based catalase formulation (ExoCAT) efficiently crossed the blood-brain barrier showing the antioxidant effect in the neuronal cells of the PD mouse model. (B) The different loading formulations were examined by I) western blot, II) catalytic enzymatic activity, and III) catalase release. ${ }^{213}$ All data were represented as mean $\pm S . E . M$ ( $n=4$ ); data were analysed using $t$-test; ${ }^{*} p<0.05,{ }^{* *} p<0.05$. Adapted with permission from Journal of Controlled Release, Vol /edition number 207, Haney MJ, Klyachko NL, Zhao Y, et al, Exosomes as drug delivery vehicles for Parkinson's disease therapy, Pages No. 18-30, Copyright (2015), with permission from Elsevier. ${ }^{213}$

In a recent study conducted by Luo et al, mesenchymal stem cell-derived exosomes (STExos) were modified by specific recognizable ligands to avoid rapid metabolism and clearance (Figure 11A). Bone marrow mesenchymal stem cell-specific aptamer (5'-ACGACGGTGATATGTCA AGGTCGTATGCACGAGTCAGAGG-3') was designed to be a stable structure with an aldehyde group modification at the $5^{\prime}$ end, which could react with the amino group of exosomal membrane proteins forming a stable Schiff base (Figure 11B). This modified aptamer conjugated to exosomes by incubation (STExo-Apt), facilitated internalization of exosomes in BMSCs with significantly higher distribution in the bone region (91.8\% positive) (Figure 11C). While investigating the 
A
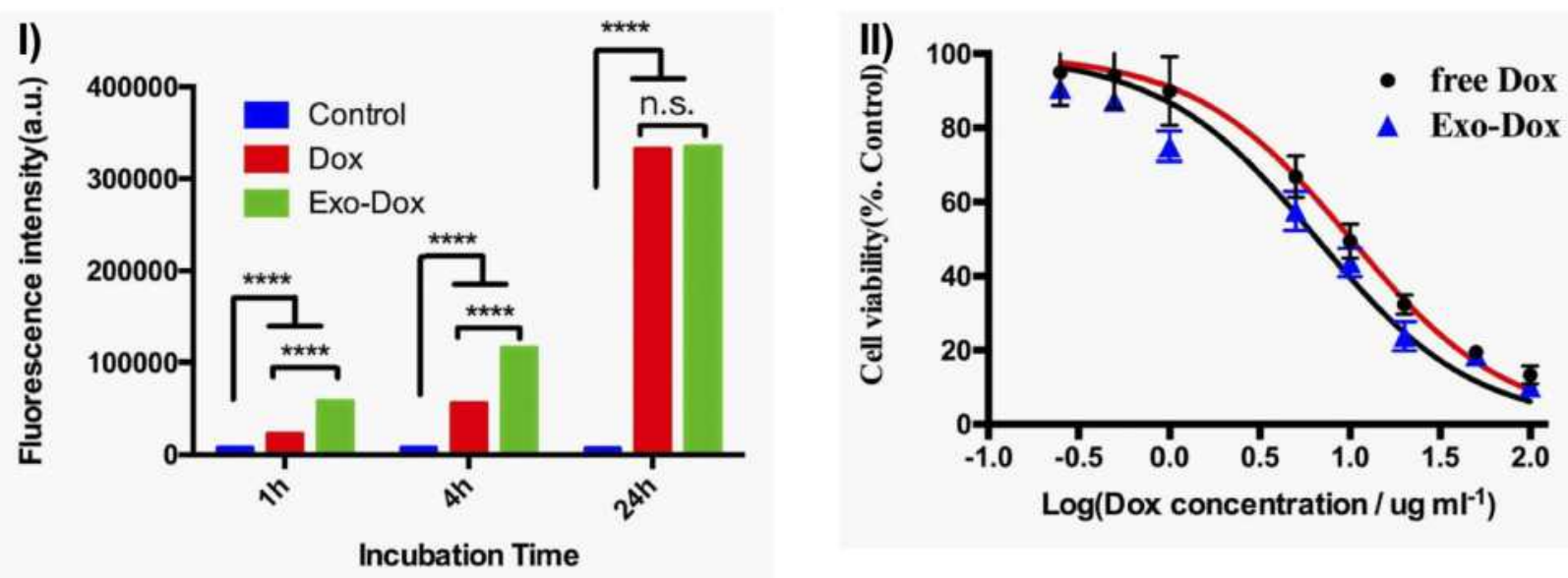

B
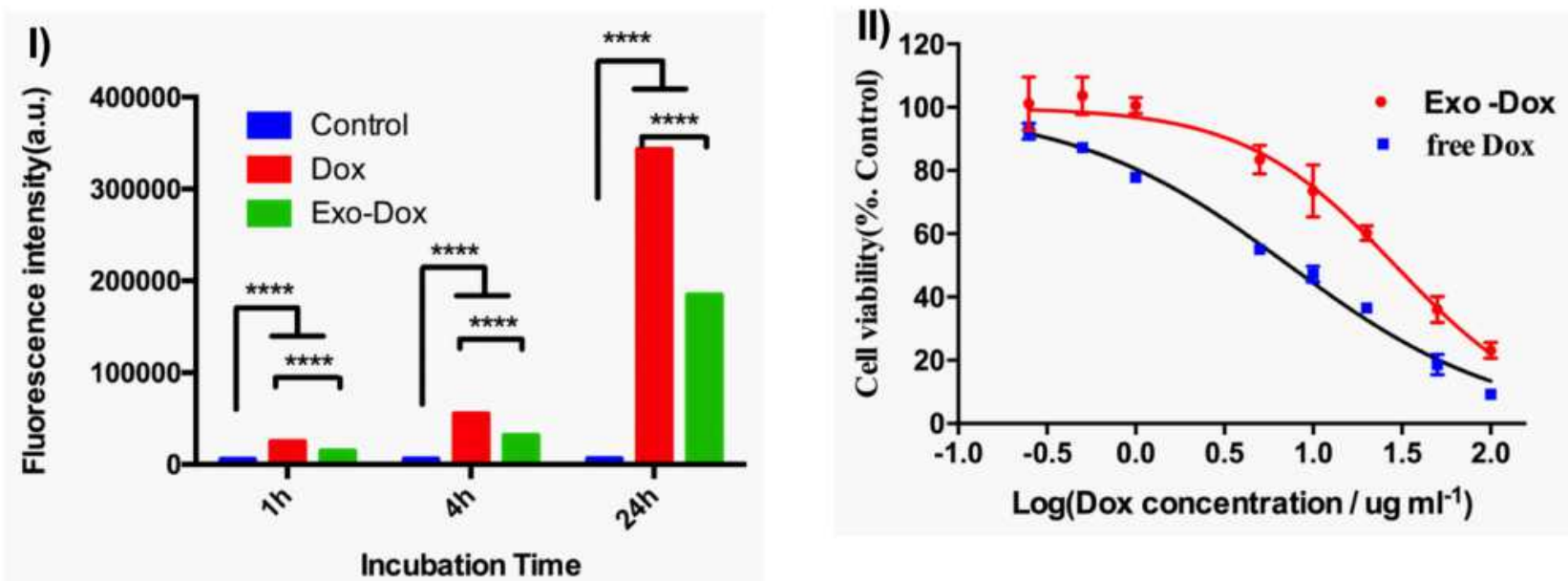

Figure 10 (A) I) Quantification of internalized Dox, Exo-Dox in MG63 cells for Ih, 4h, and 24h in terms of fluorescence intensity, II) cell viability of MG63 cells exposed to different concentrations of Exo-Dox and free Dox. (B) I) Quantification of internalized Dox, Exo-Dox in H9C2 cells for Ih, 4h and 24h in terms of fluorescence intensity, II) cell viability of $\mathrm{H} 9 \mathrm{C} 2$ cells exposed to different concentrations of Exo-Dox and free Dox. Bars represent mean \pm standard deviation ( $\mathrm{n}=3$ ); data were analysed with two-way ANOVA; n.s.: no significant difference, ****P $<0.000$ I. Adapted with permission from Wei $\mathrm{H}$, Chen J, Wang $\mathrm{S}$ et al Nanodrug Consisting Of Doxorubicin And Exosome Derived From Mesenchymal Stem Cells For Osteosarcoma Treatment In Vitro. Int J Nanomedicine. 2019;14:8603-86I0. Dove Medical Press (DMP) publishes many of its articles under a Creative Commons Attribution Non-Commercial license (CC-BY-NC). This allows for the non-commercial reuse of the published paper so long as the published paper is fully attributed. ${ }^{224}$

bone regeneration capability of STExo-Apt in postmenopausal osteoporosis mouse model after bilateral ovariectomy (OVX), once per week after two months of intravenous injection, higher trabecular volume, trabecular number, and trabecular thickness were observed as compared to vehicle or STExo treated mice. An increase in the bone mass was also observed in OVX mice by increased osteogenesis together with increased callus tissue formation and bone mineralization. ${ }^{25}$ This study provides a novel promising approach for the targeted therapeutic drug treatment of osteoporosis.

The newest enigma of using exosome-based biomimetic nano-platforms in drug delivery has been proved to be successfully loading various drugs to many disease target sites. However, their application in the treatment of bone diseases is rarely studied. ${ }^{226,227}$ Recently, Yan et al in 2020 constructed a novel biomimetic-exosome (Exo) nanoparticle formulation (Exo/Dex), by electrophoretic loading of dexamethasone sodium phosphate (Dex) with folic acid (FA)-polyethylene glycol (PEG)cholesterol (Chol) compound (FPC)- surface modification to attain FPC-Exo/Dex for achieving active targeting drug delivery system to treat rheumatoid arthritis (RA) (Figure 12A). Keeping in mind the abundant presence of folic acid receptor (FR $\beta$ ) on matured macrophages in the inflamed areas of RA, the authors decided to derive exosomes from 
A

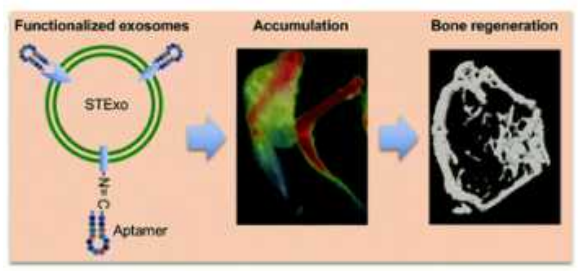

B

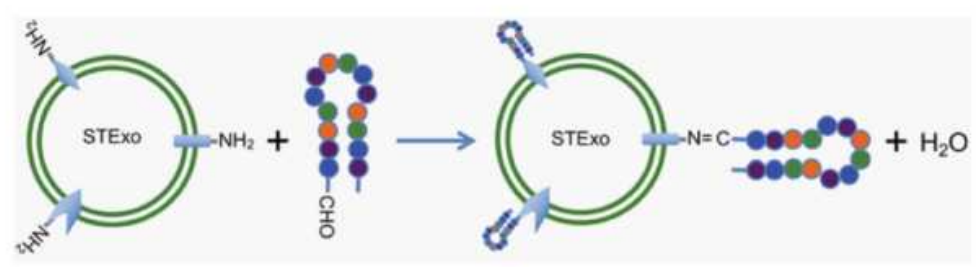

C
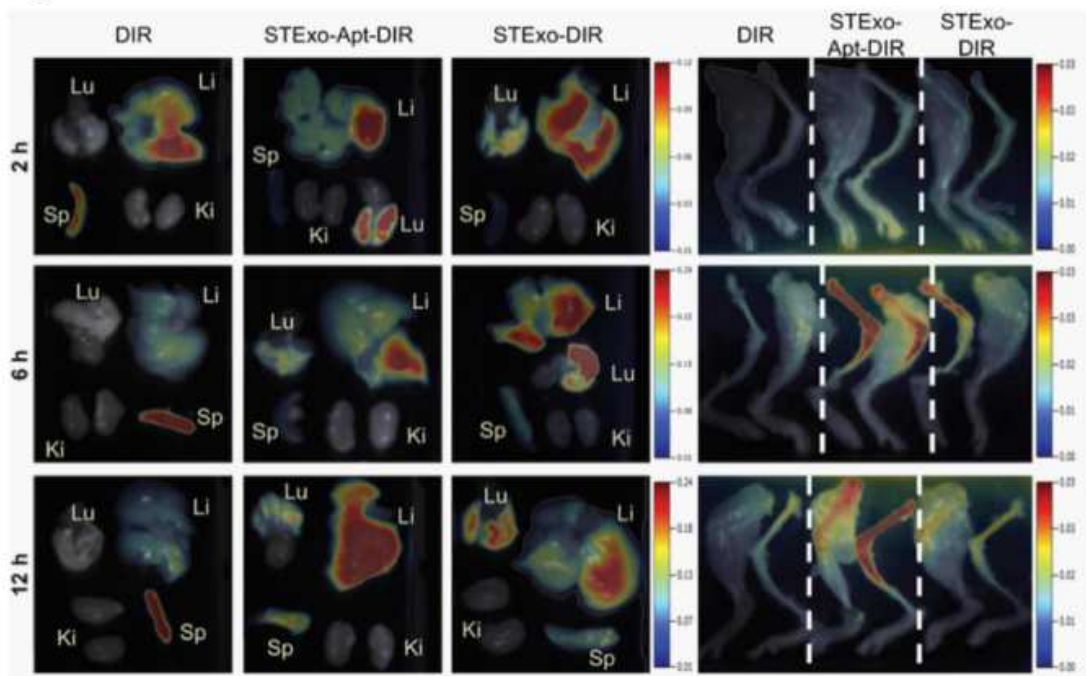

Figure I I (A) Schematic illustration of aptamer functionalized exosomes to promote bone regeneration. (B) Schematic of conjugation procedure between the aptamer and STExos. (C) Representative FMT images of FL signals showing significantly more accumulation of STExo or STExo-Aptamer in the bone as compared to spleen, lungs, liver, and kidney. Reproduced from Luo ZW, Li FXZ, Liu YW et al Aptamer-functionalized exosomes from bone marrow stromal cells target bone to promote bone regeneration. Nanoscale. 2019; I I (43):20884-20892 with permission from Royal Society of Chemistry. ${ }^{225}$

Abbreviations: Lu, lungs; Li, liver; Sp, spleens; Ki, kidneys.

RAW264.7 macrophages, so as to get maximum exosome internalization. They found that this novel formulation FPC-Exo/Dex inhibited the secretion of pro-inflammatory cytokines TNF- $\alpha$ and IL- $1 \beta$ while significantly upregulating the level of anti-inflammatory cytokine IL-10. Greater accumulation into joints was observed after intravenous injection of collagen induced arthritis (CIA) mice with FPC-Exo/Dex as compared to other formulations, proving the superior targeting ability as well as longer systemic circulation (Figure 12B). Micro CT analysis showed significantly lower ankle bone erosion with ROI values similar to that of the healthy control. Based on $\mathrm{H} \& \mathrm{E}$ staining and SO staining, the histopathology scores of ankle joints were found to be lowest in FPC-Exo/Dex treated CIA mice (Figure 12C). The reduced hepatotoxicity and all the above advantages such as better therapeutic efficacy, better stability, longer persistence suggested the usefulness of this drug delivery system for glucocorticoids to treat RA. ${ }^{228}$

\section{Translational Potential of Exosomes in the Field of Bone Therapeutics: Recent Patents}

Scientists are always trying to press forward to find out new possibilities of exosome engineering for therapeutic applications in a smarter way. Pertaining to this, some novel techniques for exosome-based bone disease diagnostics and treatment methods have been patented. The utilization of exosomes in the area of bone therapeutics holds strong translational potential as is evident from the patents available on exosomes. Based on some studies from Google patents and Espacenet (data obtained in 22/11/ 2020), a compiled list of certain recent patents that have been filed or granted on the use of exosomes in diagnostic and therapeutic applications towards bone diseases is provided in this section (Table 1). It encloses exosome-based delivery of the therapeutic drug, cargos like miRNAs to treat painful bone diseases, such as osteosarcoma, rheumatoid arthritis, and osteoporosis. The utilization of 


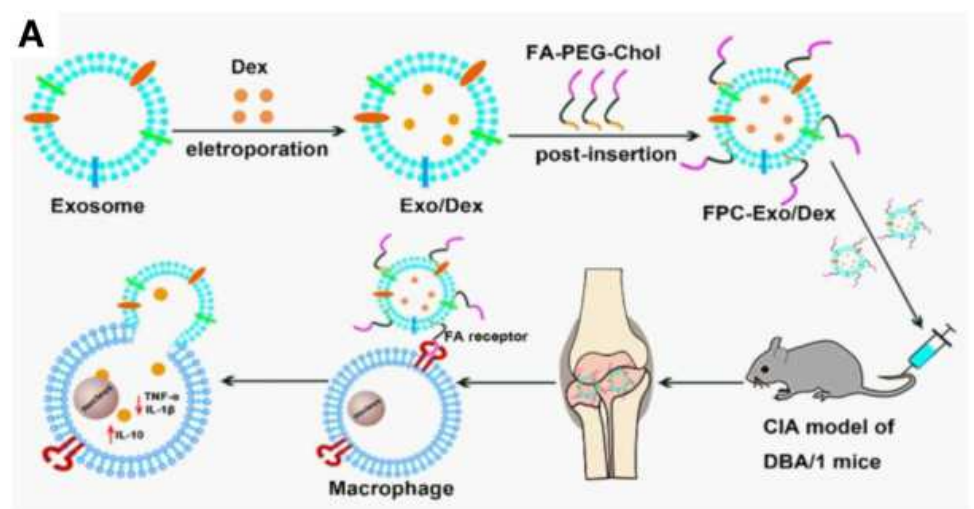

\section{B}

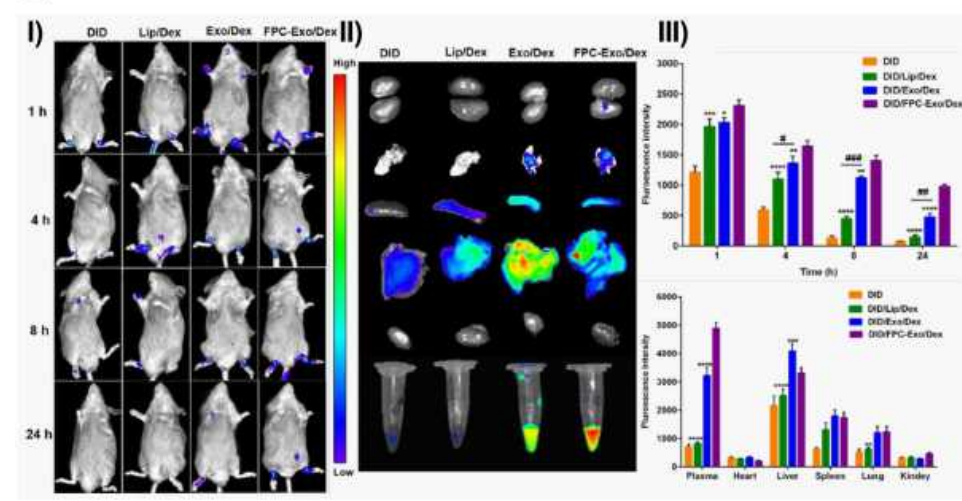

C

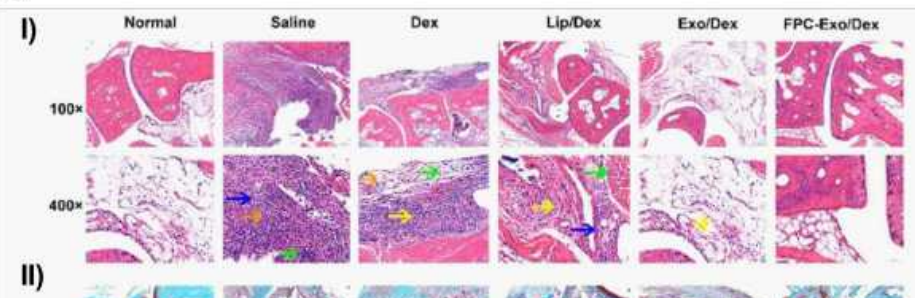

II)
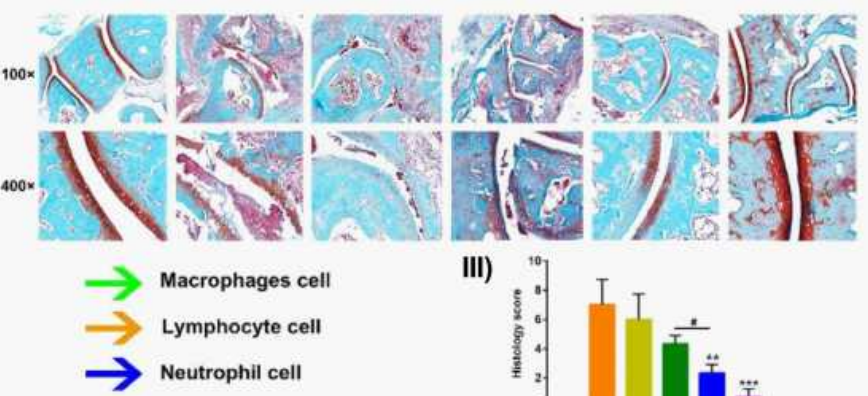

III)

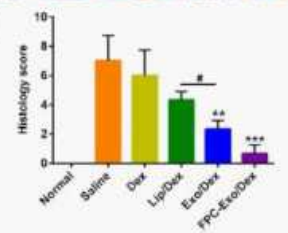

Figure 12 (A) Schematic illustration showing the preparation of novel biomimetic nanoparticles FPC-Exo/Dex, for enhanced targeting based on folic acid (FA) receptorligand interaction and better treatment of RA. (B) I) Real-time fluorescence imaging of CIA mice after i.v. injection with free DiD, Lip/Dex, Exo/Dex, and FPC-Exo/Dex, II) ex-vivo imaging of plasma and organs after $24 \mathrm{hr}$ of i.v. injection, III) semi-quantitative fluorescence intensity in joints and plasma. Data were expressed as mean \pm SD

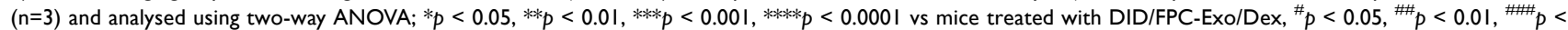
$0.00 \mathrm{I}$ are mice treated with DID/Lip/Dex compared to DID/Exo/Dex. (C) Histopathology analysis of ankle joints I) representative H\&E staining, II) representative SO staining, III) histopathology score of SO staining. Data were expressed as mean $\pm S D(n=3)$ and analysed using one-way ANOVA with Dunnett's multiple comparisons test; ${ }^{* *} p<0.0 \mathrm{I}$, ${ }^{* * *} p<0.00 \mathrm{I}$ vs mice treated with saline; ${ }^{*} p<0.05$ is mice treated with Lip/Dex compared to with Exo/dex. Adapted with permission from Yan et al (2020). This article is licensed under a Creative Commons Attribution 4.0 International License, which permits use, sharing, adaptation, distribution and reproduction in any medium or format, as long as you give appropriate credit to the original author(s) and the source, provide a link to the Creative Commons license, and indicate if changes were made. (http://creativecommons.org/licenses/by/4.0/). ${ }^{228}$ 
Table I Patents Related to the Diagnostic and Therapeutic Application of Exosomes Towards Bone Disorders

\begin{tabular}{|c|c|c|c|c|}
\hline Exosomal Source & Application No. & Applicants & Patent Title & $\begin{array}{l}\text { Patent } \\
\text { Filing } \\
\text { Yearl } \\
\text { Status }\end{array}$ \\
\hline $\begin{array}{l}\text { Serum sample of patients with } \\
\text { osteosarcoma }\end{array}$ & CNI09655608A & $\begin{array}{l}\text { Hangzhou duotai } \\
\text { Technology Co., Ltd } \\
\text { (CN) }\end{array}$ & $\begin{array}{l}\text { Exosome protein for osteosarcoma diagnosis } \\
\text { and instant detecting method thereof }\end{array}$ & $\begin{array}{l}\text { Filed on } \\
2018 / \\
\text { Granted } \\
(2020)\end{array}$ \\
\hline $\begin{array}{l}\text { Granulocyte like-Myeloid } \\
\text { derived suppressor cells } \\
\text { (G-MDSCs) }\end{array}$ & CNI072430I2B & $\begin{array}{l}\text { JIANGSU } \\
\text { UNIVERSITY }\end{array}$ & $\begin{array}{l}\text { Application of exosomes-loaded miR-93-5p in } \\
\text { treatment of rheumatoid arthritis }\end{array}$ & $\begin{array}{l}\text { Filed on } \\
2017 / \\
\text { Granted } \\
(2020)\end{array}$ \\
\hline 293T cells & CNI07034I88A & $\begin{array}{l}\text { Hospital of } \\
\text { stomatology, Sun } \\
\text { yat-sen University }\end{array}$ & $\begin{array}{l}\text { Exosome carrier of targeted bone, CRISPR/Cas } 9 \\
\text { gene editing system and application }\end{array}$ & $\begin{array}{l}\text { Filed on } \\
2017 / \\
\text { Granted } \\
(2018)\end{array}$ \\
\hline Human CAP cells & CNI09966506A & $\begin{array}{l}\text { The second people's } \\
\text { hospital of Shenzhen } \\
\text { (CN) }\end{array}$ & $\begin{array}{l}\text { Method of targeted therapy to treat } \\
\text { osteoarthritis through miRNA-I } 40 \text { delivered via } \\
\text { genetically engineered exosomes }\end{array}$ & $\begin{array}{l}\text { Filed on } \\
2019 / \text { Status } \\
\text { pending }\end{array}$ \\
\hline $\begin{array}{l}\text { Human peripheral blood } \\
\text { mononuclear cells }\end{array}$ & CNII095I685A & $\begin{array}{l}\text { Tianjin kangting } \\
\text { Biological } \\
\text { engineering group } \\
\text { Co., Ltd }(\mathrm{CN})\end{array}$ & $\begin{array}{l}\text { Monocyte source exosome preparation applied } \\
\text { to osteogenic differentiation of mesenchymal } \\
\text { stem cells }\end{array}$ & $\begin{array}{l}\text { Filed on } \\
2019 / \text { Status } \\
\text { pending }\end{array}$ \\
\hline $\begin{array}{l}\text { Bone marrow mesenchymal } \\
\text { stem cells (BM-MSCs) }\end{array}$ & CNII0I24058A & $\begin{array}{l}\text { FIRST AFFILIATED } \\
\text { HOSPITAL FUJIAN } \\
\text { MEDICAL } \\
\text { UNIVERSITY }\end{array}$ & $\begin{array}{l}\text { Preparation of exosome-adriamycin nano } \\
\text { targeted drug derived from bone marrow } \\
\text { mesenchymal stem cells and research of in-vitro } \\
\text { anti-osteosarcoma }\end{array}$ & $\begin{array}{l}\text { Filed on } \\
2019 / \\
\text { Search and } \\
\text { Examination }\end{array}$ \\
\hline $\begin{array}{l}\text { Adipose tissue-derived stem } \\
\text { cells }\end{array}$ & US20200I97443AI & $\begin{array}{l}\text { Exostemtech Co., } \\
\text { Ltd (US) }\end{array}$ & $\begin{array}{l}\text { Composition for preventing or treating } \\
\text { osteoporosis containing exosomes isolated from } \\
\text { stem cells as an active ingredient }\end{array}$ & $\begin{array}{l}\text { Field on } \\
2018 / \text { Status } \\
\text { pending }\end{array}$ \\
\hline $\begin{array}{l}\text { Human embryonic stem cells } \\
\text { (hESCs) or human-induced } \\
\text { pluripotent stem cells (hiPSCs) }\end{array}$ & CNII0I5I726A & $\begin{array}{l}\text { Shanghai 6th people's } \\
\text { hospital }\end{array}$ & $\begin{array}{l}\text { Use of resveratrol-loaded human pluripotent } \\
\text { stem cell exosomes for preparing drugs for } \\
\text { treating bone and joint degenerative diseases }\end{array}$ & $\begin{array}{l}\text { Filed on } \\
2018 / \text { Status } \\
\text { pending }\end{array}$ \\
\hline $\begin{array}{l}\text { Bone marrow-derived } \\
\text { mesenchymal stem cells (BM- } \\
\text { MSCs) and Adipose-derived } \\
\text { stem cells (ASCs) }\end{array}$ & WO20I9I39762AI & Zen-Bio, Inc. (US) & $\begin{array}{l}\text { Exosome compositions and use thereof for joint } \\
\text { disorders and diseases }\end{array}$ & $\begin{array}{l}\text { Filed on } \\
2018 / \text { Status } \\
\text { pending }\end{array}$ \\
\hline $\begin{array}{l}\text { Human umbilical cord } \\
\text { mesenchymal stem cells }\end{array}$ & CNI08478600A & $\begin{array}{l}\text { Xiangya Hospital } \\
\text { Central South } \\
\text { University }\end{array}$ & $\begin{array}{l}\text { Application of mesenchymal stem cell exosome } \\
\text { in preparation of osteoporosis prevention and } \\
\text { treatment drug }\end{array}$ & $\begin{array}{l}\text { Filed on } \\
2018 / \text { Status } \\
\text { pending }\end{array}$ \\
\hline $\begin{array}{l}\text { Human joint fluid mesenchymal } \\
\text { stem cells }\end{array}$ & CNI085429I7A & $\begin{array}{l}\text { Second people's } \\
\text { hospital of Shenzhen }\end{array}$ & $\begin{array}{l}\text { Rheumatism ostalgia disease treatment injection } \\
\text { with human joint fluid mesenchymal stem cell } \\
\text { exosome extractive and preparation method } \\
\text { thereof }\end{array}$ & $\begin{array}{l}\text { Filed on } \\
2018 / \text { Status } \\
\text { pending }\end{array}$ \\
\hline
\end{tabular}

(Continued) 
Table I (Continued).

\begin{tabular}{|l|l|l|l|l|}
\hline Exosomal Source & Application No. & Applicants & Patent Title & $\begin{array}{l}\text { Patent } \\
\text { Filing } \\
\text { Status }\end{array}$ \\
\hline $\begin{array}{l}\text { Mammal primary osteoblasts } \\
\text { and osteoblastic lineage cells }\end{array}$ & US20I80I93263AI & $\begin{array}{l}\text { FONDAZIONE } \\
\text { CITTÀ DELLA } \\
\text { SPERANZA ONLUS }\end{array}$ & $\begin{array}{l}\text { Extracellular vesicles derived from osteoblastic } \\
\text { lineage cells for therapeutic and diagnostic use }\end{array}$ & $\begin{array}{l}\text { Filed on } \\
20 I 6 / S t a t u s \\
\text { pending }\end{array}$ \\
\hline $\begin{array}{l}\text { Monocyte, macrophages, } \\
\text { mesenchymal stem cells }\end{array}$ & US20I50093363AI & BIOMATCELL AB & $\begin{array}{l}\text { Osteogenic differentiation of mesenchymal stem } \\
\text { cells }\end{array}$ & $\begin{array}{l}\text { Filed on } \\
20 I 3 / \\
\text { Abandoned }\end{array}$ \\
\hline Peripheral blood samples & US20I30I72208AI & $\begin{array}{l}\text { Hitachi Chemical } \\
\text { Co., Ltd., Hitachi } \\
\text { Chemical Research } \\
\text { Center Inc. }\end{array}$ & $\begin{array}{l}\text { Assessment of bone marrow recovery by } \\
\text { measuring plasma exosome mRNAs }\end{array}$ & $\begin{array}{l}\text { Filed on } \\
20 I 3 / 3 \\
\text { Abandoned }\end{array}$ \\
\hline
\end{tabular}

exosomes for early disease diagnosis and detection based on measuring the level of some marker proteins and mRNAs is also included in the list. In most of the cases, the exosomes are isolated from either osteoblast lineage cells, or stem cells (bone marrow, umbilical cord, and adipose-derived), or monocytes and macrophages to avoid any chances of immunogenicity. From the given list of filed patents, it can be observed that apart from the exosomes loaded with therapeutic drugs or cargoes, naturally occurring exosomes with their inherent cargo are also important in the therapeutic applications. This proves the unique advantage of opting for exosomes as drug delivery systems.

\section{Current Limitations of Using Exosomes as Drug Delivery Vehicles}

Despite the considerable advancements in the exosome research area, its therapeutic application is still in a premature phase due to some key issues to be addressed in future studies. The lack of proper isolation methods for getting a better yield of pure exosomes stands as a major obstacle in their therapeutic usage. ${ }^{229-231}$ The relatively low release of exosomes from some mammalian cells is one of the primary reasons behind this. ${ }^{44,232}$ The widely used gold standard ultracentrifugation method usually fails to provide a pure form of exosomal yield. ${ }^{233,234}$ To address this issue, attempts have been made to develop advanced isolation techniques, such as density gradient centrifugation, ${ }^{235}$ ultrafiltration, ${ }^{165}$ immunoisolation based on antigen-antibody interaction, ${ }^{236}$ precipitation method using commercially available kits, ${ }^{237}$ size-exclusion chromatography, ${ }^{238}$ and the newest chip-based microfluidics technology. ${ }^{239,240}$ However, none of these techniques qualify to be the most superior of all due to some or the other limitations like high equipment cost, the requirement of skilled manpower, lower yield, impure exosome, filter plugging, high reagent cost, laboratory standardization, etc. ${ }^{229,230,241}$ Furthermore, exosome loss during drug encapsulation method and less net output of drug-loaded naturally occurring exosomes make the use of native exosomes very tricky. ${ }^{61,242}$ Again, out of the drug-loaded exosomes, not all bind to the targeted site, and some are cleared by excretion. ${ }^{61}$ Considering the presence of MHC class I and II molecules on the surface, ${ }^{243,244}$ exosomes may trigger immunogenic reactions, resulting in rapid clearance. ${ }^{245,246}$

Utilization of exosomes secreted from immune cells like dendritic cells and macrophages should be more emphasized for addressing this issue. ${ }^{247}$ Optimization of methods to cargo encapsulation and surface engineering without corrupting the intrinsic properties of exosomes is also very important for the best utility of this delivery vehicle. Many researchers are optimistically focused on developing appropriate methods to modify exosomes and proper loading of drugs/genes to get the best out of it. Modern clinical research is coming up with smartly engineered exosomes with innovative methods as an attempt to combat these issues. ${ }^{66,218,248}$ With a proper understanding of the biology and continued efforts towards resolving the limitations, we envision that an exosome-based drug delivery system will lead to the emergence of a novel therapeutic strategy. 


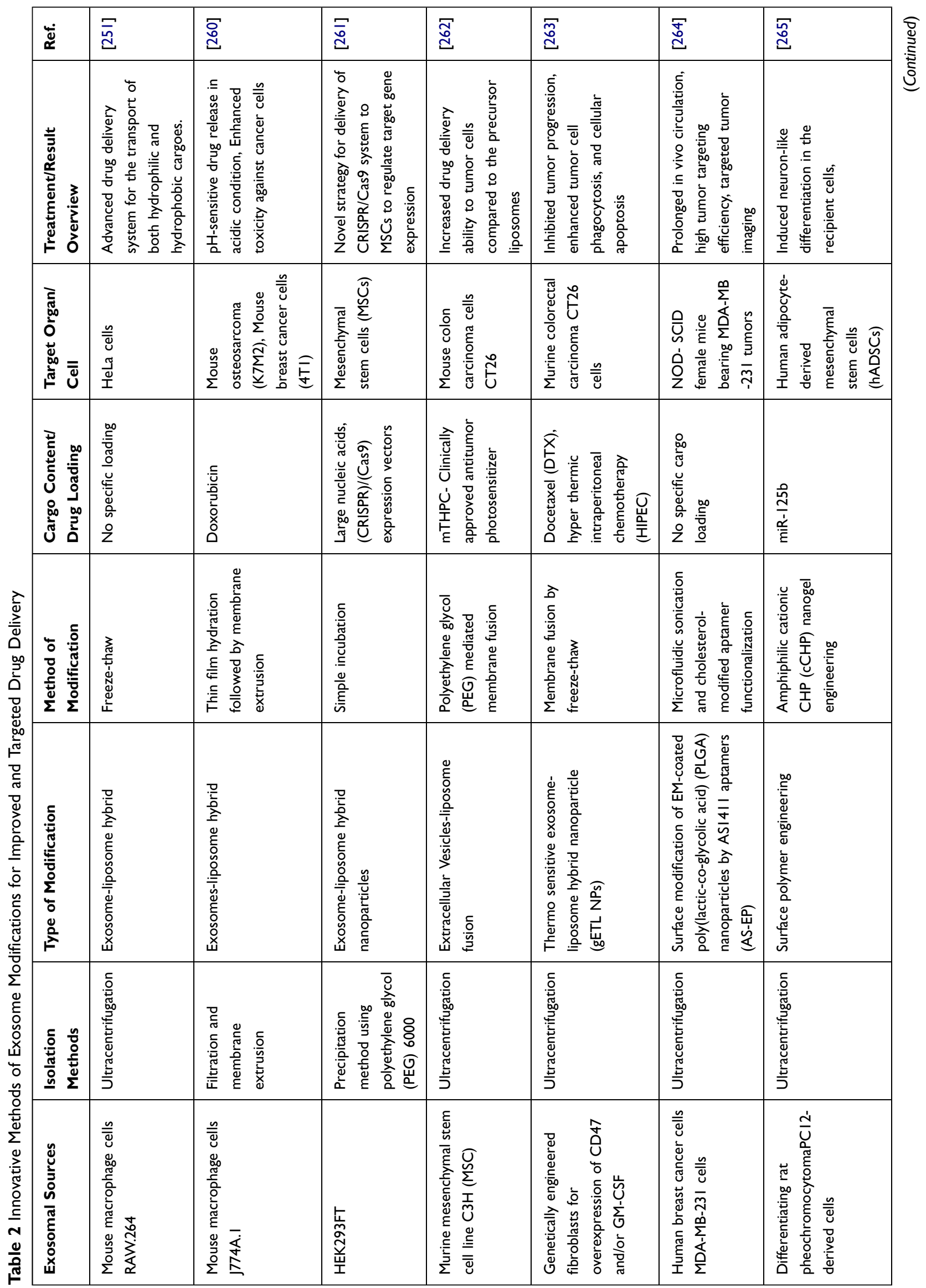




\begin{tabular}{|c|c|c|c|}
\hline 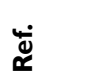 & 总 & 总 & 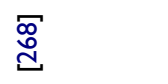 \\
\hline 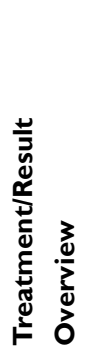 & 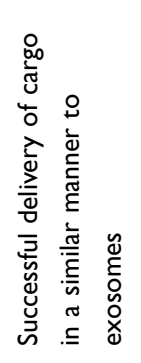 & 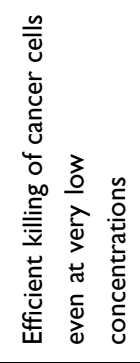 & 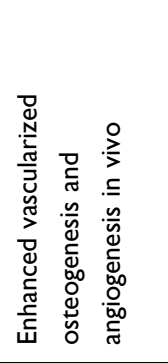 \\
\hline 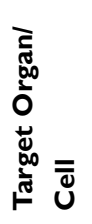 & 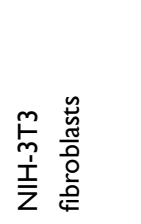 & $\begin{array}{l}\stackrel{n}{\mathcal{D}} \\
\tilde{J} \\
\stackrel{\tilde{d}}{I}\end{array}$ & 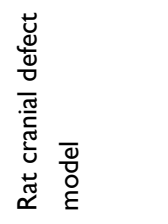 \\
\hline 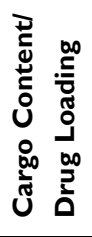 & 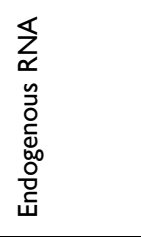 & 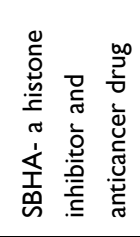 & 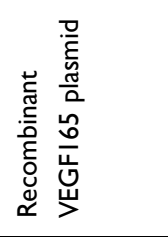 \\
\hline 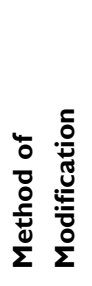 & 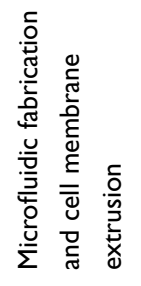 & 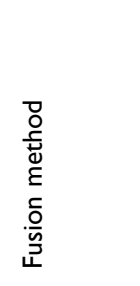 & 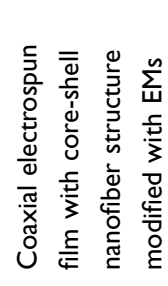 \\
\hline 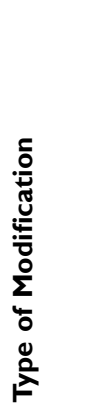 & 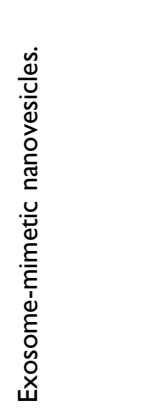 & 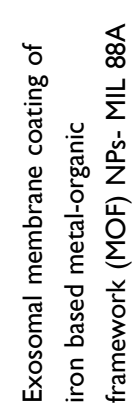 & 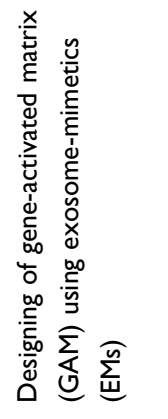 \\
\hline 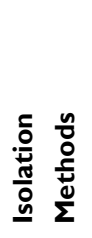 & 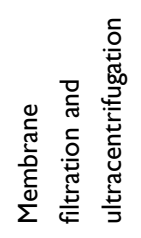 & 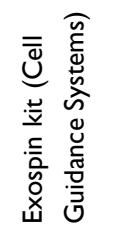 & 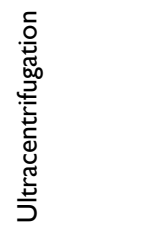 \\
\hline 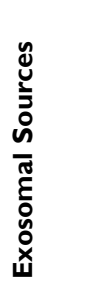 & 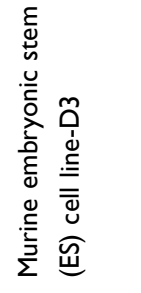 & 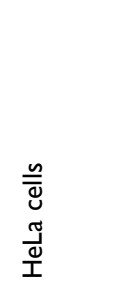 & 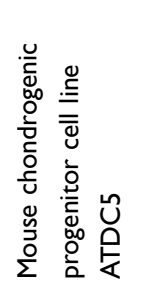 \\
\hline
\end{tabular}

\section{Perspective on Innovative Systems Utilizing Exosomes for Drug Delivery}

To improve the drug loading efficiency and half-life in blood as well as for achieving a decreased immunogenic profile, there have been several attempts. Some examples of the use of innovative methods of exosome modifications for improved and targeted drug delivery have been enlisted in Table 2. One such example is the recently trending technique of synthesizing liposome-exosome hybrid delivery systems as the smarter approach. ${ }^{249}$ This can be achieved by some of the very commonly used methods such as freeze-thaw, incubation, and sonication (Figure 13A). One of the most widely applied methodologies is the freeze-thaw method that can retain the targeting moieties of exosomal membrane and cargo loading potential of exosomes, to release both the hydrophobic and hydrophilic drug agents. ${ }^{250}$ Sato and coworkers worked on exosomes isolated from RAW264.7 cells and fused it with liposomes constituting 1,2-dioleoyl-snglycero-3-phosphocholine (DOPC; zwitterionic), 1,2-dioleoyl-sn-glycero3-phospho-l-serine; (DOPS, anionic), 1,2-dioleoyl-3-trimethylammonium propane (DOTAP; cationic) or 1,2-distearoyl-sn-glycero-3-phosphoethanolamine$\mathrm{N}-\left[\right.$ methoxy(polyethylene glycol)-2000] (PEG-DSPE) ${ }^{251}$ (Figure 13B). Basically, a proteoliposome (liposome carrying connexin) was prepared and was made to fuse with exosomal vesicle by a simple freeze-thaw technique. The hybrid system was effectively uptaken by HeLa cells and the fate of the exosomes was decided by the lipids or PEGlipids anchored onto them after the fusion process.

Another approach is the surface chemical modification of the isolated exosomes for improved targeting efficiency. Tian and team in 2018 studied modified exosomes for specifically targeting cerebral ischemia. The cyclo(ArgGly-Asp-D-Tyr-Lys) peptide [c(RGDyK)], which has the highest affinity for integrin $\alpha_{\mathrm{v}} \beta_{3}$ on active cerebral vascular endothelial cells, was conjugated to mesenchymal stromal cell (MSCs)-derived exosomes by a facile technique called bio-orthogonal chemistry. The cellular uptake pattern of MSCs-derived exosomes was thoroughly studied with HeLa and U87 glioblastoma cells, as shown in Figure 14. Similarly, the surface-modified exosomes were found to enter into microglia, astrocytes, and the region of ischemic junction. To augment the activity of surfacemodified exosomes, curcumin was loaded onto it which decreased the inflammation in the lesion area without compromising toxicity in mice. ${ }^{216}$ 
A

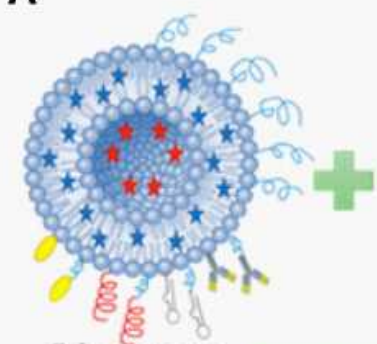

Liposome

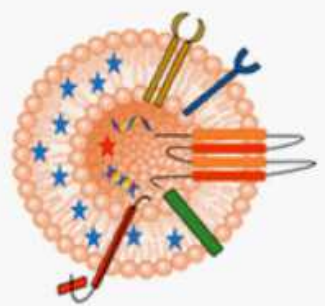

Exosome
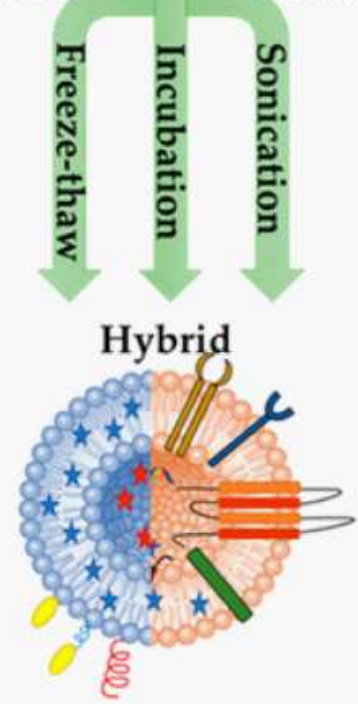

B

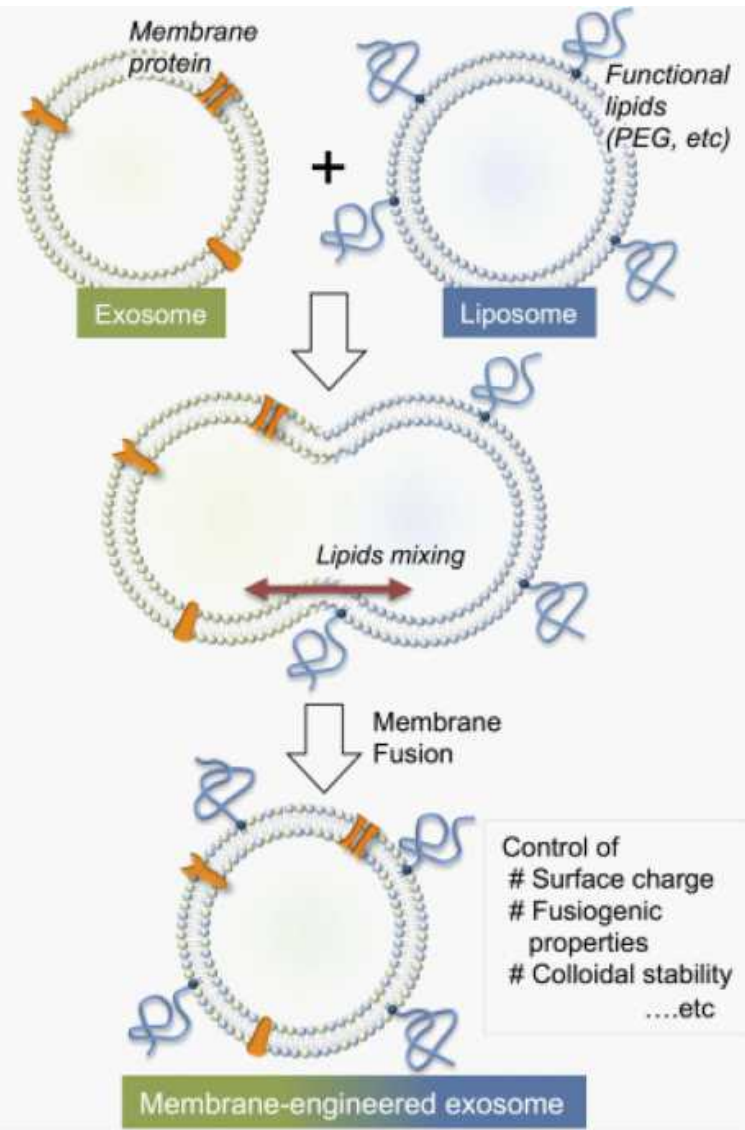

Figure 13 Synthesis of liposome-exosome hybrid nanosystem. (A) Schematic illustration of the three mainly used methods: freeze-thaw, incubation, and sonication for the synthesis. Adapted with permission from Elkhoury et al (2020). Copyright $@ 2020$ by the authors. License MDPI, Basel, Switzerland. This is an open access distributed under the terms of the Creative Commons (CC BY) license (http://creativecommons.org/licenses/by/4.0/). ${ }^{249}$ (B) Fusion of RAW 264.7 cell-derived exosomes with liposomes by using freeze-thaw technique. Adapted with permission from Sato et al Copyright (C) 2016, The Author(s). This is an open access article distributed under the terms of the Creative Commons CC BY license, which permits unrestricted use, distribution, and reproduction in any medium, provided the original work is properly cited. 251

In a similar study, Zhuang et al fabricated a synergistic system, i.e. SPION-conjugated exosomes with TNF- $\alpha$ anchored in the membrane. Recombinant plasmids carrying the sequence of cell-penetrating peptide (CPP) and TNF- $\alpha$ were synthesized and were established stably in MSC cell lines. The isolated exosomes, decorated with TNF- $\alpha$ were then conjugated with SPIONs to produce CTNF $\alpha$-exosome-SPIONs and then the anticancer activity was examined to validate the TNF- $\alpha$ mediated apoptosis. It was found that in the presence of an external magnetic field (MF) applied to the tumor site, CTNF- $\alpha$-exosomeSPION/MF exhibited higher cytotoxicity to tumor cells with less harm caused to normal cells. There was a marked increase in apoptotic cell populations, evident by the large G1 population ( $71.48 \%$ by the combination of CTNF- $\alpha$-exosome-SPIONs and MF) in the case of human melanoma cells A375 after being exposed for $24 \mathrm{~h}$ along with an increased expression of cleaved-caspases 2,3 , and
8. The in vivo biodistribution profile was gauged in A375 tumor-bearing mice by a non-invasive NIRF (near-infrared fluorescence) technique. In comparison to the absence of MF, increased Cy5.5 signal of the CTNF- $\alpha$-exosomeSPION was observed with strong MF which caused a significant reduction of tumor volume. ${ }^{252}$

Considering the relatively low release of exosomes from mammalian cells affecting their yield and purity, and the strenuous purification methods, researchers are now coming up with the idea of developing bioinspired exosome-mimetics. They display similar characteristics to exosomes in terms of membrane proteins, and at the same time, they offer advantages of high scalability and low production cost. ${ }^{253-255}$ Recently, Pisano et al developed Immune Derived Exosome Mimetics (IDEM) as a promising approach for the effective treatment of ovarian cancer. They synthesized IDEM by subjecting ThP-1 monocytic cells to serial extrusion through filters with 

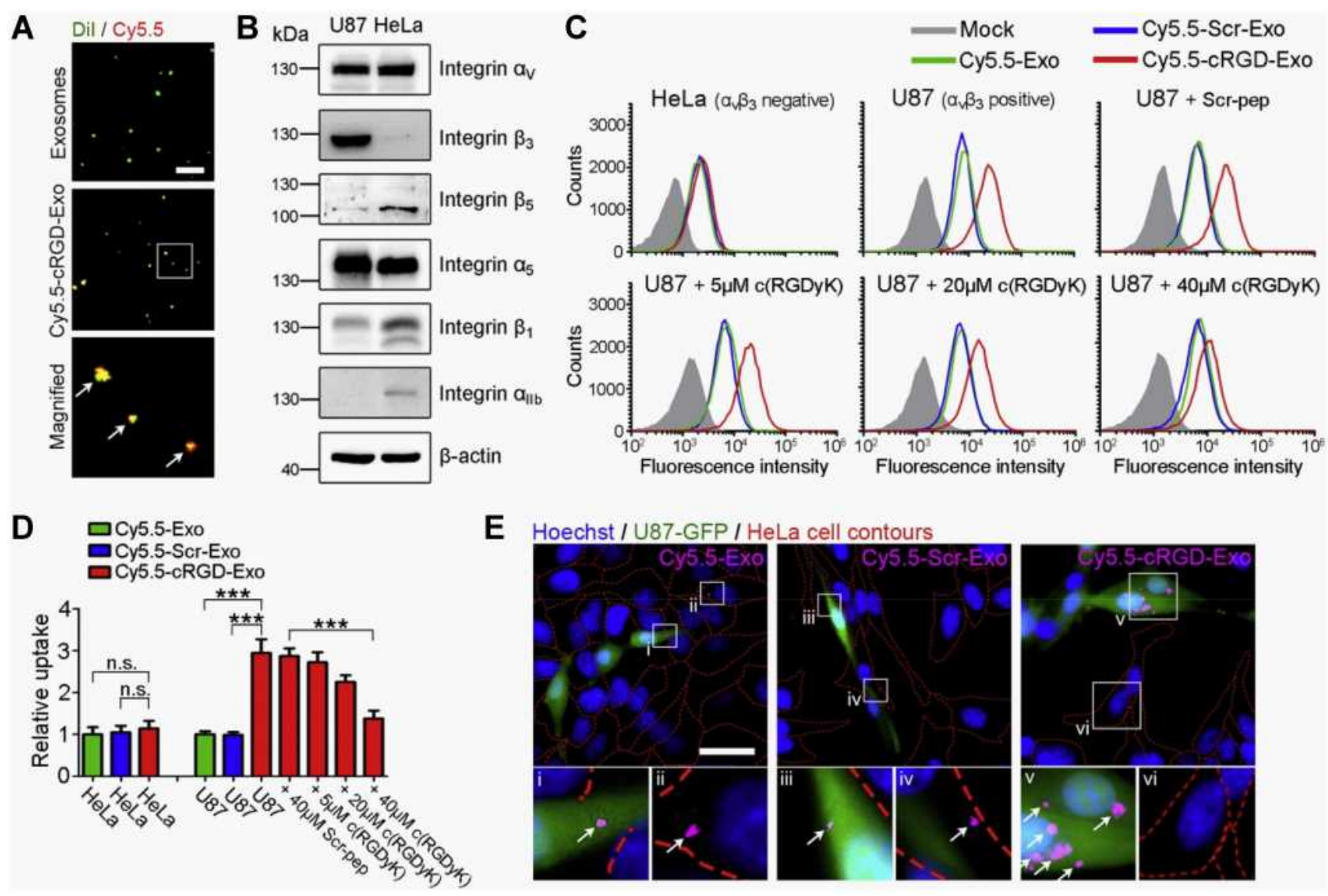

Figure 14 Representative results showing cellular tropism of cRGD-Exosomes (surface-modified exosomes) in vitro. (A) Fluorescence microscopic images of native and modified exosomes, green color indicates Dil-stained lipid membranes (of only native exosomes) and red is Cy5.5 that indicates the peptide-functionalized cy5.5 labeled exosomes, scale bar: $5 \mu \mathrm{m}$. The arrows indicate the colocalization between both the cy5.5 and Dil. (B) Western blotting of integrin subunits $\alpha_{v}, \beta_{3}$. $\beta_{5}, \alpha_{5}, \beta_{1}, \alpha_{11 \mathrm{~b}}$ from two cell lines U87 and HeLa cells that represent different integrin expression patterns, the results indicate that HeLa does not express $\alpha_{v} \beta_{3}$ while U87 cells express high levels of $\alpha_{v} \beta_{3}$. (C) Flow cytometry results indicate that the uptake level as measured by the fluorescence intensity of cRGD-Exo by $\alpha_{v} \beta_{3}$-positive U87 cells is about 3-times higher than that of exosomes. (D) The relative percentage of Cy5.5-positive HeLa or U87 cells compared to Cy5.5-Exo group, c(RGDyK) peptide acts dose-dependently. Data were represented as mean \pm SEM $(n=5)$; n.s., not significant; *** $P<0.001$ by Student's $t$-test. (E) Fluorescence images of Cy5.5-labeled exosomes or Scr-Exo (exosomes with functionalized scrambled peptide) and cRGD-Exo post 30 minutes incubation with U87-GFP and HeLa cells. Green indicates U87-GFP cells, magenta color represents Cy5.5-labeled exosomes, Scr-Exo, or cRGD-Exo and blue color indicates nuclei stained with Hoechst. cRGD-Exo entered more efficiently into U87-GFP cells as compared rest groups. The lower panel figure shows magnified images; arrows indicate internalized exosomes; scale bar, $30 \mu \mathrm{m}$. Adapted with permission from Biomaterials, Vol /edition number 150, Tian T, Zhang H-X, He C-P, et al, Surface functionalized exosomes as targeted drug delivery vehicles for cerebral ischemia therapy, Pages No. I37-I49, Copyright (2018), with permission from Elsevier. ${ }^{216}$

decreasing pore size $(10 \mu \mathrm{m}$ and $8 \mu \mathrm{m})$, followed by purifications using size-exclusion chromatography. Exosomes were isolated from the same number of ThP-1 cells using ultrafiltration followed by kit-based precipitation method. As per nanoparticle tracking analysis (NTA), IDEMe were found to be 2.8 times more concentrated than exosomes. Both were found to be positive for the exosomal marker proteins CD63 and CD81 with a rounded morphology (Figure 15A). When loaded with the drug doxorubicin (DOXO), IDEMs showed 28\% encapsulation efficiency, whereas exosomes retained $17 \%$ of the drug. IDEM-DOXO showed reduced cell viability of ovarian cancer cells (SKOV-3) with increasing concentration of DOXO with $85 \%$ cell death at $1 \mu \mathrm{g} / \mathrm{mL}$ concentration after $24 \mathrm{~h}$, whereas $90 \%$ cell death was observed at $96 \mathrm{~h}$ with EXO-DOXO treatment. A similar trend was observed for the level of apoptosis marker Caspase 3. In a 3D spheroid system that better mimics the in vivo environment, $5 \mu \mathrm{g} / \mathrm{mL}$ of both IDEM-DOXO and EXO-DOXO showed a loss of integrity with $20 \%$ reduced proliferation after $24 \mathrm{~h}$ due to increased necrosis (Figure 15B). This biomimetic system showed the potential to revolutionize the treatment of cancers due to stable drug delivery with reduced immunogenicity. ${ }^{256}$

A similar study was conducted by Kalimuthu et al in 2018, demonstrating an alternative to paclitaxel (PTX) drug delivery by synthetically prepared exosomemimetics (EMs). To isolate EMs, human mesenchymal 


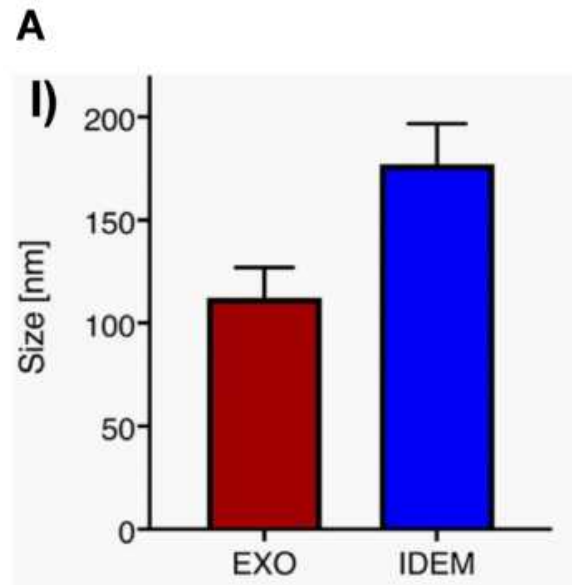

III)

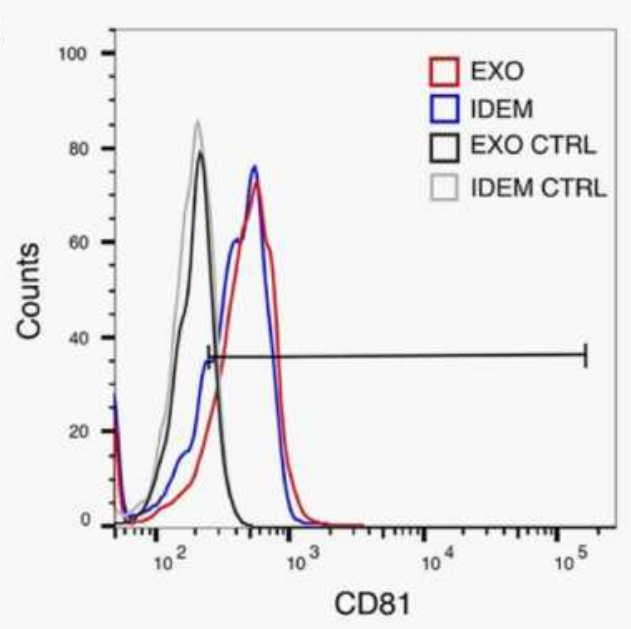

II)

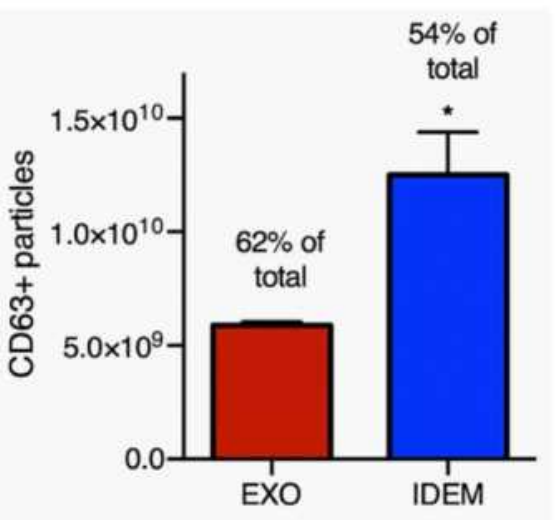

IV)

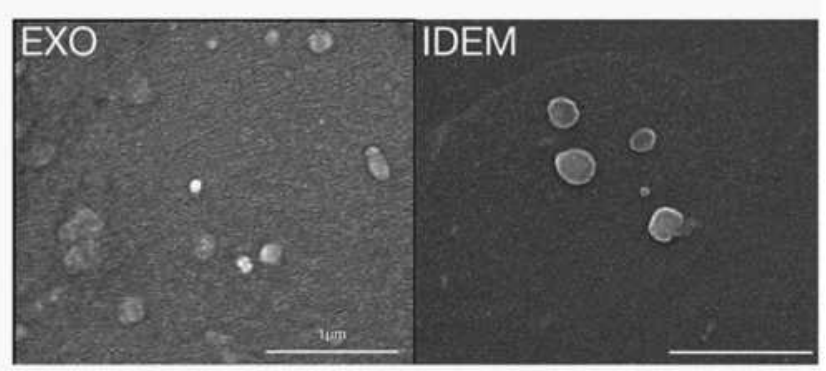

v)

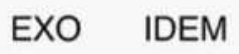

TSG-101

(50kDa)

\section{B}

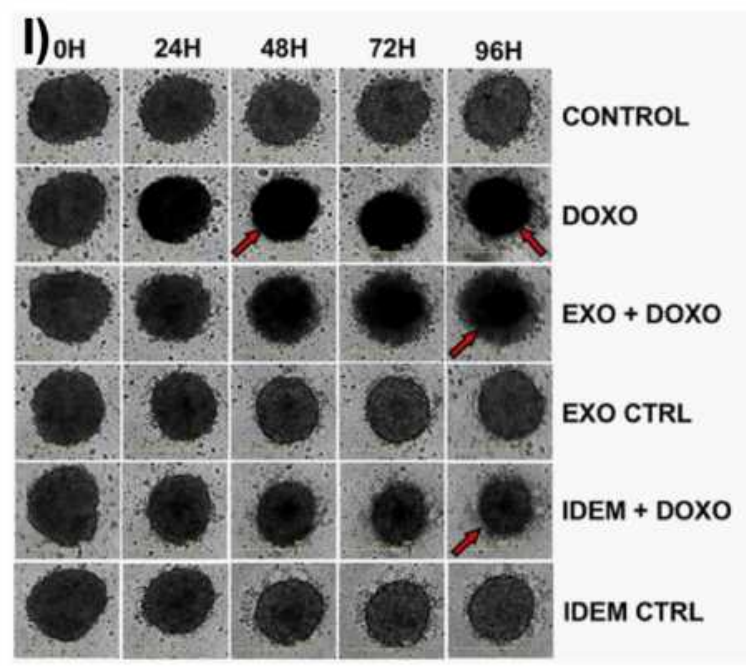

II)

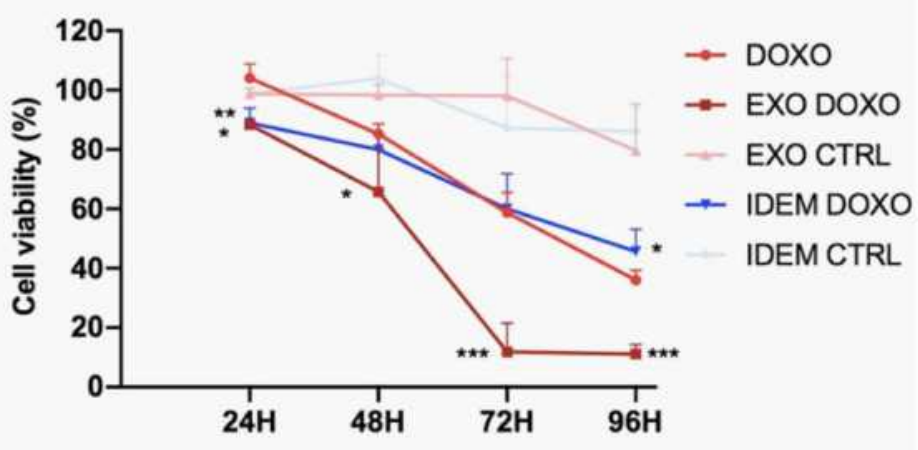

Figure 15 (A) Characterization of EXO and IDEM. I) Size (nm) and concentration (particles/mL) as per NTA, II) the number of CD63 positive EXO and IDEM obtained from ELISA (*P < 0.05), III) positive signal in flow cytometry for APC-CD8I antibody stained EXO and IDEM, IV) particle morphology revealed from scanning electron microscopy, V) presence of tsg-10I marker obtained from Western blotting. (B) I) Effect on 3D spheroid ovarian cancer model at 24h, 48h, 72h and 96h of treatment with $5 \mu \mathrm{g} / \mathrm{mL}$ of EXO and IDEM. Red arrows showing loss of integrity, change in color due to necrosis, II) percentage of cell viability showing greater effectiveness of IDEM-DOXO than only DOXO at $24 \mathrm{~h}$ and $96 \mathrm{~h}(* \mathrm{P}<0.05)$. Data indicating EXO-DOXO to be most effective at all-time points $(* * * \mathrm{P}<0.00 \mathrm{I}$ at $72 \mathrm{~h}$ and $96 \mathrm{~h})$. Data were analysed by a two-tailed Student's t-test and represented as mean \pm standard deviation; $* P<0.05, * * P<0.01$, ***P $<0.00$ I. Adapted with permission from Pisano $S$, Pierini, I, Gu Jet al Immune (Cell) Derived Exosome Mimetics (IDEM) as a Treatment for Ovarian Cancer. Front Cell Dev Biol. 2020;8: 553576.Copyright $\odot 2020$ Pisano, Perini, Gu, Gazze, Francis, Gonzalez, Conlan and Corradetti. This is an open access distributed under the terms of the Creative Commons Attribution License (CC BY). ${ }^{256}$ 
stem cells (MSCs) were treated with PTX and serially extruded using polycarbonate membrane filters in a miniextruder similar to the previously discussed example. This was followed by filtration and ultracentrifugation to get PTX-MSC-EMs. These synthesized EMs were successfully internalized into triple-negative breast cancer cellline MDA-MB-231 where they showed cytotoxicity with increasing concentration of PTX from 25 to $50 \mu \mathrm{g} / \mathrm{mL}$. When injected intratumorally into a xenograft MDA-MB -231 cancer mouse model, PTX-MSC-EMs inhibited tumor growth and a significant reduction of tumor weight was observed after 5 days of treatment. Their study revealed the therapeutic efficiency of the innovative exosome mimetic system, against breast cancer cells, which can be used as novel drug delivery vehicles for cancer treatment. $^{257}$

Exosomes exert valuable biological properties that endow advantages for a suitable delivery vehicle. Its intrinsic cargo loading capacity, along with its high targeting potential due to the presence of membrane proteins, makes it an advanced nanosystem. ${ }^{258}$ However, due to issues like low plasma half-life and rapid clearance, it has been on demand to make innovative and hybrid exosomes to bring overall stability in the nanosystem. Although in the pilot stage, this area is proving to be one of the hot topics in exosome research. Bone defects are hard to cure and the regimens currently available for skeletal-related events and other bone diseases like osteoarthritis and osteosarcoma are ineffective. ${ }^{30}$ To minimize the possible off-target effects that are mainly seen with signaling pathway crosstalk in poor drug delivery systems, it is essential to develop nanosystems that will enhance the drug deposition in the bone niche with a better biodistribution profile. ${ }^{259}$ For these valid reasons, effective and advanced nanosystems are of keen interest in the treatment of bone diseases. Synthetic nanosystems that are highly developing still lack some features and often fail in the mice model being recognized as foreign material. $^{258}$ It will not be futile to state the fact that innovative ideas as discussed in this section will be interesting to make the naturally occurring exosomes a stable nanosystem, which will be more in demand in the long run.

\section{Conclusion}

In line with the title of the review, a lot of information on exosomes has been already deciphered while a long way is still to go before we can evidence bench to bedside results. Based on the results that have been obtained so far, exosomes are definitely promising candidates for therapeutics and at the same time, the scalability and a non-expensive user-friendly technique for isolation is the need of the hour. Other features like biocompatibility and efficient cellular internalization together with high therapeutic loading capacity are inherently present. Another advantage of using exosome mediation is the cell-free approach that it offers which eliminates a lot of drawbacks. The lipid bilayer also looks promising in terms of chemistries that can be taken up to further functionalize this system towards effective targeting. However, looking at the number of patents that have been generated so far, it appears that the field is still open with ample scopes that must be explored to fully utilize the exosome-based systems for effectively acting as drug delivery vehicles to the bone. The review of the literature and presentation of our perspective is an effort towards that direction.

\section{Acknowledgments}

Mamoni Dash acknowledges the Ramalingaswami Fellowship 2016-17 (D.O.NO.BT/HRD/35/02/2006), Department of Biotechnology, Government of India, Institute of Life Sciences (ILS), Sasmita Samal acknowledges the Council of Scientific and Industrial Research (CSIR), New Delhi, Government of India, Institute of Life Sciences, Pratigyan Dash acknowledges UGC, Government of India. Dr Sandra Van Vlierberghe, Lana Van Damme, are highly acknowledged for valuable discussion on the topic.

\section{Disclosure}

The authors report no conflicts of interest in this work.

\section{References}

1. Boskey AL, Posner AS. Bone structure, composition, and mineralization. Orthop Clin North Am. 1984;15(4):597-612. doi:10.1016/S0030-5898(20)31258-X

2. Buckwalter JA, Cooper RR. Bone structure and function. Instr Course Lect. 1987;36:27-48.

3. Shea JE, Miller SC. Skeletal function and structure: implications for tissue-targeted therapeutics. Adv Drug Deliv Rev. 2005;57(7):945-957. doi:10.1016/j.addr.2004.12.017

4. Weiner S, Wagner HD. THE MATERIAL BONE: structure-Mechanical Function Relations. Adv Musculoskeletal Dis. 1998;28(1):271-298.

5. Florencio-Silva R, Sasso GR, Sasso-Cerri E, Simões MJ, Cerri PS. Biology of bone tissue: structure, function, and factors that influence bone cells. Biomed Res Int. 2015;2015:421746. doi:10.1155/2015/421746

6. Nakashima T, Hayashi M, Fukunaga T, et al. Evidence for osteocyte regulation of bone homeostasis through RANKL expression. Nat Med. 2011;17(10):1231-1234. doi:10.1038/nm.2452 
7. Rodan GA. Bone homeostasis. Proce Nat Acad Sci United States Am. 1998;95(23):13361-13362. doi:10.1073/pnas.95.23.13361

8. Baron R, Kneissel M. WNT signaling in bone homeostasis and disease: from human mutations to treatments. Nat Med. 2013;19 (2):179-192. doi:10.1038/nm.3074

9. Demontiero O, Vidal C, Duque G. Aging and bone loss: new insights for the clinician. Therapeutic Adv Musculoskeletal Dis. 2012;4(2):61-76. doi:10.1177/1759720X11430858

10. Duarte MP, Farias MLF, Coelho HSM, et al. Calcium-parathyroid hormone-vitamin D axis and metabolic bone disease in chronic viral liver disease. J Gastroenterol Hepatol. 2001;16 (9):1022-1027.

11. Parfitt AM. The actions of parathyroid hormone on bone: relation to bone remodeling and turnover, calcium homeostasis, and metabolic bone disease: part IV of IV parts: the state of the bones in uremic hyperparathyroidism - The mechanisms of skeletal resistance to PTH in renal failure and pseudohypoparathyroidism and the role of PTH in osteoporosis, osteopetrosis, and osteofluorosis. Metabolism. 1976;25(10):1157-1188. doi:10.1016/0026-0495(76) 90024-x

12. Westendorf JJ, Kahler RA, Schroeder TM. Wnt signaling in osteoblasts and bone diseases. Gene. 2004;341:19-39. doi:10.1016/j.gene.2004.06.044

13. Wada T, Nakashima T, Hiroshi N, Penninger JM. RANKLRANK signaling in osteoclastogenesis and bone disease. Trends Mol Med. 2006;12(1):17-25. doi:10.1016/j.molmed.2005.11.007

14. Shoback D. Update in Osteoporosis and Metabolic Bone Disorders. J Clin Endocrinol Metab. 2007;92(3):747-753. doi:10.1210/jc.2007-0042

15. Black DM, Rosen CJ. Postmenopausal Osteoporosis. $N$ Eng $J$ Med. 2016;374(3):254-262. doi:10.1056/NEJMcp1513724

16. Coleman RE, Rubens RD. The clinical course of bone metastases from breast cancer. Br J Cancer. 1987;55(1):61-66. doi:10.1038/ bjc. 1987.13

17. Picci P. Osteosarcoma (Osteogenic sarcoma). Orphanet J Rare Dis. 2007;2(1):6. doi:10.1186/1750-1172-2-6

18. Schett G, Gravallese E. Bone erosion in rheumatoid arthritis: mechanisms, diagnosis and treatment. Nat Rev Rheumatol. 2012;8(11):656-664. doi:10.1038/nrrheum.2012.153

19. Kravets I. Paget's Disease of Bone: diagnosis and Treatment. Am $J \quad$ Med. 2018;131(11):1298-1303. doi:10.1016/j. amjmed.2018.04.028

20. Rodan GA, Martin TJ. Therapeutic Approaches to Bone Diseases. Science (New York, N.Y.). 2000;289(5484):1508-1514. doi:10.1126/science.289.5484.1508

21. Cano A, Hermenegildo C. The endometrial effects of SERMs. Hum Reprod Update. 2000;6(3):244-254. doi:10.1093/humupd/6.3.244

22. Brisson J, Brisson B, Coté G, Maunsell E, Bérubé S, Robert J. Tamoxifen and Mammographic Breast Densities. Cancer Epidemiol Biomarkers. 2000;9(9):911-915.

23. Salari P, Abdollahi M. Long Term Bisphosphonate Use in Osteoporotic Patients; A Step Forward, Two Steps Back. J Pharm Pharmaceutical Sci. 2012;15(2):305-317. doi:10.18433/ J3RK5J

24. Dimopoulos MA, Kastritis E, Anagnostopoulos A, et al. Osteonecrosis of the jaw in patients with multiple myeloma treated with bisphosphonates: evidence of increased risk after treatment with zoledronic acid. Haematologica. 2006;91(7):968-971.

25. Kennel KA, Drake MT. Adverse Effects of Bisphosphonates: implications for Osteoporosis Management. Mayo Clinic Proceedings. 2009;84(7):632-638. doi:10.1016/S0025-6196(11)60752-0

26. Gallagher AM, Rietbrock S, Olson M, van Staa TP. Fracture Outcomes Related to Persistence and Compliance With Oral Bisphosphonates. J Bone Mineral Res. 2008;23(10):1569-1575.
27. Adami S, Zamberlan N. Adverse Effects of Bisphosphonates. Drug Safety. 1996;14(3):158-170. doi:10.2165/00002018199614030-00003

28. Yang L, Webster TJ. Nanotechnology controlled drug delivery for treating bone diseases. Expert Opin Drug Deliv. 2009;6 (8):851-864. doi:10.1517/17425240903044935

29. Yang X, Chen S, Liu X, Yu M, Liu X. Drug Delivery Based on Nanotechnology for Target Bone Disease. Curr Drug Deliv. 2019;16(9):782-792. doi:10.2174/1567201816666190917123948

30. Gu W, Wu C, Chen J, Xiao Y. Nanotechnology in the targeted drug delivery for bone diseases and bone regeneration. Int J Nanomedicine. 2013;8:2305-2317. doi:10.2147/IJN.S44393

31. Ram Prasad S, Jayakrishnan A, Sampath Kumar TS. Hydroxyapatite-poly(vinyl alcohol) core-shell nanoparticles for dual delivery of methotrexate and gemcitabine for bone cancer treatment. J Drug Deliv Sci Technol. 2019;51:629-638. doi:10.1016/j.jddst.2019.03.041

32. Jayaraman P, Gandhimathi C, Venugopal JR, Becker DL, Ramakrishna S, Srinivasan DK. Controlled release of drugs in electrosprayed nanoparticles for bone tissue engineering. $A d v$ Drug Deliv Rev. 2015;94:77-95. doi:10.1016/j.addr.2015.09.007

33. Sunoqrot S, Bugno J, Lantvit D, Burdette JE, Hong S. Prolonged blood circulation and enhanced tumor accumulation of folate-targeted dendrimer-polymer hybrid nanoparticles. $J$ Controlled Release. 2014;191:115-122. doi:10.1016/j.jconrel.2014.05.006

34. Low SA, Kopeček J. Targeting polymer therapeutics to bone. Adv Drug Deliv Rev. 2012;64(12):1189-1204. doi:10.1016/j. addr.2012.01.012

35. Hengst V, Oussoren C, Kissel T, Storm G. Bone targeting potential of bisphosphonate-targeted liposomes: preparation, characterization and hydroxyapatite binding in vitro. Int $J$ Pharm. 2007;331(2):224-227. doi:10.1016/j.ijpharm.2006.11.024

36. Cole LE, Vargo-Gogola T, Roeder RK. Targeted delivery to bone and mineral deposits using bisphosphonate ligands. Adv Drug Deliv Rev. 2016;99:12-27. doi:10.1016/j.addr.2015.10.005

37. Ramanlal Chaudhari K, Kumar A, Megraj Khandelwal VK, et al. Bone metastasis targeting: a novel approach to reach bone using Zoledronate anchored PLGA nanoparticle as carrier system loaded with Docetaxel. $J$ Controlled Release. 2012;158 (3):470-478. doi:10.1016/j.jconrel.2011.11.020

38. Hasani-Sadrabadi MM, Dashtimoghadam E, Bahlakeh G, et al. On-chip synthesis of fine-tuned bone-seeking hybrid nanoparticles. J Bone Mineral Res. 2015;10(23):3431-3449.

39. Song Y-F, Liu D-Z, Cheng Y. Charge Reversible and Mitochondria/Nucleus Dual Target Lipid Hybrid Nanoparticles To Enhance Antitumor Activity of Doxorubicin. Mol Pharm. 2018;15(3):1296-1308. doi:10.1021/acs.molpharmaceut.7b01109

40. Ortiz de Solorzano I, Alejo T, Abad M. Cleavable and thermo-responsive hybrid nanoparticles for on-demand drug delivery. $J$ Colloid Interface Sci. 2019;533:171-181. doi:10.1016/j.jcis.2018.08.069

41. Park K. Facing the Truth about Nanotechnology in Drug Delivery. ACS Nano. 2013;7(9):7442-7447. doi:10.1021/nn404501g

42. Neuberger T, Schöpf B, Hofmann H, Hofmann M, von Rechenberg B. Superparamagnetic nanoparticles for biomedical applications: possibilities and limitations of a new drug delivery system. J Magn Magn Mater. 2005;293(1):483-496. doi:10.1016/ j.jmmm.2005.01.064

43. Manzoor AA, Lindner LH, Landon CD, et al. Overcoming Limitations in Nanoparticle Drug Delivery: triggered, Intravascular Release to Improve Drug Penetration into Tumors. Cancer Research. 2012;72(21):5566-5575. doi:10.1158/00085472.CAN-12-1683

44. Hessvik NP, Llorente A. Current knowledge on exosome biogenesis and release. Cell Mol Life Sci. 2018;75(2):193-208. 
45. Bobrie A, Colombo M, Raposo G, Théry C. Exosome Secretion: molecular Mechanisms and Roles in Immune Responses. Traffic (Copenhagen, Denmark). 2011;12(12):1659-1668. doi:10.1111/ j.1600-0854.2011.01225.x

46. Vlassov AV, Magdaleno S, Setterquist R, Conrad R. Exosomes: current knowledge of their composition, biological functions, and diagnostic and therapeutic potentials. Biochimica et Biophysica Acta. 2012;1820(7):940-948. doi:10.1016/j. bbagen.2012.03.017

47. Jiang L, Gu Y, Du Y, Liu J. Exosomes: diagnostic Biomarkers and Therapeutic Delivery Vehicles for Cancer. Mol Pharm. 2019;16 (8):3333-3349. doi:10.1021/acs.molpharmaceut.9b00409

48. Munson P, Shukla A. Exosomes: potential in Cancer Diagnosis and Therapy. Medicines. 2015;2(4):310-327. doi:10.3390/ medicines 2040310

49. Johnstone RM, Adam M, Hammond JR, Orr L, Turbide C. Vesicle formation during reticulocyte maturation. Association of plasma membrane activities with released vesicles (exosomes). J Biol Chem. 1987;262(19):9412-9420.

50. Thébaud B, Stewart DJ. Exosomes. Circulation. 2012;126 (22):2553-2555. doi:10.1161/CIRCULATIONAHA.112.146738

51. Pegtel DM, Cosmopoulos K, Thorley-Lawson DA, et al. Functional delivery of viral miRNAs via exosomes. Proce Nat Acad Sci United States Am. 2010;107(14):6328-6333. doi:10.1073/pnas.0914843107

52. Sun D, Zhuang X, Zhang S, et al. Exosomes are endogenous nanoparticles that can deliver biological information between cells. Adv Drug Deliv Rev. 2013;65(3):342-347. doi:10.1016/j. addr.2012.07.002

53. Valadi H, Ekström K, Bossios A, Sjöstrand M, Lee JJ, Lötvall JO. Exosome-mediated transfer of mRNAs and microRNAs is a novel mechanism of genetic exchange between cells. Nat Cell Biol. 2007;9(6):654-659. doi:10.1038/ncb1596

54. Hurley JH, Odorizzi G. Get on the exosome bus with ALIX. Nat Cell Biol. 2012;14(7):654-655. doi:10.1038/ncb2530

55. Anand S, Samuel M, Kumar S, Mathivanan S. Ticket to a bubble ride: cargo sorting into exosomes and extracellular vesicles. Biochimica et Biophysica Acta. 2019;1867(12):140203. doi:10.1016/j.bbapap.2019.02.005

56. Mathieu M, Martin-Jaular L, Lavieu G, Théry C. Specificities of secretion and uptake of exosomes and other extracellular vesicles for cell-to-cell communication. Nat Cell Biol. 2019;21(1):9-17. doi:10.1038/s41556-018-0250-9

57. Danzer KM, Kranich LR, Ruf WP, et al. Exosomal cell-to-cell transmission of alpha synuclein oligomers. Mol Neurodegener. 2012;7(1):42. doi:10.1186/1750-1326-7-42

58. Tan A, Rajadas J, Seifalian AM. Exosomes as nano-theranostic delivery platforms for gene therapy. Adv Drug Deliv Rev. 2013;65 (3):357-367. doi:10.1016/j.addr.2012.06.014

59. Li Y, Zhang Y, Li Z, Zhou K, Feng N. Exosomes as Carriers for Antitumor Therapy. ACS Biomater Sci Eng. 2019;5 (10):4870-4881. doi:10.1021/acsbiomaterials.9b00417

60. Kumar S, Michael IJ, Park J, Granick S, Cho Y-K. Cloaked Exosomes: biocompatible. Durable Degradable Encapsulation. 2018;14(34):1802052.

61. Yang M, Wu SY. The Advances and Challenges in Utilizing Exosomes for Delivering Cancer Therapeutics. Front Pharmacol. 2018;9:735.

62. Felicetti F, De Feo A, Coscia C, et al. Exosome-mediated transfer of miR-222 is sufficient to increase tumor malignancy in melanoma. J Transl Med. 2016;14(1):56. doi:10.1186/s12967-016-0811-2

63. Zheng M, Huang M, Ma X, Chen H, Gao X. Harnessing Exosomes for the Development of Brain Drug Delivery Systems. Bioconjug Chem. 2019;30(4):994-1005. doi:10.1021/ acs.bioconjchem.9b00085
64. Khongkow M, Yata T, Boonrungsiman S, Ruktanonchai UR, Graham D, Namdee K. Surface modification of gold nanoparticles with neuron-targeted exosome for enhanced blood-brain barrier penetration. Sci Rep. 2019;9(1):8278. doi:10.1038/ s41598-019-44569-6

65. Liu C, Su C. Design strategies and application progress of therapeutic exosomes. Theranostics. 2019;9(4):1015-1028. doi:10.7150/thno.30853

66. Sherif AY, Harisa GI, Alanazi FK, Youssof AME. Engineering of Exosomes: steps Towards Green Production of Drug Delivery System. Curr Drug Targets. 2019;20(15):1537-1549. doi:10.2174/1389450120666190715104100

67. Xie Y, Chen Y, Zhang L, Ge W, Tang P. The roles of bone-derived exosomes and exosomal microRNAs in regulating bone remodelling. $J$ Cell Mol Med. 2017;21(5):1033-1041. doi:10.1111/jcmm.13039

68. Cappariello A, Loftus A, Muraca M, Maurizi A, Rucci N, Teti A. Osteoblast-Derived Extracellular Vesicles Are Biological Tools for the Delivery of Active Molecules to Bone. J Bone Mineral Res. 2018;33(3):517-533.

69. Deng L, Wang Y, Peng Y, et al. Osteoblast-derived microvesicles: a novel mechanism for communication between osteoblasts and osteoclasts. Bone. 2015;79:37-42. doi:10.1016/j.bone.2015.05.022

70. Sun W, Zhao C, Li Y, et al. Osteoclast-derived microRNA-containing exosomes selectively inhibit osteoblast activity. Cell Discovery. 2016;2(1):16015. doi:10.1038/ celldisc. 2016.15

71. Kobayashi-Sun J, Yamamori S, Kondo M, Kuroda J, Ikegame M, Suzuki N. Uptake of osteoblast-derived extracellular vesicles promotes the differentiation of osteoclasts in the zebrafish scale. Commun Biol. 2020;3(1):190. doi:10.1038/s42003-020-0925-1

72. Qin Y, Wang L, Gao Z, Chen G, Zhang C. Bone marrow stromal/ stem cell-derived extracellular vesicles regulate osteoblast activity and differentiation in vitro and promote bone regeneration in vivo. Sci Rep. 2016;6(1):21961. doi:10.1038/srep21961

73. Furuta T, Miyaki S, Ishitobi $\mathrm{H}$, et al. Mesenchymal Stem Cell-Derived Exosomes Promote Fracture Healing in a Mouse Model. Stem Cells Translational Med. 2016;5(12):1620-1630. doi:10.5966/sctm.2015-0285

74. Zhao P, Xiao L, Peng J, Qian YQ, Huang CC. Exosomes derived from bone marrow mesenchymal stem cells improve osteoporosis through promoting osteoblast proliferation via MAPK pathway. Eur Rev Med Pharmacol Sci. 2018;22(12):3962-3970. doi:10.26355/eurrev_201806_15280

75. Qiu M. Bone marrow mesenchymal stem cells-derived exosomal microRNA-150-3p promotes osteoblast proliferation and differentiation in osteoporosis. Human Gene Therapy. 2021

76. Chindamo G, Sapino S, Peira E, Chirio D, Gonzalez MC, Gallarate M. Bone Diseases: current Approach and Future Perspectives in Drug Delivery Systems for Bone Targeted Therapeutics. Nanomaterials. 2020;10(5):875. doi:10.3390/ nano10050875

77. Farrell KB, Karpeisky A, Thamm DH, Zinnen S. Bisphosphonate conjugation for bone specific drug targeting. Bone Reports. 2018;9:47-60. doi:10.1016/j.bonr.2018.06.007

78. Brown JP, Morin S, Leslie W, et al. Bisphosphonates for treatment of osteoporosis: expected benefits, potential harms, and drug holidays. Can Fam Physician. 2014;60(4):324-333.

79. Faienza MF, Chiarito M, D'amato G, et al. Monoclonal antibodies for treating osteoporosis. Expert Opin Biol Ther. 2018;18 (2):149-157. doi:10.1080/14712598.2018.1401607

80. Bilezikian JP. Combination anabolic and antiresorptive therapy for osteoporosis: opening the anabolic window. Curr Osteoporos Rep. 2008;6(1):24-30. doi:10.1007/s11914-008-0005-9 
81. Cosman F, Nieves JW, Dempster DW. Treatment Sequence Matters: anabolic and Antiresorptive Therapy for Osteoporosis. J Bone Mineral Res. 2017;32(2):198-202. doi:10.1002/ jbmr.3051

82. Saikali Z, Singh G. Doxycycline and other tetracyclines in the treatment of bone metastasis. Anti-Cancer Drugs. 2003;14 (10):773-778. doi:10.1097/00001813-200311000-00001

83. Eilber F, Giuliano A, Eckardt J, Patterson K, Moseley S, Goodnight J. Adjuvant chemotherapy for osteosarcoma: a randomized prospective trial. J Clin Oncol. 1987;5(1):21-26. doi:10.1200/JCO.1987.5.1.21

84. Carrle D, Bielack SS. Current strategies of chemotherapy in osteosarcoma. Int Orthop. 2006;30(6):445-451. doi:10.1007/ s00264-006-0192-x

85. Notelovitz M. Estrogen Therapy and Osteoporosis: principles \& Practice. Am J Med Sci. 1997;313(1):2-12. doi:10.1097/ 00000441-199701000-00002

86. Ganesan K, Roane D. Bisphosphonate. Treasure Island (FL): StatPearls Publishing; 2019.

87. Favus MJ. Bisphosphonates for Osteoporosis. $N$ Eng J Med. 2010;363(21):2027-2035. doi:10.1056/NEJMct1004903

88. Watts NB. Erratum. J Clin Endocrinol Metab. 2010;95(7):3565. doi:10.1210/jcem.95.7.9997

89. Michaelson MD, Smith MR. Bisphosphonates for treatment and prevention of bone metastases. J clin oncol. 2005;23 (32):8219-8224. doi:10.1200/JCO.2005.02.9579

90. Pfannkuchen N, Meckel M, Bergmann R, et al. Novel Radiolabeled Bisphosphonates for PET Diagnosis and Endoradiotherapy of Bone Metastases. Pharmaceuticals. 2017;10(2):45. doi:10.3390/ph10020045

91. Wu VM, Mickens J, Uskoković V. BisphosphonateFunctionalized Hydroxyapatite Nanoparticles for the Delivery of the Bromodomain Inhibitor JQ1 in the Treatment of Osteosarcoma. ACS Appl Mater Interfaces. 2017;9 (31):25887-25904. doi:10.1021/acsami.7b08108

92. Inoue R, Matsuki N-A, Jing G. The inhibitory effect of alendronate, a nitrogen-containing bisphosphonate on the PI3K-AktNFkappaB pathway in osteosarcoma cells. $\mathrm{Br} J$ Pharmacol. 2005;146(5):633-641. doi:10.1038/sj.bjp.0706373

93. Cremers S, Drake MT, Ebetino FH, Bilezikian JP, Russell RGG. Pharmacology of bisphosphonates. Br J Clin Pharmacol. 2019;85 (6):1052-1062. doi:10.1111/bcp.13867

94. Rogers MJ, Gordon S, Benford HL, et al. Cellular and molecular mechanisms of action of bisphosphonates. Cancer. 2000;88 (S12):2961-2978.

95. Tanaka Y, Iwasaki M, Murata-Hirai K, et al. Anti-Tumor Activity and Immunotherapeutic Potential of a Bisphosphonate Prodrug. Sci Rep. 2017;7(1):5987. doi:10.1038/s41598-017-05553-0

96. Heymann D, Ory B, Gouin F, Green JR, Rédini F Bisphosphonates: new therapeutic agents for the treatment of bone tumors. Trends Mol Med. 2004;10(7):337-343. doi:10.1016/j.molmed.2004.05.007

97. Miller PD. Denosumab: anti-RANKL antibody. Curr Osteoporos Rep. 2009;7(1):18-22. doi:10.1007/s11914-009-0004-5

98. Moen MD, Keam SJ. Denosumab. Drugs Aging. 2011;28 (1):63-82. doi:10.2165/11203300-000000000-00000

99. Cummings SR, Martin JS, McClung MR, et al. Denosumab for prevention of fractures in postmenopausal women with osteoporosis. N Eng J Med. 2009;361(8):756-765. doi:10.1056/ NEJMoa0809493

100. Anandarajah AP, Schwarz EM. Anti-RANKL therapy for inflammatory bone disorders: mechanisms and potential clinical applications. J Cell Biochem. 2006;97(2):226-232.

101. Baron R, Ferrari S, Russell RGG. Denosumab and bisphosphonates: different mechanisms of action and effects. Bone. 2011;48 (4):677-692. doi:10.1016/j.bone.2010.11.020
102. Anastasilakis AD, Papapoulos SE, Polyzos SA, AppelmanDijkstra NM, Makras P. Zoledronate for the Prevention of Bone Loss in Women Discontinuing Denosumab Treatment. A Prospective Clin Trial. 2019;34(12):2220-2228.

103. Matuoka JY, Kahn JG, Secoli SR. Denosumab versus bisphosphonates for the treatment of bone metastases from solid tumors: a systematic review. Eur $J$ Health Economics. 2019;20 (4):487-499. doi:10.1007/s10198-018-1011-1

104. Perrin DD. Binding of Tetracyclines to Bone. Nature. 1965;208 (5012):787-788. doi:10.1038/208787a0

105. Kim Y, Kim J, Lee $\mathrm{H}$, et al. Tetracycline Analogs Inhibit Osteoclast Differentiation by Suppressing MMP-9-Mediated Histone H3 Cleavage. J Cell Biochem. 2019;20(16):4038.

106. Hochdörffer K, Abu Ajaj K, Schäfer-Obodozie C, Kratz F. Development of Novel Bisphosphonate Prodrugs of Doxorubicin for Targeting Bone Metastases That Are Cleaved pH Dependently or by Cathepsin B: synthesis, Cleavage Properties, and Binding Properties to Hydroxyapatite As Well As Bone Matrix. J Med Chem. 2012;55(17):7502-7515. doi:10.1021/jm300493m

107. Ye W-L, Zhao Y-P, Li H-Q. Doxorubicin-poly (ethylene glycol)-alendronate self-assembled micelles for targeted therapy of bone metastatic cancer. Sci Rep. 2015;5(1):14614. doi:10.1038/ srep 14614

108. Chun R, Kurzman ID, Couto CG, Klausner J, Henry C, MacEwen EG. Cisplatin and Doxorubicin Combination Chemotherapy for the Treatment of Canine Osteosarcoma: a Pilot Study. J Veterinary Internal Med. 2000;14(5):495-498. doi:10.1892/0891-6640(2000)014<0495:cadccf $>2.3 . c 0 ; 2$

109. Heymann D, Ory B, Blanchard F, et al. Enhanced tumor regression and tissue repair when zoledronic acid is combined with ifosfamide in rat osteosarcoma. Bone. 2005;37(1):74-86. doi:10.1016/j.bone.2005.02.020

110. Cassano WF, Graham-Pole J, Dickson N. Etoposide, cyclophosphamide, cisplatin, and doxorubicin as neoadjuvant chemotherapy for osteosarcoma. Cancer. 1991;68(9):1899-1902. doi:10.1002/10970142(19911101)68:9<1899::aid-cncr2820680909>3.0.co;2-x

111. Holmboe L, Andersen AM, Mørkrid L, Slørdal L, Hall KS. High dose methotrexate chemotherapy: pharmacokinetics, folate and toxicity in osteosarcoma patients. $\mathrm{Br} J$ Clin Pharmacol. 2012;73(1):106-114. doi:10.1111/j.13652125.2011.04054.x

112. Joseph DL, Sahitya D, Jiaqiang Q, et al. Future Therapies for Human Osteosarcoma. Curr Cancer Ther Rev. 2013;9(1):55-77. doi:10.2174/1573394711309010006

113. Ma H, He C, Cheng $\mathrm{Y}$, et al. Localized Co-delivery of Doxorubicin, Cisplatin, and Methotrexate by Thermosensitive Hydrogels for Enhanced Osteosarcoma Treatment. ACS Appl Mater Interfaces. 2015;7(49):27040-27048. doi:10.1021/ acsami.5b09112

114. Ferrari S, Serra M. An update on chemotherapy for osteosarcoma. Expert Opin Pharmacother. 2015;16(18):2727-2736. doi:10.1517/ 14656566.2015.1102226

115. Gennari L, Merlotti D, Valleggi F, Martini G, Nuti R. Selective Estrogen Receptor Modulators for Postmenopausal Osteoporosis. Drugs Aging. 2007;24(5):361-379. doi:10.2165/00002512200724050-00002

116. Peng L, Luo Q, Lu H. Efficacy and safety of bazedoxifene in postmenopausal women with osteoporosis: a systematic review and meta-analysis. J Cell Biochem. 2017;96(49):e8659.

117. Silverman SL, Christiansen C, Genant HK, et al. Efficacy of Bazedoxifene in Reducing New Vertebral Fracture Risk in Postmenopausal Women With Osteoporosis: results From a 3-Year, Randomized, Placebo-, and Active-Controlled Clinical Trial. J Bone Mineral Res. 2008;23(12):1923-1934. 
118. Gennari L, Merlotti D, Nuti R. Selective estrogen receptor modulator (SERM) for the treatment of osteoporosis in postmenopausal women: focus on lasofoxifene. Clin Interv Aging. 2010;5:19-29. doi:10.2147/CIA.S6083

119. Nelson ER, Wardell SE, McDonnell DP. The molecular mechanisms underlying the pharmacological actions of estrogens, SERMs and oxysterols: implications for the treatment and prevention of osteoporosis. Bone. 2013;53(1):42-50. doi:10.1016/j. bone.2012.11.011

120. Watts NB, Diab DL. Long-Term Use of Bisphosphonates in Osteoporosis. J Clin Endocrinol Metab. 2010;95(4):1555-1565. doi:10.1210/jc.2009-1947

121. Whitaker M, Guo J, Kehoe T, Benson G. Bisphosphonates for Osteoporosis - where Do We Go from Here? $N$ Eng J Med. 2012;366(22):2048-2051. doi:10.1056/NEJMp1202619

122. Compston J. Practical guidance for the use of bisphosphonates in osteoporosis. Bone. 2020;136:115330. doi:10.1016/j. bone.2020.115330

123. Domschke C, Schuetz F. Side Effects of Bone-Targeted Therapies in Advanced Breast Cancer. Breast Care. 2014;9(5):332-336. doi:10.1159/000368844

124. Vannala V, Palaian S, Shankar P. Therapeutic dimensions of bisphosphonates: a clinical update. Int $J$ Preventive Med. 2020;11(1):166. doi:10.4103/ijpvm.IJPVM_33_19

125. Cheng H, Chawla A, Yang Y, et al. Development of nanomaterials for bone-targeted drug delivery. Drug Discov Today. 2017;22 (9):1336-1350. doi:10.1016/j.drudis.2017.04.021

126. Tran N, Pareta RA, Taylor E, Webster TJ. Iron oxide nanoparticles: novel drug delivery materials for treating bone diseases. $A d v$ Mater Res. 2010;89-91:411-418. doi:10.4028/www.scientific.net/ AMR.89-91.411

127. Wang D, Miller S, Sima M, Kopečková P, Kopeček J. Synthesis and evaluation of water-soluble polymeric bone-targeted drug delivery systems. Bioconjug Chem. 2003;14(5):853-859. doi:10.1021/bc034090j

128. Sun W, Ge K, Jin Y, et al. Bone-targeted nanoplatform combining zoledronate and photothermal therapy to treat breast cancer bone metastasis. ACS Nano. 2019;13(7):7556-7567. doi:10.1021/ acsnano.9b00097

129. Peng Z, Miyanji EH, Zhou Y, et al. Carbon dots: promising biomaterials for bone-specific imaging and drug delivery. Nanoscale. 2017;9(44):17533-17543. doi:10.1039/C7NR05731H

130. Medina-Cruz D, Mostafavi E, Vernet-Crua A, et al. Green nanotechnology-based drug delivery systems for osteogenic disorders. Expert Opin Drug Deliv. 2020;17(3):341-356. doi:10.1080/17425247.2020.1727441

131. Wang F, Chen L, Zhang R, Chen Z, Zhu L. RGD peptide conjugated liposomal drug delivery system for enhance therapeutic efficacy in treating bone metastasis from prostate cancer. J Controlled Release. 2014;196:222-233. doi:10.1016/j.jconrel.2014.10.012

132. Marra M, Salzano G, Leonetti C, et al. New self-assembly nanoparticles and stealth liposomes for the delivery of zoledronic acid: a comparative study. Biotechnol Adv. 2012;30(1):302-309. doi:10.1016/j.biotechadv.2011.06.018

133. Martínez-Carmona M, Lozano D, Colilla M, Vallet-Regí M. Lectin-conjugated $\mathrm{pH}$-responsive mesoporous silica nanoparticles for targeted bone cancer treatment. Acta Biomaterialia. 2018;65:393-404. doi:10.1016/j.actbio.2017.11.007

134. Jawahar N, Meyyanathan S. Polymeric nanoparticles for drug delivery and targeting: a comprehensive review. J Bone Mineral Res. 2012;1(4):217-223.

135. Rai R, Alwani S, Badea I. Polymeric Nanoparticles in Gene Therapy: new Avenues of Design and Optimization for Delivery Applications. J Bone Mineral Res. 2019;11(4):745.
136. Masood F. Polymeric nanoparticles for targeted drug delivery system for cancer therapy. Mater Sci Eng. 2016;60:569-578. doi:10.1016/j.msec.2015.11.067

137. Son J, Yang SM, Yi G, et al. Folate-modified PLGA nanoparticles for tumor-targeted delivery of pheophorbide a in vivo. Biochem Biophys Res Commun. 2018;498(3):523-528. doi:10.1016/j.bbrc.2018.03.013

138. Dangi R, Hurkat P, Jain A, et al. Targeting liver cancer via ASGP receptor using 5-FU-loaded surface-modified PLGA nanoparticles. $J$ Microencapsul. 2014;31(5):479-487. doi:10.3109/02652048.2013.879929

139. Salmaso S, Caliceti P. Stealth Properties to Improve Therapeutic Efficacy of Drug Nanocarriers. J Drug Deliv. 2013;2013:374252. doi:10.1155/2013/374252

140. Wang B, Yu X-C, Xu S-F, Xu M. Paclitaxel and etoposide co-loaded polymeric nanoparticles for the effective combination therapy against human osteosarcoma. J Nanobiotechnology. 2015;13(1):22. doi:10.1186/s12951-015-0086-4

141. Garay RP, El-Gewely R, Armstrong JK, Garratty G, Richette P. Antibodies against polyethylene glycol in healthy subjects and in patients treated with PEG-conjugated agents. Expert Opin Drug Deliv. 2012;9(11):1319-1323. doi:10.1517/17425247.2012.720969

142. Elsabahy M, Perron M-Ė, Bertrand N. Solubilization of Docetaxel in Poly(ethylene oxide)-block-poly(butylene/styrene oxide) Micelles. Biomacromolecules. 2007;8(7):2250-2257. doi:10.1021/bm070226v

143. Chen Y, Zhang YX, Wu ZF, et al. Biodegradable poly(ethylene glycol)-poly( $\varepsilon$-carprolactone) polymeric micelles with different tailored topological amphiphilies for doxorubicin (DOX) drug delivery. RSC Adv. 2016;6(63):58160-58172. doi:10.1039/ C6RA06040D

144. Liu T, Romanova S, Wang S, et al. Alendronate-Modified Polymeric Micelles for the Treatment of Breast Cancer Bone Metastasis. Mol Pharm. 2019;16(7):2872-2883. doi:10.1021/acs. molpharmaceut.8b01343

145. Kulthe SS, Choudhari YM, Inamdar NN, Mourya V. Polymeric micelles: authoritative aspects for drug delivery. Designed Monomers Polymers. 2012;15(5):465-521. doi:10.1080/ 1385772X.2012.688328

146. Tomalia DA, Fréchet JMJ. Discovery of dendrimers and dendritic polymers: a brief historical perspective. J Bone Mineral Res. 2002;40(16):2719-2728.

147. Patel H, Patel P. Dendrimer applications-a review. Chem Commun. 2013;4(2):454-463.

148. Bo J, Jing Z, Yanhua L, et al. Dual-targeting Janus Dendrimer Based Peptides for Bone Cancer: synthesis and Preliminary Biological Evaluation. Lett Org Chem. 2013;10(8):594-601. doi:10.2174/15701786113109990024

149. Pasut G, Veronese FM. Polymer-drug conjugation, recent achievements and general strategies. Prog Polym Sci. 2007;32 (8):933-961. doi:10.1016/j.progpolymsci.2007.05.008

150. Kwon S, Singh RK, Perez RA, Abou Neel EA, Kim H-W, Chrzanowski W. Silica-based mesoporous nanoparticles for controlled drug delivery. J Tissue Eng. 2013;4:2041731413503357.

151. Lin Y-S, Abadeer N, Haynes CL. Stability of small mesoporous silica nanoparticles in biological media. Chem Commun. 2011;47 (1):532-534. doi:10.1039/C0CC02923H

152. Ma X, Zhao Y, Ng KW, Zhao Y. Integrated Hollow Mesoporous Silica Nanoparticles for Target Drug/siRNA Co-Delivery. Chemistry. 2013;19(46):15593-15603. doi:10.1002/chem.201 302736

153. Pasqua L, De Napoli IE, De Santo M, et al. Mesoporous silica-based hybrid materials for bone-specific drug delivery. Nanoscale Adv. 2019;1(8):3269-3278. doi:10.1039/ C9NA00249A 
154. Shahbazi M-A, Herranz B, Santos HA. Nanostructured porous Si-based nanoparticles for targeted drug delivery. Biomatter. 2012;2(4):296-312. doi:10.4161/biom.22347

155. Piao Y, Kim J, Na HB, et al. Wrap-bake-peel process for nanostructural transformation from $\beta$-FeOOH nanorods to biocompatible iron oxide nanocapsules. Nat Mater. 2008;7(3):242-247. doi:10.1038/nmat2118

156. Kandasamy R, Kandasamy R. A novel single step synthesis and surface functionalization of iron oxide magnetic nanoparticles and thereof for the copper removal from pigment industry effluent. Sep Purif Technol. 2017;188:458-467. doi:10.1016/j. seppur.2017.07.059

157. Hu FX, Neoh KG, Kang ET. Synthesis and in vitro anti-cancer evaluation of tamoxifen-loaded magnetite/PLLA composite nanoparticles. Biomaterials. 2006;27(33):5725-5733. doi:10.1016/j.biomaterials.2006.07.014

158. Sharma P, Rana S, Barick KC, Kumar C, Salunke HG, Hassan PA. Biocompatible phosphate anchored Fe3O4 nanocarriers for drug delivery and hyperthermia. New J Chem. 2014;38 (11):5500-5508. doi:10.1039/C4NJ01431F

159. Gul S, Khan SB, Rehman IU, Khan MA, Khan MI, Comprehensive A. Review of Magnetic Nanomaterials Modern Day Theranostics. J Tissue Eng. 2019;6:179.

160. Çağdaş M, Sezer AD, Bucak S. Liposomes as Potential Drug Carrier Systems for Drug Delivery. Application Nanotechnol Drug Delivery. 2014.

161. Boakye CHA, Patel K, Singh M. Doxorubicin liposomes as an investigative model to study the skin permeation of nanocarriers. Int $J \quad$ Pharm. 2015;489(1):106-116. doi:10.1016/j. ijpharm.2015.04.059

162. Gu Q, Yang H, Shi Q. Macrophages and bone inflammation. $J$ Orthopaedic Translation. 2017;10:86-93. doi:10.1016/j. jot.2017.05.002

163. Neog MK, Rasool M. Targeted delivery of p-coumaric acid encapsulated mannosylated liposomes to the synovial macrophages inhibits osteoclast formation and bone resorption in the rheumatoid arthritis animal model. Eur $J$ Pharmaceutics Biopharmaceutics. 2018;133:162-175. doi:10.1016/j. ejpb.2018.10.010

164. Olusanya TOB, Haj Ahmad RR, Ibegbu DM, Smith JR, Elkordy AA. Liposomal Drug Delivery Systems and Anticancer Drugs. Molecules. 2018;23(4):907.

165. Gheinani AH, Vögeli M, Baumgartner U, et al. Improved isolation strategies to increase the yield and purity of human urinary exosomes for biomarker discovery. Sci Rep. 2018;8(1):3945. doi:10.1038/s41598-018-22142-x

166. Dash P, Piras AM, Dash M. Cell membrane coated nanocarriers - an efficient biomimetic platform for targeted therapy. J Controlled Release. 2020;327:546-570. doi:10.1016/j. jconrel.2020.09.012

167. Luk BT, Zhang L. Cell membrane-camouflaged nanoparticles for drug delivery. J Controlled Release. 2015;220:600-607. doi:10.1016/j.jconrel.2015.07.019

168. Li Z, Hu S, Cheng K. Platelets and their biomimetics for regenerative medicine and cancer therapies. J Mater Chem B. 2018;6 (45):7354-7365. doi:10.1039/C8TB02301H

169. Fang $\mathrm{RH}, \mathrm{Hu} \mathrm{C}-\mathrm{MJ}$, Luk BT, et al. Cancer Cell Membrane-Coated Nanoparticles for Anticancer Vaccination and Drug Delivery. Nano Lett. 2014;14(4):2181-2188. doi:10.1021/ nl500618u

170. Fan Z, Li PY, Deng J, Bady SC, Cheng H. Cell membrane coating for reducing nanoparticle-induced inflammatory responses to scaffold constructs. Nano Res. 2018;11(10):5573-5583. doi:10.1007/s12274-018-2084-y
171. György B, Szabó TG, Pásztói M, et al. Membrane vesicles, current state-of-the-art: emerging role of extracellular vesicles. Cell Mol Life Sci. 2011;68(16):2667-2688.

172. Théry C, Zitvogel L, Amigorena S. Exosomes: composition, biogenesis and function. Nat Rev Immunol. 2002;2(8):569-579. doi: $10.1038 /$ nri855

173. Gulei D, Irimie AI, Cojocneanu-Petric R, Schultze JL, BerindanNeagoe I. Exosomes-Small Players, Big Sound. Bioconjug Chem. 2018;29(3):635-648. doi:10.1021/acs.bioconjchem.8b00003

174. Keerthikumar S, Chisanga D, Ariyaratne D, et al. ExoCarta: a Web-Based Compendium of Exosomal Cargo. $J$ Mol Biol. 2016;428(4):688-692. doi:10.1016/j.jmb.2015.09.019

175. Pathan M, Fonseka P, Chitti SV, et al. Vesiclepedia 2019: a compendium of RNA, proteins, lipids and metabolites in extracellular vesicles. Nucleic Acids Res. 2018;47(D1):D516-D519. doi:10.1093/nar/gky1029

176. Qureshi MZ. Introducing Vesiclepedia. Nat Methods. 2013;10 (3):194. doi:10.1038/nmeth.2384

177. Boriachek K, Islam MN, Möller A, et al. Biological Functions and Current Advances in Isolation and Detection Strategies for Exosome Nanovesicles. Small. 2017;14(6):1702153. doi:10.1002/ smll.201702153

178. Mathivanan S, Fahner CJ, Reid GE, Simpson RJ. ExoCarta 2012: database of exosomal proteins, RNA and lipids. Nucleic Acids Res. 2012;40(Database issue):D1241-D1244. doi:10.1093/nar/gkr828

179. Farooqi AA, Desai NN, Qureshi MZ, et al. Exosome biogenesis, bioactivities and functions as new delivery systems of natural compounds. Biotechnol Adv. 2018;36(1):328-334. doi:10.1016/j. biotechadv.2017.12.010

180. Yokoi A, Yoshioka Y, Yamamoto Y, et al. Malignant extracellular vesicles carrying MMP1 mRNA facilitate peritoneal dissemination in ovarian cancer. Nat Commun. 2017;8(1):14470. doi:10.1038/ncomms 14470

181. Lv -L-L, Feng Y, Wu M, et al. Exosomal miRNA-19b-3p of tubular epithelial cells promotes M1 macrophage activation in kidney injury. Cell Death Differ. 2020;27(1):210-226. doi:10.1038/s41418-019-0349-y

182. Wu M, Ouyang Y, Wang Z, et al. Isolation of exosomes from whole blood by integrating acoustics and microfluidics. Proce National Acad Sci. 2017;114(40):10584. doi:10.1073/pnas.1709210114

183. El Andaloussi S, Mäger I, Breakefield XO, Wood MJA. Extracellular vesicles: biology and emerging therapeutic opportunities. Nat Rev Drug Discov. 2013;12(5):347-357. doi:10.1038/nrd3978

184. Liu Y, Zhang X-L, Chen L, et al. Epigenetic mechanisms of bone regeneration and homeostasis. Prog Biophys Mol Biol. 2016;122 (2):85-92. doi:10.1016/j.pbiomolbio.2016.01.005

185. Roodman GD. Mechanisms of Bone Metastasis. $N$ Eng $J$ Med. 2004;350(16):1655-1664. doi:10.1056/NEJMra030831

186. Yoshiko Y, Minamizaki T. Emerging roles of microRNAs as extracellular vesicle cargo secreted from osteoblasts. J Oral Biosci. 2020;62(3):228-234. doi:10.1016/j.job.2020.05.006

187. Cui Y, Luan J, Li H, Zhou X, Han J. Exosomes derived from mineralizing osteoblasts promote ST2 cell osteogenic differentiation by alteration of microRNA expression. FEBS Lett. 2016;590 (1):185-192. doi:10.1002/1873-3468.12024

188. Boyce BF, Xing L. Functions of RANKL/RANK/OPG in bone modeling and remodeling. Arch Biochem Biophys. 2008;473 (2):139-146. doi:10.1016/j.abb.2008.03.018

189. Sojod B, Chateau D, Mueller CG, et al. RANK/RANKL/OPG Signalization Implication in Periodontitis: new Evidence from a RANK Transgenic Mouse Model. Frontiers in Physiology. 2017;8(338). doi:10.3389/fphys.2017.00338

190. Jimi E. The role of osteoclastic bone resorption on bone remodeling. Clin Calcium. 2017;27(12):1689-1695. 
191. Huynh N, VonMoss L, Smith D, et al. Characterization of Regulatory Extracellular Vesicles from Osteoclasts. J Dent Res. 2016;95(6):673-679. doi:10.1177/0022034516633189

192. Gao M, Gao W, Papadimitriou JM, Zhang C, Gao J, Zheng M. Exosomes-the enigmatic regulators of bone homeostasis. Bone Res. 2018;6:36. doi:10.1038/s41413-018-0039-2

193. Liu M, Sun Y, Zhang Q. Emerging Role of Extracellular Vesicles in Bone Remodeling. J Dent Res. 2018;97(8):859-868. doi:10.1177/0022034518764411

194. Cappariello A, Loftus A, Muraca M, Maurizi A, Rucci N, Teti A. Osteoblast-Derived Extracellular Vesicles Are Biological Tools for the Delivery of Active Molecules to Bone. J Bone Mineral Res. 2018;33(3):517-533. doi:10.1002/jbmr.3332

195. Tiwari G, Tiwari R, Sriwastawa B, et al. Drug delivery systems: an updated review. Int $J$ Pharm Investig. 2012;2(1):2-11. doi:10.4103/2230-973X.96920

196. Tan ML, Choong PFM, Dass CR. Recent developments in liposomes, microparticles and nanoparticles for protein and peptide drug delivery. Peptides. 2010;31(1):184-193. doi:10.1016/j. peptides.2009.10.002

197. Gregoriadis G. Liposomes in Drug Delivery: how It All Happened. Pharmaceutics. 2016;8(2):19. doi:10.3390/ pharmaceutics8020019

198. El-Hammadi MM, Arias JL. An update on liposomes in drug delivery: a patent review (2014-2018). Expert Opin Ther Pat. 2019;29(11):891-907. doi:10.1080/13543776.2019.1679767

199. Mao J, Li Y, Wu T, et al. Responsive Prodrug-Based Polymeric Micelles for Drug Delivery. ACS Appl Mater Interfaces. 2016;8 (27):17109-17117. doi:10.1021/acsami.6b04247

200. Janas C, Mostaphaoui Z, Schmiederer L, Bauer J, Wacker MG. Novel polymeric micelles for drug delivery: material characterization and formulation screening. Int $J$ Pharm. 2016;509 (1):197-207. doi:10.1016/j.ijpharm.2016.05.029

201. Sur S, Rathore A, Dave V, Reddy KR, Chouhan RS, Sadhu V. Recent developments in functionalized polymer nanoparticles for efficient drug delivery system. Nano Structures Nano Objects. 2019;20:100397. doi:10.1016/j.nanoso.2019.100397

202. Patra JK, Das G, Fraceto LF, Campos EVR, Rodriguez-Torres M. Nano based drug delivery systems: recent developments and future prospects. J Nanobiotechnology. 2018;16(1):71. doi:10.1186/s12951-018-0392-8

203. Elsharkasy OM, Nordin JZ, Hagey DW, et al. Extracellular vesicles as drug delivery systems: why and how? Adv Drug Deliv Rev. 2020;159:332-343. doi:10.1016/j.addr.2020.04.004

204. Vader P, Mol EA, Pasterkamp G, Schiffelers RM. Extracellular vesicles for drug delivery. Adv Drug Deliv Rev. 2016;106:148-156. doi:10.1016/j.addr.2016.02.006

205. Gudbergsson JM, Jønsson K, Simonsen JB, Johnsen KB. Systematic review of targeted extracellular vesicles for drug delivery - considerations on methodological and biological heterogeneity. J Controlled Release. 2019;306:108-120. doi:10.1016/j.jconrel.2019.06.006

206. Huang D, Wu D. Biodegradable dendrimers for drug delivery. Mater Sci Eng. 2018;90:713-727. doi:10.1016/j.msec.2018.03.002

207. Wang Y, Luo Y, Zhao Q, Wang Z, Xu Z, Jia X. An Enzyme-Responsive Nanogel Carrier Based on PAMAM Dendrimers for Drug Delivery. ACS Appl Mater Interfaces. 2016;8(31):19899-19906. doi:10.1021/acsami.6b05567

208. Peng H, Ji W, Zhao R, et al. Exosome: a significant nano-scale drug delivery carrier. J Mater Chem B. 2020;8(34):7591-7608. doi:10.1039/D0TB01499K

209. Maia J, Caja S, Strano Moraes MC, Couto N, Costa-Silva B. Exosome-based cell-cell communication in the tumor microenvironment. Front Cell Dev Biol. 2018;6(18). doi:10.3389/fcell.2018.00018
210. Jiang X-C, Gao J-Q. Exosomes as novel bio-carriers for gene and drug delivery. Int J Pharm. 2017;521(1):167-175. doi:10.1016/j. ijpharm.2017.02.038

211. Ohno S-I, Takanashi M, Sudo K. Systemically Injected Exosomes Targeted to EGFR Deliver Antitumor MicroRNA to Breast Cancer Cells. Mol Therapy. 2013;21(1):185-191. doi:10.1038/mt.2012.180

212. Sun D, Zhuang X, Xiang X, et al. Drug delivery system: the anti-inflammatory activity of curcumin is enhanced when encapsulated in exosomes. Mol Therapy. 2010;18(9):1606-1614. doi:10.1038/mt.2010.105

213. Haney MJ, Klyachko NL, Zhao Y, et al. Exosomes as drug delivery vehicles for Parkinson's disease therapy. $J$ Controlled Release. 2015;207:18-30. doi:10.1016/j.jconrel.2015.03.033

214. Aqil F, Munagala R, Jeyabalan J, et al. Milk exosomes - Natural nanoparticles for siRNA delivery. Cancer Lett. 2019;449:186-195. doi:10.1016/j.canlet.2019.02.011

215. Morishita M, Takahashi Y, Nishikawa M, Takakura Y. Pharmacokinetics of Exosomes-An Important Factor for Elucidating the Biological Roles of Exosomes and for the Development of Exosome-Based Therapeutics. J Pharm Sci. 2017;106(9):2265-2269. doi:10.1016/j.xphs.2017.02.030

216. Tian T, Zhang H-X, He C-P, et al. Surface functionalized exosomes as targeted drug delivery vehicles for cerebral ischemia therapy. Biomaterials. 2018;150:137-149. doi:10.1016/j. biomaterials.2017.10.012

217. Salunkhe S, Basak M, Chitkara D, Mittal A. Surface functionalization of exosomes for target-specific delivery and in vivo imaging \& tracking: strategies and significance. J Controlled Release. 2020;326:599-614. doi:10.1016/j.jconrel.2020.07.042

218. Luan X, Sansanaphongpricha K, Myers I, Chen H, Yuan H, Sun D. Engineering exosomes as refined biological nanoplatforms for drug delivery. Acta Pharmacol Sin. 2017;38(6):754-763. doi:10.1038/aps.2017.12

219. Zhuang X, Xiang X, Grizzle W, et al. Treatment of brain inflammatory diseases by delivering exosome encapsulated anti-inflammatory drugs from the nasal region to the brain. $\mathrm{Mol}$ Therapy. 2011;19(10):1769-1779. doi:10.1038/mt.2011.164

220. Qu M, Lin Q, Huang L, et al. Dopamine-loaded blood exosomes targeted to brain for better treatment of Parkinson's disease. J Controlled Release. 2018;287:156-166. doi:10.1016/j. jconrel.2018.08.035

221. Bunggulawa EJ, Wang W, Yin T, et al. Recent advancements in the use of exosomes as drug delivery systems. J Nanobiotechnology. 2018;16(1):81. doi:10.1186/s12951-018-0403-9

222. Song H, Li X, Zhao Z, et al. Reversal of osteoporotic activity by endothelial cell-secreted bone targeting and biocompatible exosomes. Nano Lett. 2019;19(5):3040-3048. doi:10.1021/acs. nanolett.9b00287

223. Mehryab F, Rabbani S, Shahhosseini S, et al. Exosomes as a next-generation drug delivery system: an update on drug loading approaches, characterization, and clinical application challenges. Acta Biomaterialia. 2020;113:42-62. doi:10.1016/j. actbio.2020.06.036

224. Wei H, Chen J, Wang S, et al. Of Doxorubicin And Exosome Derived From Mesenchymal Stem Cells For Osteosarcoma Treatment In Vitro. Int J Nanomedicine. 2019;14:8603-8610. doi:10.2147/IJN.S218988

225. Luo Z-W, Li F-X-Z, Liu Y-W, et al. Aptamer-functionalized exosomes from bone marrow stromal cells target bone to promote bone regeneration. Nanoscale. 2019;11(43):20884-20892. doi:10.1039/C9NR02791B

226. Lin Q, Qu M, Zhou B, et al. Exosome-like nanoplatform modified with targeting ligand improves anti-cancer and anti-inflammation effects of imperialine. J Controlled Release. 2019;311:104-116. doi:10.1016/j.jconrel.2019.08.037 
227. Yuan D, Zhao Y, Banks WA, et al. Macrophage exosomes as natural nanocarriers for protein delivery to inflamed brain. Biomaterials. 2017;142:1-12. doi:10.1016/j. biomaterials.2017.07.011

228. Yan F, Zhong Z, Wang Y, et al. Exosome-based biomimetic nanoparticles targeted to inflamed joints for enhanced treatment of rheumatoid arthritis. J Nanobiotechnology. 2020;18(1):115. doi:10.1186/s12951-020-00675-6

229. Li X, Corbett AL, Taatizadeh E, et al. Challenges and opportunities in exosome research-Perspectives from biology, engineering, and cancer therapy. APL Bioeng. 2019;3(1):011503.

230. Ludwig N, Whiteside TL, Reichert TE. Challenges in Exosome Isolation and Analysis in Health and Disease. Int $J$ Mol Sci. 2019;20(19):4684.

231. Yang D, Zhang W, Zhang H, et al. Progress, opportunity, and perspective on exosome isolation - efforts for efficient exosome-based theranostics. Theranostics. 2020;10 (8):3684-3707. doi:10.7150/thno.41580

232. King HW, Michael MZ, Gleadle JM. Hypoxic enhancement of exosome release by breast cancer cells. BMC Cancer. 2012;12 (1):421. doi:10.1186/1471-2407-12-421

233. Théry C, Amigorena S, Raposo G, Clayton A. Isolation and Characterization of Exosomes from Cell Culture Supernatants and Biological Fluids. Int J Mol Sci. 2006;30(1):3.22.1-3.22.29.

234. Lobb RJ, Becker M, Wen SW, et al. Optimized exosome isolation protocol for cell culture supernatant and human plasma. $J$ Extracellular Vesicles. 2015;4:27031. doi:10.3402/jev.v4.27031

235. Gupta S, Rawat S, Arora V, et al. An improvised one-step sucrose cushion ultracentrifugation method for exosome isolation from culture supernatants of mesenchymal stem cells. Stem Cell Res Ther. 2018;9(1):180. doi:10.1186/s13287-018-0923-0

236. Pedersen KW, Kierulf B, Manger I, Oksvold MP, Li M. Direct Isolation of Exosomes from Cell Culture: simplifying Methods for Exosome Enrichment and Analysis. Int J Mol Sci. 2015;6.

237. Karttunen J, Heiskanen M, Navarro-Ferrandis V, et al. Precipitation-based extracellular vesicle isolation from rat plasma co-precipitate vesicle-free microRNAs. J Extracellular Vesicles. 2019;8(1):1555410. doi:10.1080/20013078.2018.1555410

238. Böing AN, van der Pol E, Grootemaat AE, Coumans FAW, Sturk A, Nieuwland R. Single-step isolation of extracellular vesicles by size-exclusion chromatography. $J$ Extracellular Vesicles. 2014;3(1):23430. doi:10.3402/jev.v3.23430

239. Gholizadeh S, Shehata Draz M, Zarghooni M, et al. Microfluidic approaches for isolation, detection, and characterization of extracellular vesicles: current status and future directions. Biosens Bioelectron. 2017;91:588-605. doi:10.1016/j.bios.2016.12.062

240. Contreras-Naranjo JC, Wu H-J, Ugaz VM. Microfluidics for exosome isolation and analysis: enabling liquid biopsy for personalized medicine. Lab Chip. 2017;17(21):3558-3577. doi:10.1039/ C7LC00592J

241. Konoshenko MY, Lekchnov EA, Vlassov AV, Laktionov PP. Isolation of Extracellular Vesicles: general Methodologies and Latest Trends. Biomed Res Int. 2018;2018:8545347. doi:10.1155/2018/8545347

242. Zhao X, Wu D, Ma X, Wang J, Hou W, Zhang W. Exosomes as drug carriers for cancer therapy and challenges regarding exosome uptake. Biomed Pharmacotherapy. 2020;128:110237. doi:10.1016/j.biopha.2020.110237

243. Buschow SI, van Balkom BWM, Aalberts M, Heck AJR, Wauben M, Stoorvogel W. MHC class II-associated proteins in B-cell exosomes and potential functional implications for exosome biogenesis. Immunology Cell Biol. 2010;88(8):851-856.

244. Denzer K, van Eijk M, Kleijmeer MJ, et al. Cells Carry MHC Class II-Expressing Microvesicles at Their Surface. J Immunol. 2000;165(3):1259-1265. doi:10.4049/jimmunol.165.3.1259
245. Quah BJC, O’Neill HC. The immunogenicity of dendritic cell-derived exosomes. Blood Cells Mol Dis. 2005;35 (2):94-110. doi:10.1016/j.bcmd.2005.05.002

246. Muhsin-Sharafaldine M-R, Saunderson SC, Dunn AC, Faed JM, Kleffmann T, McLellan AD. Procoagulant and immunogenic properties of melanoma exosomes, microvesicles and apoptotic vesicles. Oncotarget. 2016;7(35):56279-56294. doi:10.18632/ oncotarget.10783

247. Van Niel G, Mallegol J, Bevilacqua C, et al. Intestinal epithelial exosomes carry MHC class II/peptides able to inform the immune system in mice. Gut. 2003;52(12):1690-1697. doi:10.1136/ gut.52.12.1690

248. Gomari H, Forouzandeh Moghadam M, Soleimani M. Targeted cancer therapy using engineered exosome as a natural drug delivery vehicle. Onco Targets Ther. 2018;11:5753-5762. doi:10.2147/ OTT.S173110

249. Elkhoury K, Koçak P, Kang A, Arab-Tehrany E, Ellis Ward J, Shin SR. Engineering Smart Targeting Nanovesicles and Their Combination with Hydrogels for Controlled Drug Delivery. Immunology Cell Biol. 2020;12(9):849.

250. Rayamajhi S, Aryal S. Surface functionalization strategies of extracellular vesicles. J Mater Chem B. 2020;8(21):4552-4569. doi:10.1039/D0TB00744G

251. Sato YT, Umezaki K, Sawada S. Engineering hybrid exosomes by membrane fusion with liposomes. Sci Rep. 2016;6(1):21933. doi:10.1038/srep21933

252. Zhuang M, Chen X, Du D, et al. SPION decorated exosome delivery of TNF- $\alpha$ to cancer cell membranes through magnetism. Nanoscale. 2020;12(1):173-188. doi:10.1039 C9NR05865F

253. Conlan RS, Pisano S, Oliveira MI, Ferrari M, Mendes Pinto I. Exosomes as Reconfigurable Therapeutic Systems. Trends Mol Med. 2017;23(7):636-650. doi:10.1016/j.molmed.2017.05.003

254. Kooijmans SAA, Vader P, van Dommelen SM, van Solinge WW, Schiffelers RM. Exosome mimetics: a novel class of drug delivery systems. Int $J$ Nanomedicine. 2012;7:1525-1541. doi:10.2147/IJN.S29661

255. Jang SC, Kim OY, Yoon CM, et al. Bioinspired Exosome-Mimetic Nanovesicles for Targeted Delivery of Chemotherapeutics to Malignant Tumors. ACS Nano. 2013;7 (9):7698-7710. doi:10.1021/nn402232g

256. Pisano S, Pierini I, Gu J, et al. Immune (Cell) Derived Exosome Mimetics (IDEM) as a Treatment for Ovarian Cancer. Front Cell DevBiol. 2020;8(932). doi:10.3389/fcell.2020.553576

257. Kalimuthu S, Gangadaran P, Rajendran RL, et al. Approach for loading anticancer drugs into mesenchymal stem cell-derived exosome mimetics for cancer therapy. Immunology Cell Biol. 2018;9:1116

258. Johnsen KB, Gudbergsson JM, Skov MN, Pilgaard L, Moos T, Duroux M. A comprehensive overview of exosomes as drug delivery vehicles - endogenous nanocarriers for targeted cancer therapy. Biochimica et Biophysica Acta. 2014;1846(1):75-87. doi:10.1016/j.bbcan.2014.04.005

259. Biver E, Thouverey C, Magne D, Caverzasio J. Crosstalk between tyrosine kinase receptors, GSK3 and BMP2 signaling during osteoblastic differentiation of human mesenchymal stem cells. Mol Cell Endocrinol. 2014;382(1):120-130. doi:10.1016/j. mce.2013.09.018

260. Rayamajhi S, Nguyen TDT, Marasini R, Aryal S. Macrophagederived exosome-mimetic hybrid vesicles for tumor targeted drug delivery. Acta Biomaterialia. 2019;94:482-494. doi:10.1016/j. actbio.2019.05.054

261. Lin $\mathrm{Y}, \mathrm{Wu} \mathrm{J}, \mathrm{Gu} \mathrm{W}$, et al. Exosome-Liposome Hybrid Nanoparticles Deliver CRISPR/Cas9 System in MSCs. Advanced Sci. 2018;5(4):1700611. 
262. Piffoux M, Silva AKA, Wilhelm C, Gazeau F, Tareste D. Modification of extracellular vesicles by fusion with liposomes for the design of personalized biogenic drug delivery systems. ACS Nano. 2018;12(7):6830-6842. doi:10.1021/acsnano.8b02053

263. Lv Q, Cheng L, Lu Y, et al. Thermosensitive Exosome-Liposome Hybrid Nanoparticle-Mediated Chemoimmunotherapy for Improved Treatment of Metastatic Peritoneal Cancer. Advanced Sci. 2020;7(18):2000515.

264. Han Z, Lv W, Li Y, et al. Improving tumor targeting of exosomal membrane-coated polymeric nanoparticles by conjugation with aptamers. ACS Applied Bio Materials. 2020;3(5):2666-2673. doi:10.1021/acsabm.0c00181

265. Sawada S-I, Sato YT, Kawasaki R. Nanogel hybrid assembly for exosome intracellular delivery: effects on endocytosis and fusion by exosome surface polymer engineering. Biomaterials Sci. 2020;8(2):619-630. doi:10.1039/C9BM01232J
266. Jo W, Jeong D, Kim J, et al. Microfluidic fabrication of cell-derived nanovesicles as endogenous RNA carriers. Lab Chip. 2014;14(7):1261-1269. doi:10.1039/C3LC50993A

267. Illes B, Hirschle P, Barnert S, Cauda V, Wuttke S, Engelke H. Exosome-coated metal-organic framework nanoparticles: an efficient drug delivery platform. Chem Mater. 2017;29 (19):8042-8046. doi:10.1021/acs.chemmater.7b02358

268. Zha Y, Lin T, Li Y, et al. Exosome-mimetics as an engineered gene-activated matrix induces in-situ vascularized osteogenesis. Biomaterials. 2020;247:119985. doi:10.1016/j.biomaterials. 2020.119985

\section{Publish your work in this journal}

The International Journal of Nanomedicine is an international, peerreviewed journal focusing on the application of nanotechnology in diagnostics, therapeutics, and drug delivery systems throughout the biomedical field. This journal is indexed on PubMed Central, MedLine, CAS, SciSearch ${ }^{\mathbb{R}}$, Current Contents ${ }^{\mathbb{R}} /$ Clinical Medicine, $^{-}$
Journal Citation Reports/Science Edition, EMBase, Scopus and the Elsevier Bibliographic databases. The manuscript management system is completely online and includes a very quick and fair peer-review system, which is all easy to use. Visit http://www.dovepress.com/ testimonials.php to read real quotes from published authors. 